\title{
Clean Option - Berkeley Pit Water Treatment and Resource Recovery Strategy
}

\author{
M.A. Gerber \\ R. J. Orth \\ M. R. Elmore \\ B.F. Monzyk \\ Battelle Memorial Institute
}

September 1995

Prepared for

the U.S. Department of Energy

under Contract DE-AC06-76RLO 1830

Pacific Northwest Laboratory

Richland, Washington 99352-0999 



\section{DISCLAIMER}

Portions of this document may be illegible in electronic image products. Images are produced from the best available original document. 


\section{Summary}

The U.S. Department of Energy (DOE), Office of Technology Development, established the Resource Recovery Project (RRP) in 1992 as a five-year effort to evaluate and demonstrate multiple technologies for recovering water, metals, and other industrial resources from contaminated surface and groundwater. Natural water resources located throughout the DOE complex and the arid western states have been rendered unusable because of contamination from heavy metals.

The Berkeley Pit, a large, inactive, open pit copper mine located in Butte, Montana, along with its associated groundwater system, has been selected by the RRP for use as a feedstock for a test bed facility located there. The test bed facility provides the infrastructure needed to evaluate promising technologies at the pilot plant scale. Data obtained from testing these technologies was used to assess their applicability for similar mine drainage water applications throughout the western states and at DOE.

The objective of the Clean Option project is to develop strategies that provides a comprehensive and integrated approach to resource recovery using the Berkeley Pit water as a feedstock. The strategies not only consider the immediate problem of resource recovery from the contaminated water, but also manage the subsequent treatment of all resulting process streams. The strategies also employ the philosophy of waste minimization to optimize reduction of the waste volume requiring disposal, and the recovery and reuse of processing materials.

There are three types of criteria affecting the disposition of resources recovered from the Berkeley Pit and the performance criteria that need to be applied to a treatment strategy for resource recovery: 1) quality criteria for water discharged to the environment, 2) product specifications for recovered constituents, and 3) process economics.

Water quality criteria for water discharged to the environment is regulated by state and federal laws that depend on the ultimate use for the water; thus, water quality criteria are site-specific. The disposition of other resources recovered from the water are dictated by the availability of markets for alternative products, product specifications, and the ability to achieve favorable production costs.

In developing candidate flowsheets for analysis, it was apparent that a number of flowsheets could be prepared simply by substituting comparable technologies for specific unit operations and processing schemes that would be capable of recovering various constituents from the Berkeley Pit water. For example, copper can be selectively removed from water using precipitation, solvent extraction, or ion exchange. On the other hand, all flowsheets must include three basic strategies: 1) concentration of desired constituents to be recovered, 2) selective separation and purification of desired constituents, and 3) water treatment. Concentration of streams containing desired constituents is considered to be the most effective means for reducing overall processing costs, because all subsequent processing would be applied to a smaller more concentrated stream requiring smaller process scale and associated operating and maintenance costs. Selective separation and purification is necessary to optimize yield and purity of desired constituents to meet product specifications. Water treatment is necessary for meeting criteria for discharging the water to the environment. 
Although preliminary economic analyses of the flowsheets for the strategies developed are specific to the Berkeley Pit water, several observations can be made that would be applicable to any acid mine drainage because of similarities to the composition of water at other sites. Differences in key constituents at other sites would primarily affect the optimal resource recovery process and site specific economics.

Based on the preliminary cost analyses presented here for the Berkeley Pit water, it appears that none of the individual flowsheets evaluated can generate a net profit through resource recovery. However, it is possible to significantly reduce the cost of treatment and disposal primarily by reducing the amount of sludge requiring disposal in a Resource Conservation and Reclamation Act (RCRA) landfill. Furthermore, by combining the best elements for each of the flowsheets presented here, it may be possible to achieve a net profit for resource recovery.

Recovery of iron, aluminum, and manganese sulfate salts in addition to the higher valued copper and zinc concentrates are important to the overall economics of resource recovery because their recovery provides both a significant source of revenue as well as a way for reducing the amount of sulfate being converted to sludge waste. However, the practicality of recovering these constituents depends on finding a market close enough to the facility to justify added transportation costs; which can be substantial if the salts are sold as solutions.

Waste minimization through the use of sodium hydroxide as a neutralizing reagent is also an important key to favorable economics because it can eliminate the addition of lime, which adds calcium to the water and ultimately leads to a significant increase in the amount of sludge generated. Recovery of sodium hydroxide and sulfuric acid using electrodialysis for recycle also minimizes the amount of sodium and sulfate remaining in the treated water. Recovery of only monovalent cations in the electrodialysis unit also greatly simplifies its operational requirements because the electrolytic strength of the incoming stream is only partially depleted, and sodium concentration in the treated stream can be much higher than would be required for other hazardous constituents if the purpose of the unit operation was to decontaminate the incoming stream. This approach also produces excess sulfuric acid from acid waste streams that could also be sold if a market exists, even though its sale does not contribute significantly to overall economics.

Preconcentration of water requiring further treatment to remove constituents from the water is important to reducing water treatment costs, because it reduces both the capital and O\&M costs for subsequent unit operations. A preferred way to accomplish this is by nonselective separation of constituents from the feedwater using nanofiltration in tandem with reverse osmosis (RO) to produce a large volume of treated water that would be neutralized and treated using RO to remove any trace contaminants before discharge, and a smaller volume of contaminated water. However, the feasibility of nanofiltration to acid mine drainage needs to be demonstrated, because of possible adverse effects as a result of membrane fouling and degradation due to long-term exposure to low $\mathrm{pH}$. Solvent extraction can also be used to remove the desired constituents in a single stage, thereby concentrating them in the solvent phase for subsequent separation into desired product streams. Sodium hydroxide precipitation could also be applied as a concentration step followed by selective leaching of desired constituents from the resultant precipitate. In this case, the use of sodium hydroxide instead of lime not only reduces the sludge volume but also maximizes the concentration of each constituent in the sludge by minimizing the calcium sulfate inventory. Evaporation of the feedwater may also be feasible if the volume of acid mine drainage is modest. In the case of the Berkeley Pit, evaporation is not practical. 
As previously discussed, it may not be practical to recover iron and aluminum salts because there is no nearby market. However, recovery of zinc and copper may still be justified if their values are sufficiently high; they not only provide a source of revenue with readily available markets to reduce treatment costs, but they also provide for a modest reduction in the amount of sludge requiring disposal. While copper can be readily recovered in a relatively pure form using precipitation or cementation, zinc is less readily recovered because of interference from iron, which adversely affects subsequent zinc purification. Removal of iron can be achieved by either selective separation using ion exchange or solvent extraction before zinc recovery, or by precipitation of zinc, aluminum, and iron at a relatively neutral $\mathrm{pH}$ followed by selective leaching of the zinc-rich concentrate, as is currently practiced by industry for zinc ore. 


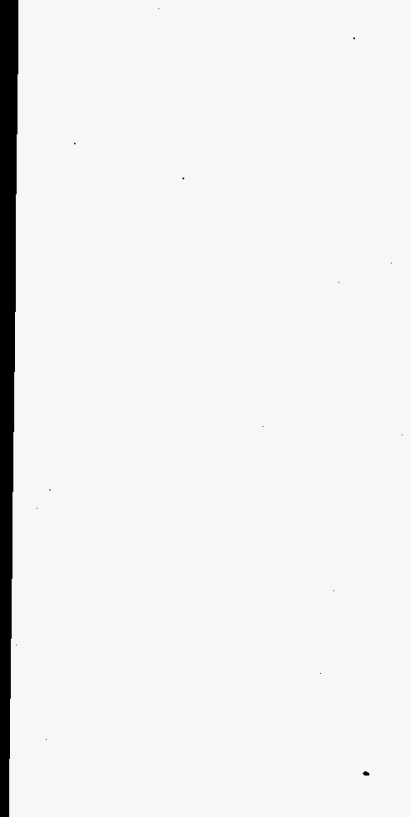

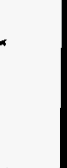




\section{Contents}

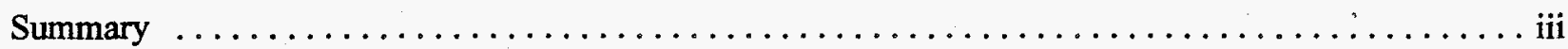



Treatment Criteria and Potential Markets for Constituents Recovered from Treating Berkeley Pit Water . 3

Treatment Criteria for Berkeley Pit Water Treatment $\ldots \ldots \ldots \ldots \ldots \ldots \ldots \ldots \ldots \ldots \ldots$

Potential Markets and Treatment Criteria for Recoverable Constituents

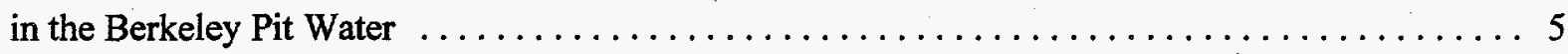

Flowsheet Development for Recovering Constituents from Berkeley Pit Water ............ 9

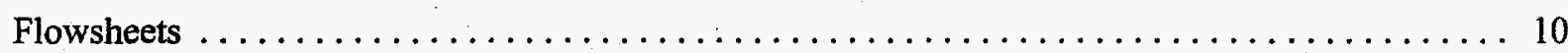

Series Separation of Individual Constituents $\ldots \ldots \ldots \ldots \ldots \ldots \ldots \ldots \ldots \ldots \ldots \ldots$

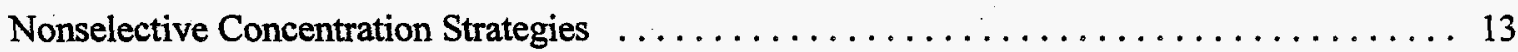

Preconcentration Feedwater Using Nanofiltration $\ldots \ldots \ldots \ldots \ldots \ldots \ldots \ldots \ldots \ldots \ldots$

Semiselective Separations of Constituents from Feedwater Stream Using Solvent Extraction . . 17

Semiselective Separations of Constituents from Feedwater Stream Using Precipitation . . . . 20

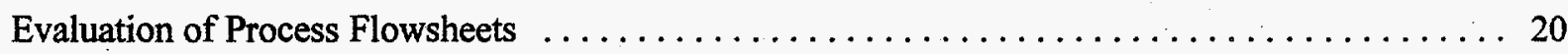



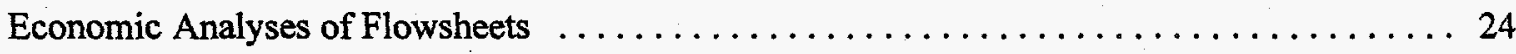

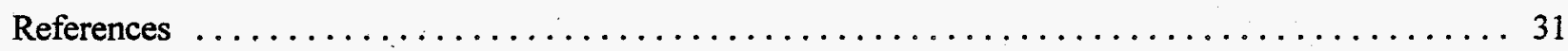

Appendix A: Physical and Chemical Characteristics of the Berkeley Pit Water $\ldots \ldots \ldots \ldots \ldots$ A.1

Appendix B: Constituent Disposition as Potentially Marketable Products . . . . . . . . . . B.1

Appendix C: Identification of Technologies Suitable for Treating Berkeley Pit Water .......... C.1

Appendix D: Stream Flow Material Balance for Flowsheet Showing Series Separation of

Constituents from Feedwater . . . . . . . . . . . . . . . . . .

Appendix E: Stream Flow Material Balance for Flowsheet Showing Nonselective

Concentration of All Constituents from Feedwater . 
Appendix F: Stream Flow Material Balance for Flowsheet Showing Semiselective

Separation of Constituents from Feedwater Using Solvent Extraction . . . . . . . . F.1

Appendix G: Stream Flow Material Balance for Flowsheet Showing Semiselective

Separation of Constituents from Feedwater Using Precipitation $\ldots \ldots \ldots \ldots \ldots \ldots$ G.1 


\section{Figures}

1 Alternative Treatment Strategies $\ldots \ldots \ldots \ldots \ldots \ldots \ldots \ldots \ldots \ldots \ldots \ldots \ldots \ldots \ldots$

2 Flowsheet Showing Series Separation of Constituents $\ldots \ldots \ldots \ldots \ldots \ldots \ldots \ldots \ldots \ldots \ldots$

3 Flowsheet Showing Preconcentration of Feedwater Using Nanofiltration $\ldots \ldots \ldots \ldots \ldots \ldots$

4 Flowsheet Showing Semiselective Separation of Constituents from Feedwater

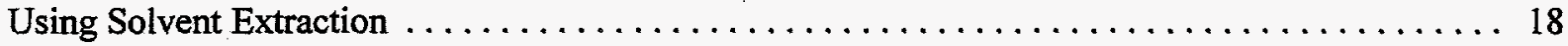

5 Flowsheet Showing Semiselective Separation of Constituents from Feedwater

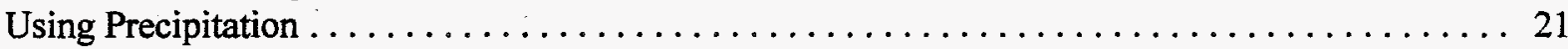

\section{Tables}

1 Water Discharge Performance Criteria $\ldots \ldots \ldots \ldots \ldots \ldots \ldots \ldots \ldots \ldots \ldots \ldots \ldots$

2 Potential Markets for Constituents Recovered from Berkeley Pit $\ldots \ldots \ldots \ldots \ldots \ldots \ldots \ldots$

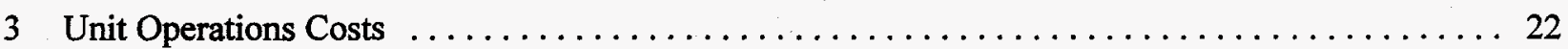

4 Preliminary Process Costs from Flowsheet Illustrating Series Separation of



5 Preliminary Value of Recovered Resources from Flowsheet Illustrating Series

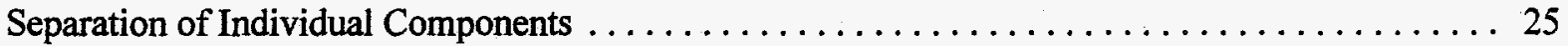

6 Preliminary Process Costs from Flowsheet Illustrating Semiselective Separation of

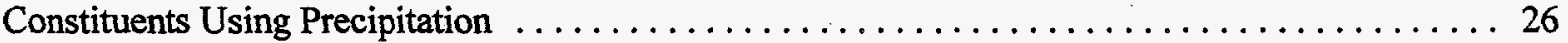

7 Preliminary Value of Recovered Resources from Flowsheet Illustrating Semiselective

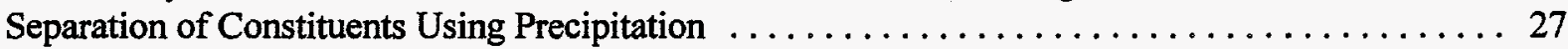

8 Preliminary Costs for Flowsheet Showing Preconcentration of Feedwater $\ldots \ldots \ldots \ldots \ldots \ldots 28$

9 Preliminary Value of Recovered Resources from Flowsheet Illustrating

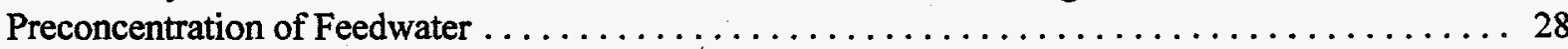

10 Preliminary Costs of Recovered Resources from Flowsheet Illustrating Semiselective Separation of Constituents from the Feedwater Using Solvent Extraction

11 Preliminary Value of Recovered Resources from Flowsheet Illustrating Semiselective Separation of Constituents from the Feedwater Using Solvent Extraction 



\section{Introduction}

The U.S. Department of Energy (DOE), Office of Technology Development, established the Resource Recovery Project (RRP) in 1992 as a five-year effort to evaluate and demonstrate multiple technologies for recovering water, metals, and other industrial resources from contaminated surface and groundwater. Natural water resources located throughout the DOE complex and the arid western states have been rendered unusable because of contamination from heavy metals.

The Berkeley Pit is a large, inactive, open pit copper mine located in Butte, Montana. Berkeley Pit is an important component of the Butte Mine Flooding Operable Unit located within the Butte Addition to the Silver Bow Creek/Butte Area National Priorities List (NPL). The pit is approximately 1 mile wide and $1400 \mathrm{ft}$ deep, and currently contains approximately 20 billion gal of contaminated water. The pit began to fill with water about 10 years ago, approximately 9 months after the underground mine water collection and pumping facility was shut down. Today, the water in the pit has filled to a depth of over $700 \mathrm{ft}$ and is currently filling at an average rate of about 5 million gal/day ( $3500 \mathrm{gpm})$. The pit is fed by both surface water and groundwater. The main surface source, called the Horseshoe Bend Seep, contributes approximately 1.5 million gal/day of contaminated water. Groundwater entering the pit includes clean groundwater, acid mine drainage from the underground mines, and groundwater that has been contaminated by water leaking from the nearby Yankee Doodle tailing impoundment. Total groundwater flow is approximately $3.5 \mathrm{million}$ gal/day.

The Berkeley Pit, along with its associated groundwater system, has been selected by the RRP for use as a feedstock for a test bed facility located there. The test bed facility provides the infrastructure needed to evaluate promising technologies at the pilot plant scale. Data obtained from testing these technologies is used to assess their applicability for similar mine drainage water applications throughout the western states and at DOE sites.

The objective of the Clean Option project, conducted by Pacific Northwest Laboratory (PNL) ${ }^{(a)}$ for the $R R P$, is to develop strategies that provide a comprehensive and integrated approach to resource recovery using the Berkeley Pit water as a feedstock. The strategies not only consider the immediate problem of resource recovery from the contaminated water, but also manage the subsequent treatment of all resulting process streams. The strategies also employ the philosophy of waste minimization to optimize reduction of the waste volume requiring disposal, and the recovery and reuse of processing materials.

(a) Pacific Northwest Laboratory is operated for the U.S. Department of Energy by Battelle Memorial Institute under contract DE-AC06-76RLO 1830. 



\section{Treatment Criteria and Potential Markets for Constituents Recovered from Treating Berkeley Pit Water}

There are three types of criteria affecting the disposition of resources recovered from the Berkeley Pit and the performance criteria that need to be applied to a treatment strategy for resource recovery: 1) quality criteria for water discharged to the environment, 2) product specifications for recovered constituents, and 3 ) process economics.

Water quality criteria for water discharged to the environment is regulated by state and federal laws that depend on the ultimate use for the water; thus, water quality criteria are site-specific. The disposition of other resources recovered from the water are dictated by the availability of markets for alternative products, product specifications, and the ability to achieve favorable production costs.

\section{Treatment Criteria for Berkeley Pit Water Treatment}

The Berkeley Pit water serves only as a contaminated water source to be used by the RRP test bed in Butte, Montana, to test resource recovery strategies and technologies for applicability to mining sites with acid mine drainage problems throughout the western states, and for contaminated water at DOE sites. Therefore, discharge criteria must be established that are applicable to most sites, rather than specific to the Berkeley Pit. Site-specific discharge criteria for the Berkeley Pit are established through a Record of Decision resulting from a Remedial Investigation/Feasibility Study for the Butte Mine Flooding Operable Unit.

Using this basis of broad applicability, it is expected that treated water at the various sites will be discharged to an aquifer or a surface body of water. Primary concerns at these sites is the protection of aquatic species and drinking water supplies. Site-specific industrial and agricultural uses for the water are of secondary importance, but could provide local market opportunities for the treated water and, in many cases, less stringent water quality criteria. MSE (1993a) provides a good discussion of the criteria for these other water uses.

The primary criteria for water quality are those set forth in the Safe Drinking Water Act (SDWA), enacted in 1984 and amended in 1986; and the Clean Water Act (CWA), originally enacted as the Federal Water Pollution Control Act in 1972, and amended in 1977, 1981, and 1987. Table 1 lists primary and secondary maximum contaminant limits (MCLs) from the SDWA, and the Water Quality Criteria for acute and chronic exposure from the CWA. It should be noted that the ambient water quality exposure limits for silver, cadmium, copper, nickel, and zinc are dependent on the hardness of the water measured as the concentration of $\mathrm{CaCO}_{3}$ and vary for different sites. The values in Table 1 for these elements are based on the U.S. Environmental Protection Agency's (EPA's) nominal hardness value of $100 \mathrm{mg}$ of $\mathrm{CaCO}_{3}$.

The average chemical composition of the water in the Berkeley Pit, also shown in Table 1, is based on analyses of water samples collected from the pit in 1991 at depths of $0 \mathrm{ft}, 3 \mathrm{ft}, 225 \mathrm{ft}$, and $400 \mathrm{ft}$ below the water surface. However, actual values of these constituents vary by as much as $\pm 25 \%$ about their averages over the range of depths sampled. Samples collected in 1986, 1987, and 1991 also indicate that the water chemistry at the various depths also varies significantly over time. Further discussion of the water chemistry is given in Appendix A, and is based on information reported by MSE (1993a). 
Table 1. Water Discharge Performance Criteria ${ }^{(a)}$

\begin{tabular}{|c|c|c|c|c|c|c|c|}
\hline & $\begin{array}{l}\text { Average } \\
\text { Concentra- } \\
\text { tion, mg/L }\end{array}$ & $\begin{array}{l}\text { Ambient } \\
\text { Water } \\
\text { Quality } \\
\text { Criteria } \\
\text { Acute, } \\
\text { mg/L } \mathbf{L}^{(\mathbf{b})}\end{array}$ & $\begin{array}{l}\text { Ambient } \\
\text { Water } \\
\text { Quality } \\
\text { Criteria } \\
\text { Chronic, } \\
\text { Mg/L }\end{array}$ & $\begin{array}{l}\text { Safe } \\
\text { Drinking } \\
\text { Water Act } \\
\text { Primary } \\
\text { MCLs, } \\
\text { mg/L }\end{array}$ & $\begin{array}{l}\text { Safe } \\
\text { Drinking } \\
\text { Water Act } \\
\text { Secondary } \\
\text { MCLs, } \\
\text { mg/L } \mathbf{L}^{(d)}\end{array}$ & $\begin{array}{c}\text { Clean } \\
\text { Option } \\
\text { Discharge } \\
\text { Water } \\
\text { Performance } \\
\text { Criteria, } \\
\text { mg/L } \\
\end{array}$ & $\begin{array}{c}\text { Clean Option } \\
\text { Required De- } \\
\text { contamina- } \\
\text { tion Factors }\end{array}$ \\
\hline $\mathrm{Ag}$ & 0.006 & $0.0041^{(\mathrm{e})}$ & $0.00012^{(\mathrm{e})}$ & 0.05 & 0.1 & 0.00012 & 50 \\
\hline $\mathrm{Al}$ & 279 & 0.75 & 0.087 & $\cdots$ & $.05-2.0$ & 0.087 & 3200 \\
\hline As & 0.532 & 0.36 & 0.19 & 0.05 & - & 0.05 & 11 \\
\hline B & 0.403 & - & - & $\cdots$ & - & -- & \\
\hline $\mathrm{Ca}$ & 478 & - & - & -- & - & - & - \\
\hline $\mathrm{Cd}$ & 1.67 & $0.0039^{(e)}$ & $0.0011^{(\mathrm{e})}$ & & 0.005 & 0.0011 & 1,600 \\
\hline $\mathrm{Cl}$ & 12 & - & $=$ & - & 250 & 250 & - \\
\hline Co & 1.75 & $\cdots$ & - & - & $\cdots$ & - & - \\
\hline $\mathrm{Cr}$ & 0.0548 & 1.7 & 0.21 & 0.05 & $=$ & 0.05 & $<2$ \\
\hline $\mathrm{Cu}$ & 184 & $0.018^{(\mathrm{e})}$ & $0.012^{(\mathrm{e})}$ & - & 0.1 & 0.012 & 16,000 \\
\hline$F$ & 21.1 & - & - & 4.00 & - & 4 & 6 \\
\hline $\mathrm{Fe}$ & 875 & - & $1.00^{(e)}$ & $=$ & 0.3 & 0.3 & 3,000 \\
\hline$K$ & 18.1 & - & - & - & $\cdots$ & $=$ & - \\
\hline $\mathrm{Li}$ & 0.26 & - & - & - & - & - & - \\
\hline Mo & 0.58 & - & - & - & $=$ & $=$ & - \\
\hline $\mathrm{Mg}$ & 418 & - & - & - & $=$ & - & - \\
\hline $\mathrm{Mn}$ & 186 & $=$ & - & - & 0.05 & 0.05 & $-3,800$ \\
\hline $\mathrm{Na}$ & 68.8 & $=$ & - & - & - & - & - \\
\hline $\mathrm{Ni}$ & 1.06 & $1.4^{(e)}$ & $0.16^{(e)}$ & 0.1 & $=$ & 0.1 & 11 \\
\hline $\mathrm{NO}_{3}^{-}$ & 0.275 & - & - & 10 & - & 10 & -- \\
\hline $\mathrm{Pb}$ & 0.065 & 0.082 & 0.0032 & 0.05 & - & 0.0032 & 21 \\
\hline $\mathrm{SiO}_{2}$ & 97.5 & - & - & - & - & - & - \\
\hline $\mathrm{SO}_{4}^{-2}$ & 7640 & - & - & 500 & 250 & 250 & 31 \\
\hline $\mathrm{Sr}$ & 1.36 & - & - & - & $=$ & $=$ & $=$ \\
\hline $\mathrm{Ti}$ & 0.0778 & - & -- & - & $\cdots$ & - & $=$ \\
\hline $\mathrm{V}$ & 0.105 & - & - & - & $\cdots$ & - & $=$ \\
\hline $\mathrm{Zn}$ & 5285 & $0.12^{(\mathrm{e})}$ & $0.11^{(e)}$ & 5.00 & $=$ & 0.11 & 5,000 \\
\hline $\mathrm{Zr}$ & 0.006 &  & - & - & $=$ & - & - \\
\hline $\mathrm{pH}$ & 2.7 & - & $6.5-9.0$ & - & $6.5-8.5$ & $6.5-8.5$ & $=$ \\
\hline TDS & 10800 & - & - & - & 500 & 500 & - \\
\hline \multicolumn{8}{|c|}{$\begin{array}{l}\text { Note: } \\
\text { (a) Blank spaces indicate either no criteria or no decontamination required. } \\
\text { (b) EPA } 1986 . \\
\text { (c) } 40 \text { CFR } 141,1991 . \\
\text { (d) } 40 \text { CFR } 143,1991 \text {. } \\
\text { (e) Based on } 100 \mathrm{mg} / \mathrm{L} \text { hardness value for chronic exposure. }\end{array}$} \\
\hline
\end{tabular}


The performance criteria for this project uses the more conservative of limits set by these two acts, as shown in Table 1. For the most part, the ambient water quality criteria for chronic exposure provide most of these goals. However, the secondary MCLs for manganese, iron, chromium, sulfate, total dissolved solids (TDS), and the primary MCL for nitrate are chosen as limits because protection of drinking water supplies could be relevant at some sites where the local water supply cannot be isolated from the discharge point.

Several of the major constituents in the Berkeley Pit water are not individually regulated. These include calcium, potassium, magnesium, sodium, and silica. However, collectively they are included in the TDS (secondary MCL) limit for drinking water. Meeting the $250 \mathrm{mg} / \mathrm{L}$ TDS limit also ensures that the water will be suitable for many agricultural and industrial uses, as discussed in MSE (1993b). Calcium and sodium are also indirectly regulated because they are cations associated with the sulfate anion in the water that is limited to no more than $250 \mathrm{mg} / \mathrm{L}$.

\section{Potential Markets and Treatment Criteria for Recoverable Constituents in the Berkeley Pit Water}

Potential markets were identified for various forms of aluminum, copper, iron, magnesium, manganese, and zinc, because these elements account for nearly $23 \%$ of the total dissolved solids in the Berkeley Pit water (the sulfate anion accounting for more than $70 \%$ of the TDS). The more promising markets are summarized in Table 2, and a discussion of these and other potential product markets is provided in Appendix B. Product specifications for the various products, also shown in the table, are provided because they can be limiting for primary recovery process schemes, either by placing restrictions on the composition of the final product or by limiting the composition of the feed to the separations process train.

In general, most of the potential markets were for chemical compounds containing different metals, many of which are metal sulfates. These compounds would also provide a means for marketing the sulfate in the water. Both copper and zinc also had markets for the refined metal or partially purified metal concentrate. Although aluminum and iron oxides have potential markets with smelters, little interest was shown by these industries partly because there was no information on the product specifications that could be achieved using the Berkeley Pit water. However, the markets for ferric chloride, ferric sulfate, and aluminum sulfate appeared to be sufficiently large to warrant their production. Markets exist for a number of magnesium compounds, but only modest interest was shown by the companies contacted.

The market for calcium sulfate was investigated by MSE (1994). They found a limited market for gypsum at nearby cement manufacturers, but concluded that a local wallboard manufacturer would be needed to consume the potential production rate of calcium sulfate. 
Table 2. Potential Markets for Constituents Recovered from Berkeley Pit

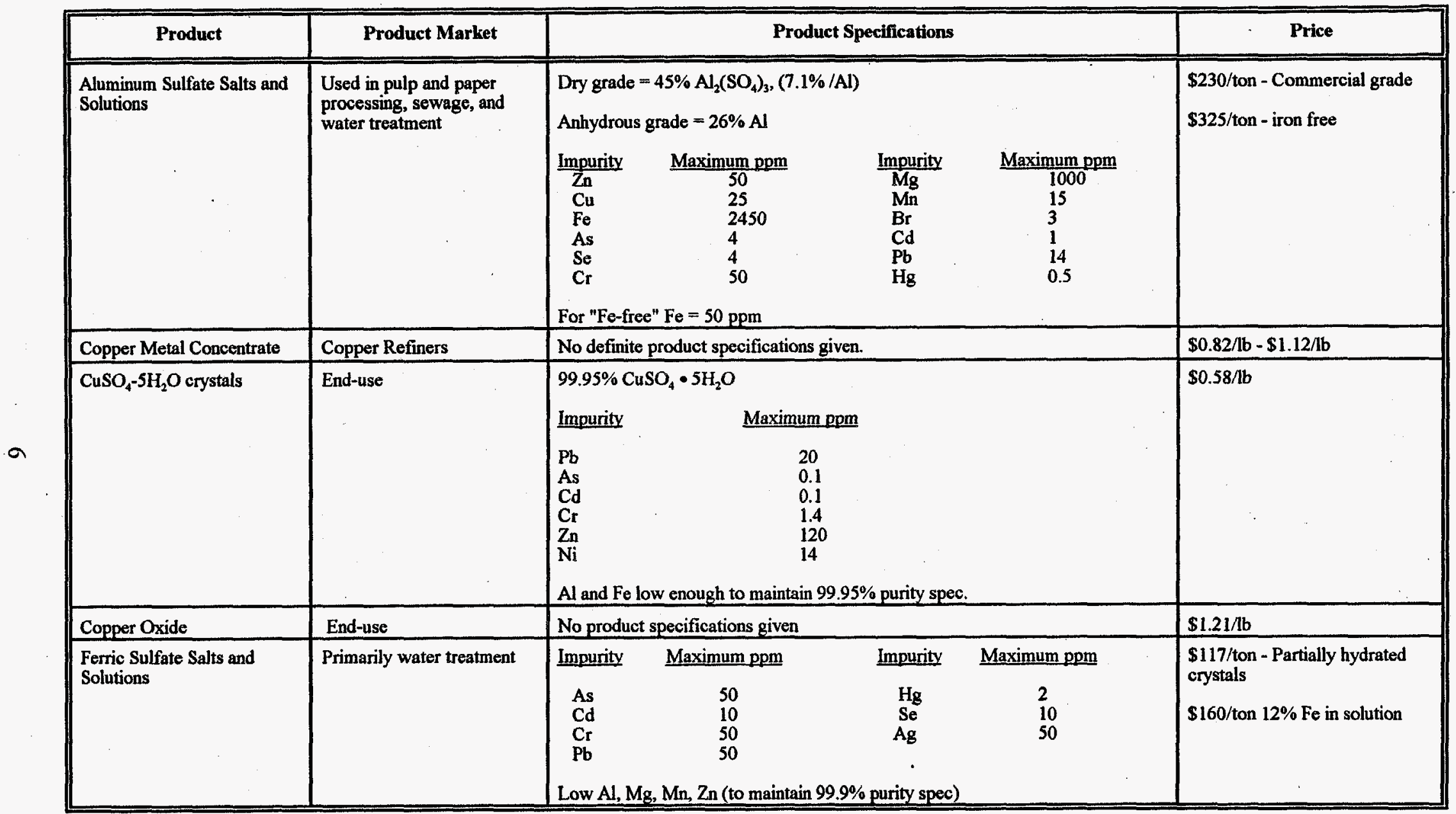


Table 2. (contd)

\begin{tabular}{|c|c|c|c|c|c|}
\hline Product & Product Market & \multicolumn{3}{|c|}{ Product Specifications } & Price \\
\hline Ferric Chloride & Waste water treatment & $\begin{array}{l}12-14 \% \\
\text { Impurity } \\
\mathrm{As} \\
\mathrm{Ni} \\
\mathrm{Cd} \\
\mathrm{Cr}\end{array}$ & $\begin{array}{lc}\left.\text { d for shipping, } 38-42 \% \mathrm{FeCl}_{3}\right) \\
\begin{array}{lc}\text { Maximum ppm } & \text { Impurity } \\
80\left(50 \text { for } \mathrm{SO}_{4}\right) & \mathrm{Pb} \\
\text { To be determine } & \mathrm{Hg} \\
20 & \mathrm{Se} \\
80 & \mathrm{Ag}\end{array}\end{array}$ & $\begin{array}{c}\text { Maximum ppm } \\
80 \\
3 \\
20 \\
80\end{array}$ & $\begin{array}{l}\$ 0.54 / \mathrm{lb} \mathrm{FeCl}_{3} \mathrm{z} \\
(\$ 4.10 / \text { ton solution at } 38 \% \\
\left.\mathrm{FeCl}_{3}\right)\end{array}$ \\
\hline Magnesium Oxide & Refractories & \multicolumn{3}{|c|}{ No definite product specifications given } & $\$ 1.65 / \mathrm{lb}$ \\
\hline Manganese Sulfate & - & \multicolumn{3}{|c|}{$\begin{array}{l}29.5 \% \text { manganese sulfate product } \\
\text { No definite product specifications given }\end{array}$} & $\$ 475 /$ ton \\
\hline Zinc Metal & End Product & $\begin{array}{l}\text { Impurity } \\
\mathrm{Pb} \\
\mathrm{Fe} \\
\mathrm{Cd} \\
\end{array}$ & \multicolumn{2}{|l|}{$\begin{array}{l}\text { Maximum ppm } \\
30-1,600 \\
30-80 \\
30-500 \\
\end{array}$} & $\$ 0.62 / \mathrm{bb}$ \\
\hline $\begin{array}{l}\text { Zinc Chloride and } \\
\text { Zinc Ammonium Chloride } \\
\text { Solutions }\end{array}$ & $\begin{array}{l}\text { Wood preservatives, } \\
\text { galvanizing and metal } \\
\text { plating }\end{array}$ & \multicolumn{3}{|c|}{$\begin{array}{l}\text { For } 45 \% \mathrm{ZnCl}_{2} \text { and } \mathrm{Zn}-\mathrm{NH}_{3}-\mathrm{Cl} \\
\text { Impurity Maximum ppm }\end{array}$} & \\
\hline
\end{tabular}





\section{Flowsheet Development for Recovering Constituents from Berkeley Pit Water}

In developing candidate flowsheets for analysis it was apparent that a number of flowsheets could be prepared simply by substituting comparable technologies for specific unit operations and processing schemes that would be capable of recovering various constituents from the Berkeley Pit water. For example, copper can be selectively removed from water using precipitation, solvent extraction, or ion exchange. On the other hand, all flowsheets must include three basic strategies: 1) concentration of desired constituents to be recovered, 2) selective separation and purification of desired constituents, and 3) water treatment. Concentration of streams containing desired constituents is considered to be the most effective means for reducing overall processing costs, because all subsequent processing would be applied to a smaller more concentrated stream requiring smaller process scale and associated operation and maintenance (O\&M) costs. Selective separation and purification is necessary to optimize yield and purity of desired constituents to meet product specifications. Water treatment is necessary for meeting criteria for discharging the water to the environment. A discussion of technologies suitable for treating Berkeley Pit water is provided in Appendix C.

Figures 1a and 1b illustrate two general strategies that could be applied in developing a flowsheet. Using the strategy shown in Figure 1a, concentration of individual constituents are achieved in a series of separation steps. In this strategy, each separation step is applied to the entire flow of Berkeley Pit water. An example of this strategy is the recently completed project at the RRP by TETRA Technologies Inc., Houston, Texas, where sequential precipitation steps were being applied to feedwater from

Figure 1a

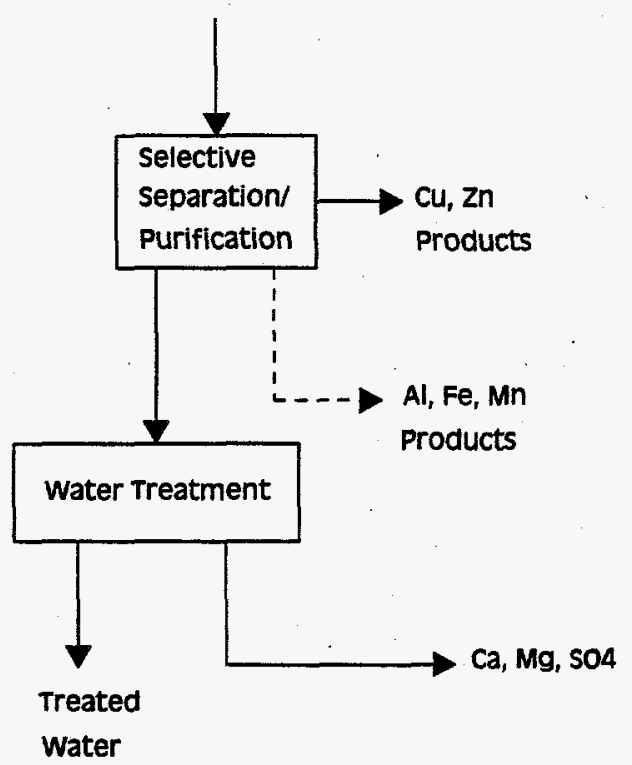

Figure 1b

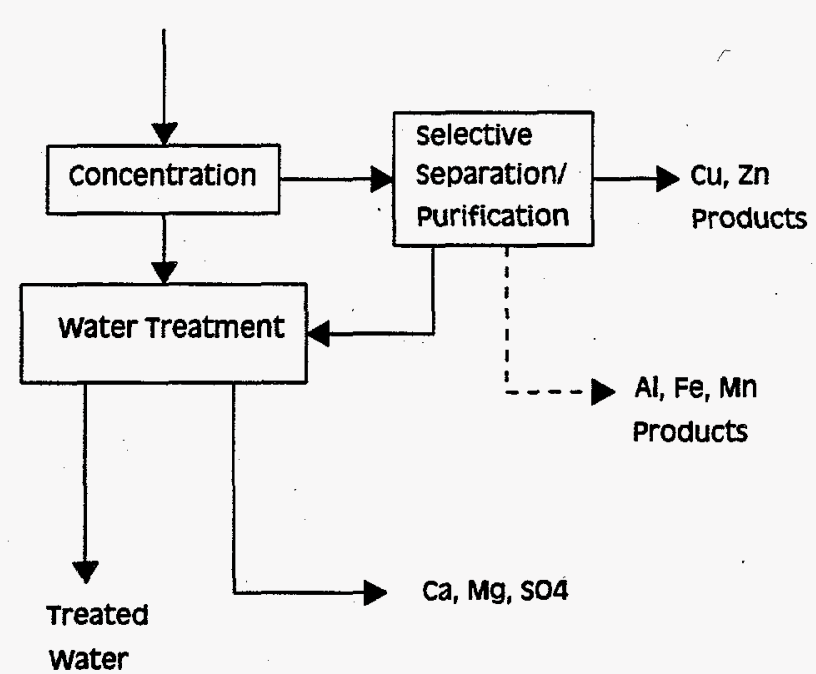

Figure 1. Alternative Treatment Strategies: 1a - Selective Separation of Constituents Followed by Water Treatment; $1 b$ - Nonselective Concentration Followed by Selective Separation and Water Treatment 
the Berkeley Pit to remove copper, zinc, iron, manganese, magnesium, and calcium precipitates in varying degrees of purity (TETRA Technologies Inc., undated). Figure $1 \mathrm{~b}$ uses a strategy of nonselectively concentrating all of the constituents in the Berkeley Pit water before selective separation. Individual separations processes are applied in sequence to the concentrated stream to separate and purify individual constituents.

Variations in flowsheet development also depend on the choice of constituents specifically targeted for recovery, their purity requirements, and secondary opportunities for recovering other constituents while separating and purifying the primary ones, or to meet water discharge criteria. As shown in Figure 1, copper and zinc are considered significant constituents with a number of established markets in different forms. Aluminum, iron, and manganese salts have specialty markets and would be major revenue producers if they can be produced in a cost-effective manner. Otherwise, they would be further concentrated and disposed without further separation. Calcium and magnesium salts do not have firm markets available, even though their concentrations in the Berkeley Pit water are relatively large and must be significantly reduced in the water to meet discharge criteria.

\section{Flowsheets}

Four flowsheets were prepared for consideration in treating the Berkeley Pit water. These flowsheets illustrate various applications of the two strategies (described above) that provide for the recovery of primary constituents. Three of the flowsheets provide for recovery of all primary and most secondary constituents of interest. Material flows for these flowsheets are provided in Appendixes D, E, and F. The fourth flowsheet illustrates a strategy aimed only at the recovery of the primary constituents, zinc and copper. Insufficient data was available to prepare a comprehensive material balance for this flowsheet, but Appendix $G$ does provide an abbreviated material balance that can be used for evaluating the merits of this process.

In developing these flowsheets, it was assumed that all of the dissolved iron in the Berkeley Pit water is in the +2 oxidation state. This assumption is based on the fact that the current location of the pump inlet used to retrieve water for the RRP test bed is located at a depth of $200 \mathrm{ft}$ from the surface and the analysis of water samples indicates that ferrous iron is the dominant state at depths below $10 \mathrm{ft}$. It was also assumed that only relatively simple precipitates $\left(\mathrm{CaSO}_{4}, \mathrm{MgOH}\right.$, etc. $)$ are produced in each process flowsheet even though more complex salts such as jarosite $(\mathrm{KFe})_{3}\left(\mathrm{SO}_{4}\right)_{2}(\mathrm{OH})_{6}$, and alunite $\mathrm{KAl}_{3}\left(\mathrm{SO}_{4}\right)_{2}(\mathrm{OH})_{6}$ are thermodynamically possible with the current water chemistry. It was also assumed that the suspended solids in the feedwater are negligible in comparison to suspended solids produced during precipitation processes. This assumption is based on analyses of suspended solids that slowly increase from about $16 \mathrm{mg} / \mathrm{L}$ at the water surface to $59 \mathrm{mg} / \mathrm{L}$ at $130 \mathrm{ft}$ of depth in the pit. However, for those processes that are sensitive to solids content of the water, either in the feedwater or due to precipitation of solids in the process, it may be necessary to consider the implications of these solids.

\section{Series Separation of Individual Constituents}

The flowsheet shown in Figure 2 describes an integrated process for treating the Berkeley Pit water in a series of separation steps to recover copper as cement copper sponge and zinc metal as the primary products, and ferric chloride, manganese dioxide, and aluminum sulfate as byproducts. Stream flow rates and compositions are described in Appendix D. This process consists of cementation to recover copper; ion exchange to recover iron as ferric chloride; hydroxide precipitation and solid-liquid 




Figure 2. Flowsheet Showing Series Separation of Constituents

separation, followed by dissolution/leaching of the solids to recover aluminum sulfate, zinc, and manganese sulfate concentrate; electrowinning to recover zinc metal; and neutralization of manganese dioxide to produce manganese sulfate. Electrodialysis is used to recover caustic from the process, which is used as the precipitation reagent for the process flowsheet. Most of the sulfuric acid, also recovered in the electrodialysis, is used in the various neutralization, leach, and dissolution steps.

As shown in Figure 2, the Berkeley Pit water is passed through a scrap iron bed in the cementation process where it is reduced by the iron scrap to produce an $80 \%$ pure copper sponge. This product is assumed to be sold to copper smelters as feedstock. However, other process options could be used onsite to further process the copper by dissolving the copper sponge and separating iron from the solution using precipitation or ion exchange, described below. Alternatively, sulfide precipitation could be used to recover relatively pure copper sulfide, or a mixture of copper and zinc precipitates with nickel and cadmium also precipitating out, as demonstrated by TETRA Technologies (undated). 
Following copper cementation, the pit water is pretreated before an ion-exchange process to remove iron (III) from the water. The pretreatment step consists of a combination of sulfuric acid addition and oxidation to achieve these conditions. The flowsheet indicates that air would be used as the oxidant, but permanganate or magnesium dioxide may also be needed in small quantities to achieve the necessary high conversion of ferrous iron to the ferric state.

The ion-exchange process is based on preliminary data obtained from Dick Fish of Lawrence Berkeley Laboratory, Davis, California, from ongoing research sponsored by DOE to remove trivalent cations from a mixture of cations of various oxidation states. According to their most recent work, the ionexchange resin, which consists of an iron-selective organic ligand attached to a divinylbenzenepolystyrene resin, removes ferric iron from a solution adjusted to a $\mathrm{pH}$ of about 2.1 to keep the ferric ion in solution. According to batch data achieved using the ion-exchange resin, a separation factor of about 500 is achieved between ferric cation and divalent cations (copper), and a separation factor of about 10 between ferric cations and the trivalent aluminum cations. The flowsheet uses a $1 \mathrm{M} \mathrm{HCl}$ solution to recover the ferric cation as ferric chloride and to regenerate the ion-exchange resin, but sulfuric acid could also be used to produce ferric sulfate. A concentration factor of 30 is assumed between the Berkeley Pit water and the stripping solution. A $99.3 \%$ pure $\mathrm{FeCl}_{3}$ solution $(12 \% \mathrm{Fe})$ is produced.

The aqueous effluent from the ion exchanger (stream 5) is passed through the first of 2 hydroxide precipitation stages. A $1.0 \mathrm{M}$ sodium hydroxide solution is metered into the stream to adjust the $\mathrm{pH}$ to 6.0. Addition of sodium hydroxide does not cause calcium sulfate to precipitate. The partitioning of the various constituents was estimated using data obtained from the treatability data for precipitation using caustic (Canonie Environmental Services 1993). The first stage removes about $95 \%$ of the aluminum along with trace contaminants at a pH of 6 . This precipitate (stream 6) is leached at a pH of 5.5 to separate any zinc and iron from the aluminum precipitate. The leached precipitate (stream 23) is completely dissolved in $1.0 \mathrm{M}$ sulfuric acid to produce an approximate $10 \%$ aluminum sulfate solution that could be further concentrated to produce a $45 \% \mathrm{Al}_{2}\left(\mathrm{SO}_{4}\right)_{3}$ product. According to the material balance, this solution would need to be further refined to remove arsenic, cadmium, and silica to meet product specifications, but this would need to be determined experimentally.

The second precipitation takes place by adding $1.0 \mathrm{M}$ sodium hydroxide to adjust $\mathrm{pH}$ to 10.8 to remove the zinc and about $98 \%$ of the manganese from the incoming stream (stream 7). This precipitate is redissolved, combined with the leach liquor from the previous precipitation step (stream 22), and sent to an electrowinning process to produce zinc metal and a manganese dioxide byproduct. The manganese dioxide can be sold as a byproduct or further converted to a sulfate (as shown in the flowsheet) to consume sulfuric acid. A portion of the manganese dioxide could also be used in the aeration step to assist oxidation. The flowsheet for the dissolution/electrowinning process is not rigorous because the exact conditions and process configuration for the electrowinning step would need to be determined. The flowsheet produces a pure manganese dioxide stream for tracking the manganese and determining stoichiometric sulfuric acid requirements to convert it to a sulfate. The actual precipitate likely contains other contaminants as well as liquid. Similarly, a waste stream is indicated for the electrowinning process to track the need to dispose of impurities. In fact, the discharge from the electrowinning step usually contains about half of the zinc entering the process. This stream is typically recycled to the previously described leach step. Eventually a slip stream (not shown) will need to be taken and further treated to prevent the buildup of impurities. Treatment of the slip stream would likely be incorporated into the water treatment process following the second precipitation step. 
The supernate from the second precipitation step (stream 9) is treated using electrodialysis to recover sulfuric acid and caustic from the water for use in the process. A neutralization pretreatment step is included to minimize fouling by calcium and magnesium in the subsequent membrane separation processes, particularly in the reverse osmosis (RO) step (discussed below) where these species are concentrated. The neutralization step precedes electrodialysis to recover and recycle the added sulfuric acid.

The electrodialysis process is used to recover sodium hydroxide and sulfuric acid from the neutralized process stream (stream 10). It was assumed that $98 \%$ rejection of multivalent cations would be achieved in the alkaline product stream, with only $5 \%$ rejection of monovalent cations. It was also assumed that only $5 \%$ rejection of monovalent anions would be achieved for the acid stream. The product stream flows were adjusted to produce $1 \mathrm{M} \mathrm{NaOH}$ and $1 \mathrm{M}_{2} \mathrm{SO}_{4}$ product streams. Sodium hydroxide recovered in the electrodialysis system would provide $96 \%$ of the caustic requirements shown in the flowsheet. Sulfuric acid recovered would provide a little over $135 \%$ of system flowsheet requirements. Surplus acid would need to be sold, or neutralized and disposed.

The treated process stream leaving the electrodialysis system (stream 11) is processed in a RO system. It is assumed that an $80 \%$ recovery of treated water, based on the feed to the unit would be achieved, with $99 \%$ rejection of all ions from the permeate. These values are considered reasonable for the low concentrations encountered for each ion species. With these assumptions, all of the permeate from the RO system meets the Clean Option discharge goals for the constituents shown in Table 1 . The concentrate from the RO system contains about $2000 \mathrm{mg} / \mathrm{l}$ calcium and magnesium as well as a number of contaminants of interest. According to the treatability data these concentrations would remain in solution even up to a pH of 8.2. The concentrate stream (stream 13) would contain about $20 \%$ of the original feed from the Berkeley Pit, and would require further treatment to precipitate solids from the stream.

There are several options for treating the concentrate from the RO unit, but none were developed in the flowsheet. All options need to focus on the removal of sulfate and sodium from stream 13 and precipitation of the heavy metals in the stream. Sulfate removal can be accomplished in four ways: 1) lime precipitation to produce calcium sulfate and magnesium hydroxide salts; 2) bioreduction to precipitate calcium carbonate and reduce the sulfate to elemental sulfur and hydrogen sulfide gas; 3) evaporation/ crystallization or freeze crystallization of the concentrate to produce calcium and magnesium sulfate salts; and 4) addition of sodium carbonate to precipitate the calcium followed by electrodialysis to recover sodium and sulfuric acid. One possible approach would be to add sodium hydroxide to remove magnesium hydroxide, and softening using $\mathrm{NaHCO}_{3}$, to precipitate calcium carbonate followed by electrodialysis to separate the sodium sulfate stream into sodium hydroxide and sulfuric acid, as described previously. In this approach, relatively pure magnesium hydroxide can be recovered by first adding caustic to raise the $\mathrm{pH}$ up to about 11.5 to precipitate magnesium, and then softening in a separate step to recover calcium carbonate; however, it is questionable whether a sufficient market exists for magnesium hydroxide or magnesium sulfate to justify the separation, in which case both steps would be combined to produce a mixed precipitate. Presumably, the other contaminants will precipitate in the precipitation steps.

\section{Nonselective Concentration Strategies}

There are several methods available to preconcentrate the constituents to be recovered from the water. The three flowsheets described in the following sections provide examples of three different 
approaches: 1) preconcentration of feedwater using nanofiltration; 2) semiselective separation of constituents using solvent extraction; and 3) semiselective separation of constituents using precipitation.

\section{Preconcentration of Feedwater Using Nanofiltration}

The flowsheet shown in Figure 3 includes a nonselective concentration step, followed by selective separation/purification of the concentrate and secondary water treatment steps. Products recovered from the Berkeley Pit water include copper sulfate, ferric sulfate, zinc sulfate, and manganese sulfate. All selective separation processes use solvent extraction (e.g., Lo, Baird, and Hanson 1983; Ritcey and Ashbrook 1979). Nanofiltration, RO, electrodialysis, and precipitation are used to remove other contaminants from the water. The processing steps and the assumptions made in the performance of those processing steps are given below. A simplified material balance, based on ideal splits of constituents to the various streams for the flowsheet, is provided in Appendix E. This is necessary because experimental testing would be required to determine these splits using a specific solvent extraction process.

The primary concentration step is nanofiltration, where a two-fold concentration of metals is assumed. It may be possible to concentrate the stream even further; however, in this case only a two-fold increase in concentration was assumed to guard against metals precipitation. The metals-laden stream (stream 3 ) then goes to an aeration step. The water resulting from the nanofiltration step containing sulfuric acid (stream 2) goes to an acid concentration/secondary water treatment step. In this step, it has been assumed that all of the multivalent metals are removed during nanofiltration. In actuality, some trace amounts of these metals may be present in this stream. In the flowsheet, RO is shown to be the acid concentration step. A ten-fold acid concentration step is assumed here and the resulting acid stream, now at a $\mathrm{pH}$ of 1.7 , can be re-used elsewhere in other processing steps. The discharge water resulting from the $\mathrm{RO}$ step is assumed to be at a $\mathrm{pH}$ of 6.5 , and is also assumed to meet the water discharge requirements for other contaminants. In the flowsheet, this stream is shown to be free from impurities; however, the impurity levels need to be verified experimentally. Other polishing steps, such as ion exchange, may need to be employed if necessary to remove some of these contaminants to allow for discharge of the water. Recovered contaminants would be returned to the stream entering the aeration step (stream 3) described below.

The aeration step is used to oxidize iron (II) to iron (III), which is extracted in the next step. Hydrogen peroxide is shown as the oxidant in this flowsheet. Acid is added during aeration to maintain a pH of 2.7 by replacing acid consumed by oxidation of the iron. The aeration step follows nanofiltration because the iron (III) is more likely to foul the filtration membranes, and it is assumed that the water from the Berkeley Pit is recovered from a depth where iron is predominantly in the +2 state.

The oxidized stream (stream 8) is next treated by solvent extraction to remove the iron from the stream. A possible extractant that could be used in the iron extraction step is versatic acid. This extractant shows good affinity for iron (III) at a pH of 2.7. Other metals of interest (such as copper, zinc, and manganese) are not extracted at this $\mathrm{pH}$. Caustic is added to maintain a $\mathrm{pH}$ of 2.7 as the iron is extracted. Iron (III) can be efficiently stripped from the extractant at $\mathrm{pH}<1$. Therefore, the sulfuric acid recovered from the RO step or from the salt-splitting step (downstream in the process) could be further concentrated and used to strip the iron (III) from the extractant. The resulting iron (III) sulfatecontaining stream can then undergo further processing if necessary, or be sold directly as a high purity (i.e., 99.9\%) iron-sulfate-containing stream, as was discussed for the previous flowsheet. 


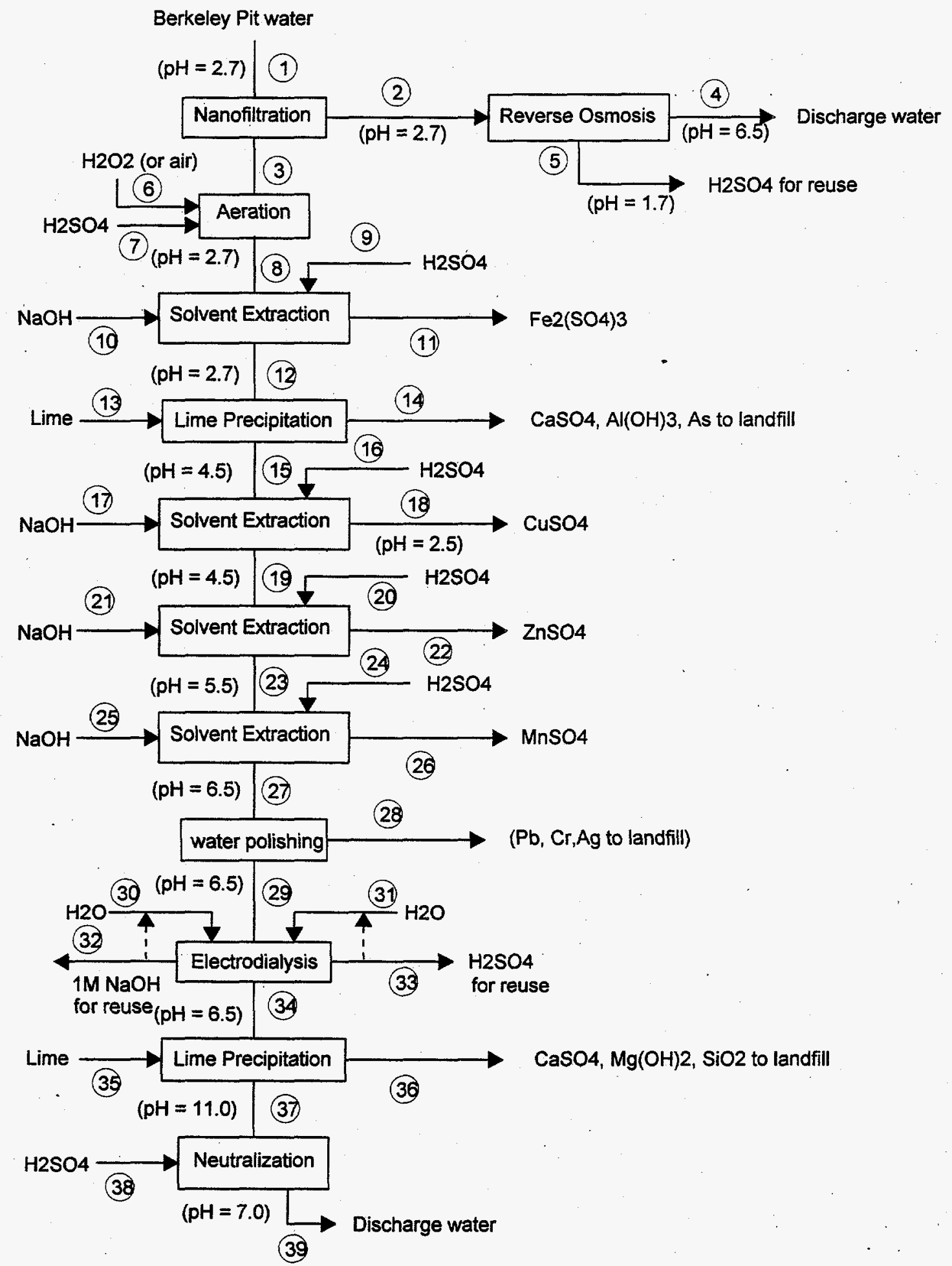

Figure 3. Flowsheet Showing Preconcentration of Feedwater Using Nanofiltration 
The next processing step involves the addition of lime to the raffinate stream (stream 12) from the preceding iron removal step. The addition of lime serves two purposes: 1) it allows for the precipitation and removal of unwanted waste components (e.g., aluminum and calcium), and 2) it aids in adjusting the stream to the desired $\mathrm{pH}$ for copper removal via solvent extraction, which occurs in the next processing step. The precipitated solids, consisting primarily of calcium and aluminum (and arsenic), are assumed to be concentrated to $20 \mathrm{wt} \%$ solids and disposed of in a landfill.

The supernatant (stream 15) is sent to a solvent extraction step for the removal and purification of copper. Versatic acid is a potential extractant that has good affinity for copper at a pH of 4.5, while not extracting zinc and manganese. Additional caustic is required to maintain the $\mathrm{pH}$ at 4.5 as the copper is extracted. Copper is also efficiently stripped from this extractant at $\mathrm{pH}<2.5$; therefore, the sulfuric acid recovered previously in the RO step could be used to strip the copper from the organic phase. The resulting copper-sulfate solution can then be further concentrated in a crystallization step (not shown) and sold directly as high-purity (i.e., 99.9\%) copper sulfate crystals or undergo electrowinning to recover copper metal.

The raffinate stream (stream 19) from the copper solvent extraction circuit then is sent to a zinc solvent extraction circuit. Sodium hydroxide is added as zinc is extracted to bring the $\mathrm{pH}$ to 5.5. Adjustment of the $\mathrm{pH}$ to approximately 5.5 allows for the efficient extraction of zinc via an extractant such as versatic acid. Other metals most likely to be extracted include cadmium, cobalt, and nickel. A cementation step using zinc dust could be added to the flowsheet, if necessary, to remove these unwanted metals. In the flowsheet, manganese is not shown to be extracted with zinc; however, it may in fact be extracted to some extent. If this is the case then both zinc and manganese could be extracted here, and could potentially be separated from one another by other means (e.g., electrowinning), and the manganese solvent extraction step (downstream) would not be used. The resulting zinc-laden organic stream can be stripped at $\mathrm{pH}<3.5$ using the sulfuric acid that was recovered via $\mathrm{RO}$. If it is assumed that all of the cadmium, cobalt, and nickel (and no manganese) are also extracted and stripped, the resulting stream would contain approximately $99.2 \%$ zinc on a metals basis. This stream could be further processed via electrowinning, for example, to obtain zinc metal, or could be sold directly as a high purity $(99.2 \%)$ zinc sulfate solution.

The raffinate stream (stream 23) from the zinc recovery step is then sent to a manganese solvent extraction step. Adjustment of the $\mathrm{pH}$ to approximately 6.5 allows for extraction of manganese via an extractant such as versatic acid. The resulting organic stream, containing manganese can be stripped at $\mathrm{pH}$ $<4.5$ using the sulfuric acid that was recovered via RO. This stream could be further processed via electrowinning, for example, to obtain manganese metal, or could be sold directly as a high purity manganese-bearing solution (i.e., $99.9 \%$ is assumed).

In the flowsheet it has been assumed that silver, chromium, lead, and magnesium were not removed in any of the solvent extraction steps. Thus, the raffinate stream (stream 27) from the manganese recovery and purification step would contain silver, chrome, lead, magnesium, and sulfate in quantities large enough that removal of these components is necessary so that the resulting water can be discharged. In the flowsheet, polishing steps to remove the metals in relatively low concentrations (i.e., silver, chrome, and lead) are shown. Ion exchange is a potential method for removing these metal ions because of their relatively low concentrations. After removal by ion exchange, the loaded ion-exchange material can either be eluted, and the metals precipitated out, or if it is economically and practically feasible to do so, the loaded ion-exchange materials can be sent directly to a landfill. 
The treated stream from the ion exchanger (stream 29) is then sent to an electrodialysis step. The electrodialysis system lowers the sulfate concentration in the effluent stream (stream 34) to help meet sulfate discharge criteria, and it produces sulfuric acid and sodium hydroxide streams for reuse in the process. In this processing step, it is assumed that approximately $1 \mathrm{~N}_{2} \mathrm{SO}_{4}$ and $\mathrm{NaOH}$ streams are produced, and that magnesium flows through the process, ending in stream 34 . Both of these assumptions would have to be experimentally verified.

The stream resulting from the electrodialysis step (stream 34) is still high in TDS and sulfate. A lime precipitation step, conducted at a $\mathrm{pH}$ of 11 is shown in the flowsheet for the removal of magnesium, sulfate, and $\mathrm{SiO}_{2}$. The precipitated solids, consisting of calcium sulfate, magnesium hydroxide, and $\mathrm{SiO}_{2}$ are assumed to be concentrated to $20 \mathrm{wt} \%$ solids, and disposed in a landfill.

The final step is the addition of $\mathrm{H}_{2} \mathrm{SO}_{4}$ to adjust the $\mathrm{pH}$ to between 6.5 to 8.0 for final discharge of the water (stream 39). This stream meets all of the clean option treatment goals for discharged water.

\section{Semiselective Separation of Constituents from Feedwater Stream Using Solvent Extraction}

Figure 4 shows an alternate method for preconcentrating recoverable metals for recovery. The basis of this process is a solvent exchange process that would nonselectively remove aluminum, copper, iron, manganese, and zinc in a single extraction unit. The extractant is treated by a series of strip circuits to selectively recover each of these metals for further refining. The treated water stream is further treated to recover magnesium for regenerating the extractant and removing sulfate to meet discharge criteria. A simplified material balance is provided in Appendix F.

The initial step in this process involves semiselective extraction using the NTHA-7 extractant, which has the ability to extract zinc, copper, aluminum, iron, and manganese. Other heavy metals (silver, cadmium, cobalt, chromium, nickel, lead, and vanadium) would also be extracted. Upstream of the extraction step, air injection (not shown) would be required to convert iron (II) to iron (III). In the extraction circuit, the extractant is initially loaded with magnesium (stream 2), and extraction of the other metals in the Berkeley Pit water displaces the magnesium into the aqueous phase. The weak acid form of the extractant could also be used, but $\mathrm{pH}$ control using a base such as sodium hydroxide would be required. The extracted metals are also concentrated by a factor of about 3 in the extractant. In addition to extracting the metals, this extraction step also serves as a concentration step.

The raffinate from the extraction step (stream 3 ) is at a $\mathrm{pH}$ of approximately 9 , and is primarily a $\mathrm{MgSO}_{4}$ and $\mathrm{CaSO}_{4}$ solution containing the other constituents present in the feedwater. Trace quantities of the heavy metals (not tracked in the material balance) would also be present depending on the extraction efficiency of the solvent. Magnesium is recovered from the raffinate by adding sodium hydroxide to the stream to increase the $\mathrm{pH}$ to 11.4 , causing $\mathrm{MgOH}$ to precipitate along with the trace heavy metals (stream 6). This precipitate is recovered and would be calcined to produce magnesium carbonate for regeneration of the extractant in stream 41 with the surplus sold as a product. Sodium carbonate is added in a second precipitation step to precipitate calcium carbonate (stream 8), which is disposed in a landfill. The filtrate stream is then neutralized and sent to an electrodialysis system where sulfuric acid and sodium hydroxide are recovered for reuse in the process. A portion of the sodium hydroxide could be converted back to sodium carbonate for reuse. Excess sulfuric acid and sodium hydroxide would be sold or neutralized and landfilled. 


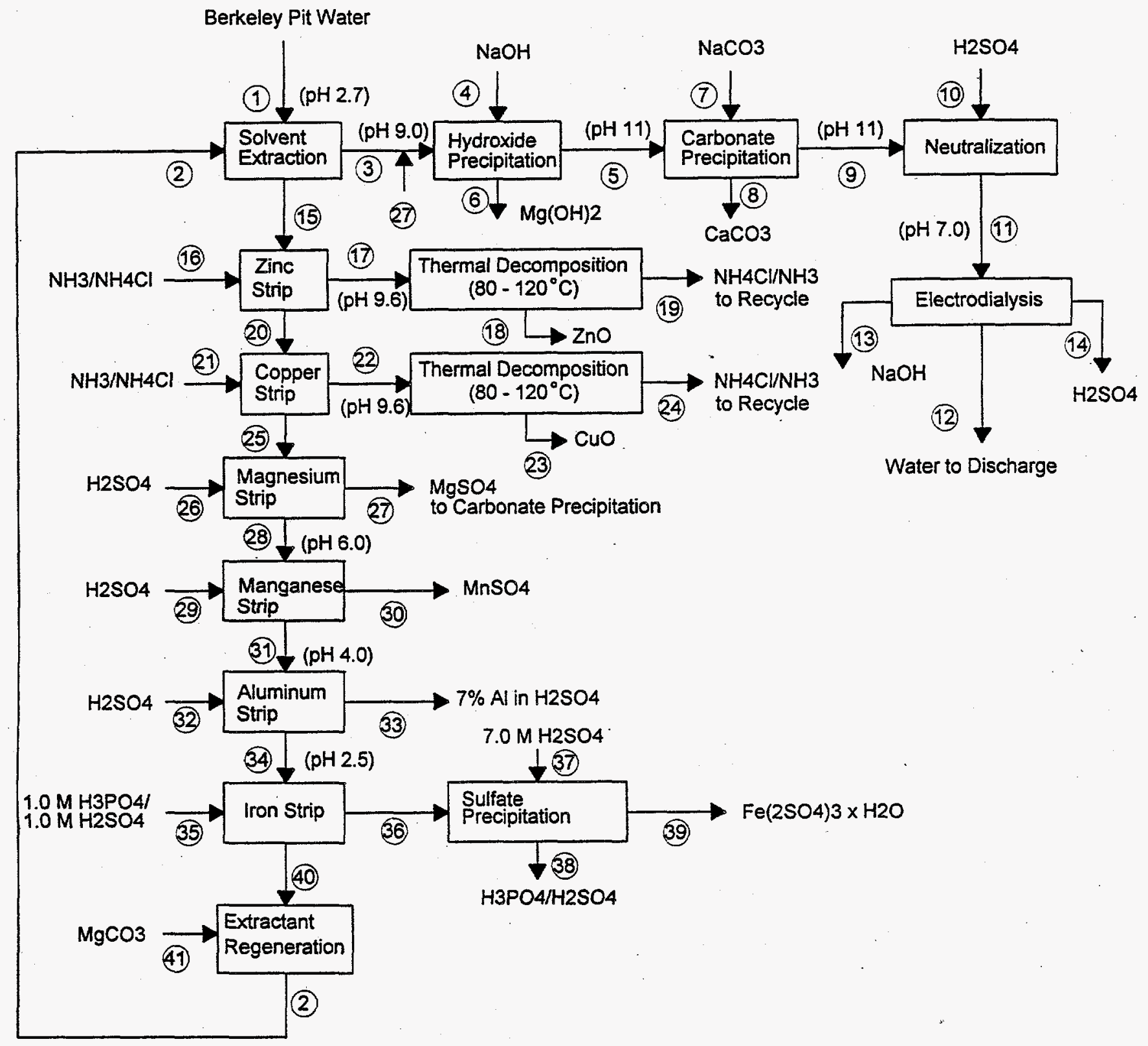

Figure 4. Flowsheet Showing Semiselective Separation of Constituents from Feedwater Using Solvent Extraction

The loaded extractant (stream 15) is sent to an ammonia strip circuit. The zinc (cadmium, silver) is stripped using counter-current flow with the aqueous phase and concentrated to a saleable $8 \%$ zinc ammonium chloride stream (stream 17). To achieve a higher concentrate, this solution could be thermally decomposed to provide a zinc oxide solid containing a cadmium trace impurity (stream 18) and an ammonia chloride aqueous stream (stream 19). The silver may remain with the aqueous ammonium 
chloride solution and be concentrated during each cycle. The ammonia could potentially be reabsorbed into the ammonium chloride solution; this solution would be recycled back to the zinc-stripping circuit.

The metal-loaded extractant stream (stream 20) then is sent to a copper-stripping circuit. Copper recovery occurs in an identical process to that used for zinc except that a stronger ammonia/ammonium chloride stripping solution is used. The trace nickel impurity would accompany the copper in the aqueous product stream (stream 22). This stream would then be thermally treated, and cupric oxide (black) would be produced as a saleable item (stream 23). The other process stream exiting the process would be an ammonia/ ammonium chloride solution (stream 24), which could be recycled back to the copper-stripping circuit.

The metal loaded extractant phase, now containing magnesium, manganese, aluminum, and iron, along with lead, chromium, and vanadium (stream 25); proceeds to an acid-stripping circuit. For selective stripping, the $\mathrm{pH}$ of each mixer is controlled by the addition of sulfuric acid solution via a $\mathrm{pH}$ controller. These acid solutions would be prepared in line from sulfuric acid that is recovered in the process.

Magnesium is the first metal recovered in the acid strip circuit and it is stripped from the extractant at a $\mathrm{pH}$ of 6 . The magnesium sulfate product-stripping solution (stream 27) is added to stream 3 and treated to recover $\mathrm{MgO}$.

The extractant phase continues to flow in a counter-current fashion in the acid-stripping circuit (stream 28). Manganese is removed next, along with trace levels of lead at a pH of 4 . The acid feed stream to the circuit is an $8 \%$ sulfuric acid solution (stream 29). The manganese strip product solution (stream 30) can be further processed to recover $\mathrm{MnSO}_{4}$. Excess sulfuric acid from processing would be recovered and reused as the acid feed stream (i.e., stream 29) at this part of the acid circuit.

A $40 \%$ sulfuric acid feed stream (stream 32) is used to strip aluminum out of the extractant phase (stream 31) in the next section of the acid-stripping circuit. The resulting strip solution contains approximately $90 \mathrm{~g} / 1$ ( $7 \mathrm{wt} \%$ ) aluminum in a sulfate solution (stream 33), and would be sold as a product. This stream represents a significant sulfate purge stream, providing that the $40 \%$ sulfuric acid used in the process originated from further concentration of stream 14.

The last metal to be removed from the extractant is the strongly held ferric iron. The use of a sulfuric acid/phosphoric acid blend (stream 35) has been shown to readily strip the iron due to the formation of a iron (III)-phosphate soluble complex. The iron (with trace vanadium) is concentrated to approximately $160 \mathrm{~g} / \mathrm{L}(14 \mathrm{wt} \%)$ by internal aqueous recycle and by counter-current flow, and then purged from the circuit (stream 36 ). Concentrated sulfuric acid can then be added to the purge stream, whereupon ferric sulfate is crystallized, isolated, and sold. The sulfuric acid/phosphoric acid supernatant could then be recovered and recycled back to the strip circuit (i.e., stream 35). The phosphoric acid is not consumed in the process. There is only one water of hydration in the ferric sulfate salt, and therefore a minimal amount of water needs to be shipped in the product.

After the iron is removed, the extractant is completely free of metals and is in the weak acid form (stream 40). Before returning the extractant phase to the extraction operation, it needs to be converted back into the magnesium form using some of the product in stream 6 . The weak acid form of the extractant could be used directly, however, $\mathrm{pH}$ control would be required (e.g., with $\mathrm{NaOH}$ addition). The magnesium form of the extractant is then routed to the extraction portion of the circuit (i.e., stream 2). 


\section{Semiselective Separation of Constituents from Feedwater Stream Using Precipitation}

The flowsheet (shown in Figure 5), is based on the flowsheet in Figure 2, adapted to include a conventional flowsheet (outlined in the figure) used by industry to recover zinc from a roasted zinc concentrate (Rosenqvist 1974). A simplified material balance is provided in Appendix $G$ for those operations not included in the treatment of the precipitate stream (stream 7). Insufficient information was available to rigorously evaluate the two-stage leaching process or acid recycle from the electrowinning process. This flowsheet shows a way to recover only zinc and copper without incurring unnecessary processing. to remove other constituents. A key element in this flowsheet is the two-stage leaching system that is used to separate zinc, and manganese from copper, cadmium nickel, iron, aluminum, and silica impurities. The flowsheet uses the copper cementation step to recover copper from the feed stream, in a concentrated form followed by a single sodium hydroxide precipitation step at a $\mathrm{pH}$ of 10.8 to remove all remaining major constituents except calcium and magnesium. Sodium hydroxide is added (stream 6 ) instead of lime to minimize precipitation of calcium sulfate, which would dilute the zinc values in the precipitate. The supernate from the precipitation step (stream 9) is further treated to meet discharge criteria in the same manner as was done in the first flowsheet.

The precipitate stream (stream 7 ) is treated in the same manner as the calcine from roasted zinc sulfide or concentrate, which consists principally of zinc oxide and some zinc sulfate mixed with iron, aluminum, silica as well as other trace impurities (Rosenqvist 1974). This concentrate is subjected to two leach steps to separate zinc and trace quantities of copper, nickel, cobalt, and cadmium from the precipitate.

The first leach step is conducted at a $\mathrm{pH}$ of about 5 to leach a portion of the zinc and copper from the precipitate, while precipitating iron and aluminum leached in the second step. In the second leach step, the precipitate leaving the first leach step is leached at a pH of about 2 to separate any remaining zinc and copper in the precipitate. The majority of the iron and aluminum remain undissolved in this step, probably as a basic sulfate. The precipitate from the acid leach is neutralized and discharged to a landfill or further treated to recover iron salts, and the leachate is returned to the neutral leach step. Recovery of aluminum salts to recover from the precipitate may not be practical because of the relatively high silica-to-aluminum ratio.

The leachate from the neutral leach step is passed through a cementation process where zinc dust is used to precipitate copper, nickel, and cadmium. The cemented copper and cadmium would have to be removed periodically and either treated to recover the copper and cadmium or discharged. The leachate leaving the cementation step (stream 19) is sent to an electrowinning step where $99.9 \%$ zinc metal and manganese dioxide are recovered. The electrolyte leaving this step is adjusted to a $\mathrm{pH}$ of 2 and returned to the acid leach step.

\section{Evaluation of Process Flowsheets}

The costs for different technologies and their sensitivities to process scale vary widely for both capital and $O \& M$ because of several factors including process complexity, material and energy requirements, minimum and maximum processing scale, and efficiency requirements. Consequently, accurate costs can only be obtained through more detailed site-specific economic analysis. Table 3 provides approximate unit operations cost for the various processes considered in flowsheet development. For the purpose of providing a preliminary evaluation of the flowsheets, only the average value of the O\&M 


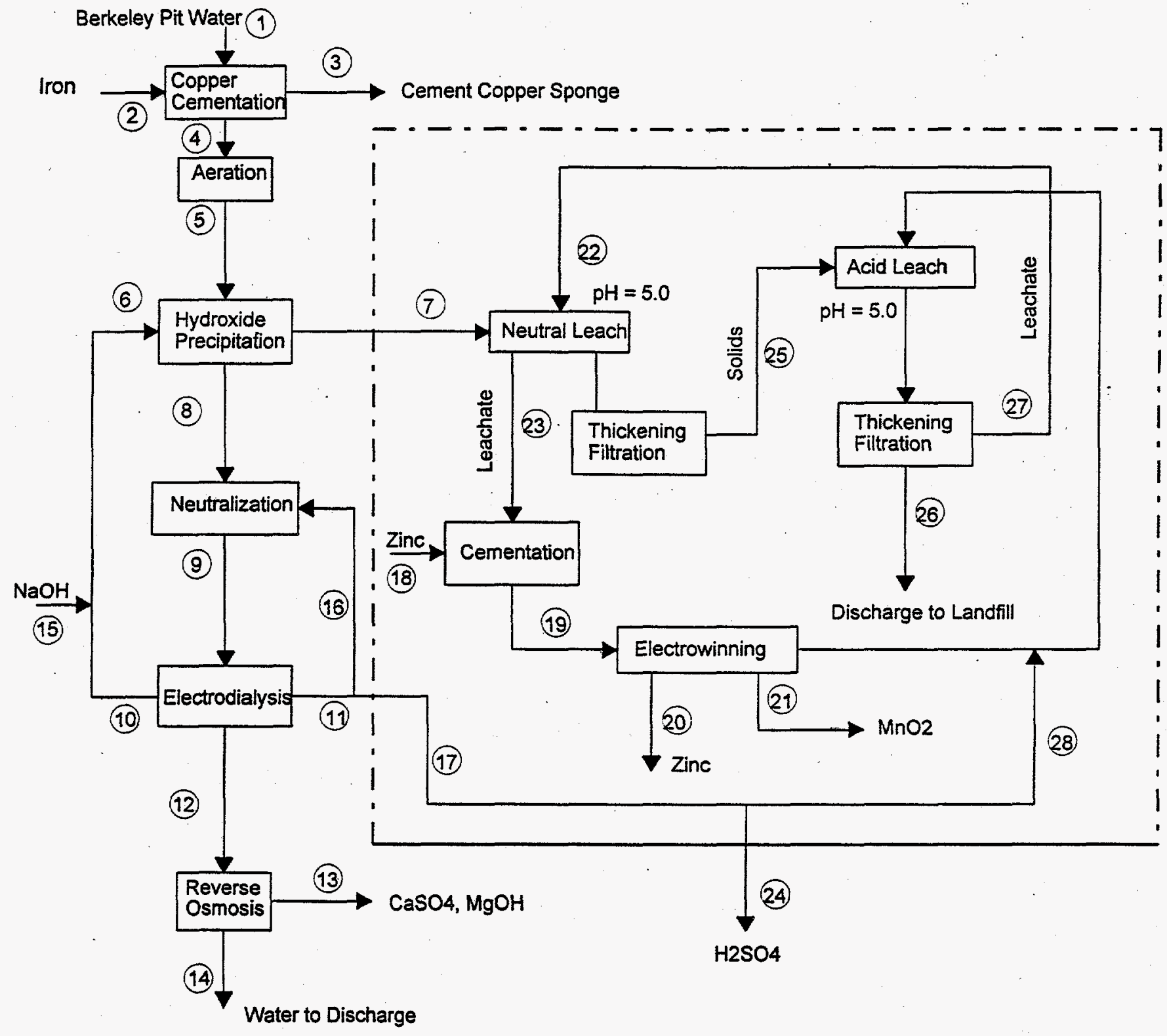

Figure 5. Flowsheet Showing Semiselective Separation of Constituents from Feedwater Using Precipitation

costs was used except where noted, recognizing that recovery of capital costs will increase the total process cost. Economic feasibility of resource recovery from a hazardous waste also needs to consider the minimum cost treatment of water and subsequent sludge disposal. These costs can total more than $\$ 23 / 1000 \mathrm{gal}$ of feedwater as described below. 
Minimum water treatment needed to achieve clean option goals for discharge water includes aeration and precipitation to remove heavy metals from the water, neutralization of the water to meet $\mathrm{pH}$ limits, and RO to reduce sulfate levels to less than $500 \mathrm{mg} / \mathrm{L}$. Concentrate from the RO step would still need to be further treated as it does in the four flowsheets. Using the average O\&M costs for these unit operations, shown in Table 3, treatment would cost $\$ 7 / 1000$ gal.

Table 3. Unit Operations Costs

\begin{tabular}{|c|c|c|c|}
\hline Process & Capital Costs & O\&M Costs & References \\
\hline Ion Exchange & Moderate to High & $\$ 7-11 / 1000$ gal & ARCO 1994 \\
\hline $\begin{array}{l}\text { Aeration/Precipitation } \\
\text { Cementation }\end{array}$ & Low To Moderate & $\$ 2-4 / 1000 \mathrm{gal}$ & ARCO 1994 \\
\hline Neutralization & Low & $\$ 1 / 1000$ gal & $\begin{array}{l}\text { Estimate relative to } \\
\text { precipitation costs }\end{array}$ \\
\hline Reverse Osmosis & $\begin{array}{l}\text { Moderate } \\
\$ 0.5 \text { - 5/GPD }\end{array}$ & $\begin{array}{l}\$ 1-5 / 1000 \mathrm{gal}^{(\mathrm{a})} \\
\$ 1-3 / 1000 \mathrm{gal}^{2}\end{array}$ & $\begin{array}{l}\text { ARCO } 1994 \\
\text { Cartwright } 1994\end{array}$ \\
\hline Leaching/Dissolution & $\begin{array}{l}\$ 80,000 \text { for a } \\
5 \text { ton/day plant }\end{array}$ & $\begin{array}{l}\text { \$0.61/Ton solids } \\
\text { processed (1978 } \\
\text { dollars) }\end{array}$ & DeRenzo 1978 \\
\hline Nanofiltration & $\$ 0.5-5 / G P D$ & $\$ 0.75-3 / 1000 \mathrm{gal}$ & Cartwright 1994 \\
\hline $\begin{array}{l}\text { Solvent Extraction/ } \\
\text { Electrowinning }\end{array}$ & Moderate to High & $\$ 7-11 / 1000 \mathrm{gal}$ & ARCO 1994 \\
\hline Electrowinning & Moderate to High & $\$ 1-2 / 1000$ gal & De Renzo 1978 \\
\hline Electrodialysis & $\$ 0.5-4 / G P D$ & $\$ 0.5-1 / 1000 \mathrm{gal}$ & Cartwright 1994 \\
\hline Evaporation & Moderate to High & $\$ 7-11 / 1000 \mathrm{gal}$ & ARCO 1994 \\
\hline
\end{tabular}

According to data from a treatability study for one-stage neutralization of the Berkeley Pit water (Canonie Environmental Services 1993), there would be about $14 \mathrm{~g}$ of solids produced from lime precipitation with aeration of $1 \mathrm{~L}$ of feed (or $117 \mathrm{lb}$ solids $/ 1000$ gal water treated). According to data reported by Teringo 1987 , this sludge can be pressure filtered to a about $35 \%$ solids corresponding to $334 \mathrm{lb}$ sludge $/ 1000 \mathrm{gal})$. About $150 \mathrm{~mL}$ of precipitate sludge would be produced for each liter of feedwater. Disposal costs for Land Disposal Restricted waste is on the order of $\$ 100 /$ ton. This translates into about $\$ 16.70 / 1000$ gal of water treated, not counting transportation costs. This cost also does not include disposal of additional sludge produced to further concentrate and precipitate sulfate in the filtrate to meet water discharge goals. However, treatment of the water to recover resources using the first flowsheet effectively produces no sludge, achieving the same degree of decontamination (also not counting further concentration and precipitation to meet sulfate goals for discharged water). Total treatment and disposal costs would be $\$ 23.7 / 1000$ gal. 


\section{Overview of Results}

Although an economic analysis of the previously described flowsheets are specific to the Berkeley Pit water, several observations can be made that would be applicable to any acid mine drainage because of the similarity in the composition of water at other sites. Differences in key constituents at other sites would primarily affect the optimal resource recovery process and site-specific economics.

Based on the preliminary cost analyses presented for the Berkeley Pit water, it appears that none of the individual flowsheets evaluated can generate a net profit through resource recovery. However, it is possible to significantly reduce the cost of treatment and disposal primarily by reducing the amount of sludge requiring disposal in a Resource Conservation and Reclamation Act (RCRA) landfill. Furthermore, by combining the best elements of the flowsheets, it may be possible to achieve a net profit for resource recovery.

Recovery of iron, aluminum, and manganese sulfate salts in addition to higher valued copper and zinc concentrates are important to the overall economics of resource recovery because their recovery provides both a significant source of revenue as well as a way for reducing the amount of sulfate being converted to sludge. However, the practicality of recovering these constituents depends on finding a market close enough to the facility to justify added transportation costs, which can be substantial if the salts are sold as solutions.

Waste minimization through the use of sodium hydroxide as a neutralizing reagent is also an important key to favorable economics because it can eliminate the addition of lime, which adds calcium to the water and ultimately leads to a significant increase in the amount of sludge generated. Recovery of sodium hydroxide and sulfuric acid using electrodialysis for recycle also minimizes the amount of sodium and sulfate remaining in the treated water. Recovery of only monovalent cations in the electrodialysis unit also greatly simplifies its operational requirements because the electrolytic strength of the incoming stream is only partially depleted, and sodium concentration in the treated stream can be much higher than would be required for other hazardous constituents if the purpose of the unit operation was to decontaminate the incoming stream. This approach also produces excess sulfuric acid from acid waste streams that could also be sold if a market exists, even though its sale does not contribute significantly to overall economics.

Preconcentration of water requiring further treatment to remove constituents from the water is important to reducing water treatment costs, because it reduces both the capital and O\&M costs for subsequent unit operations. A preferred way to accomplish this is by nonselective separation of constituents from the feedwater using nanofiltration in tandem with RO to produce a large volume of treated water that would be neutralized and treated using RO to remove any trace contaminants before discharge, and a smaller volume of contaminated water. However, the feasibility of nanofiltration to acid mine drainage needs to be demonstrated, because of possible adverse effects as a result of membrane fouling and degradation due to long-term exposure to low $\mathrm{pH}$. Solvent extraction can also be used to remove the desired constituents in a single stage, thereby concentrating them in the solvent phase for subsequent separation into desired product streams. Sodium hydroxide precipitation could also be applied as a concentration step followed by selective leaching of desired constituents from the resultant precipitate. In this case, the use of sodium hydroxide instead of lime not only reduces the sludge volume but also maximizes the concentration of each constituent in the sludge by minimizing the calcium sulfate 
inventory. Evaporation of the feedwater may also be feasible if the volume of acid mine drainage is modest. In the case of the Berkeley Pit, evaporation is not practical.

As previously discussed, it may not be practical to recover iron and aluminum salts because there is no nearby market. However, recovery of zinc and copper may still be justified if their values are sufficiently high; they not only provide a source of revenue with readily available markets to reduce treatment costs, but they also provide for a modest reduction in the amount of sludge requiring disposal. While copper can be readily recovered in a relatively pure form using precipitation or cementation, zinc is less readily recovered because of interference from iron, which adversely affects subsequent zinc purification. Removal of iron can be achieved by either selective separation using ion exchange or solvent extraction before zinc recovery, or by precipitation of zinc, aluminum, and iron at a relatively neutral $\mathrm{pH}$ followed by selective leaching of the zinc-rich concentrate, as is currently practiced by industry for zinc ore.

In all flowsheets analyzed for resource recovery, two sulfate-rich streams are produced but not further treated in this study. One stream is the calcium sulfate-rich waste stream produced either as a concentrate stream from a RO unit or from the neutralization of a high $\mathrm{pH}$ stream following lime precipitation. The second stream results from the net production of sulfuric acid from the pit water that may not have a ready market. A couple of techniques that warrant investigation are available for treating these streams.

The concentrated stream from a RO unit is substantially reduced in volume. In this case evaporation of the stream to recover calcium (and magnesium) salts may be economically feasible. Alternatively, the stream could be treated with sodium carbonate to precipitate out calcium carbonate and treated with electrodialysis to recover the sodium and sulfuric acid. If markets are not available for either product, it may be possible to calcine the sulfuric acid and calcium sulfate to produce sulfur dioxide and calcium carbonate (the latter can be disposed in a conventional landfill). The sulfur dioxide can then be reduced to elemental sulfur, as is done in other industries, and then disposed in a landfill.

\section{Economic Analyses of Flowsheets}

Tables 4 and 5 summarize the costs and income expected from resource recovery using the flowsheet in Figure 2 that used unit operations in a series to maximize recovery of constituents from the Berkeley Pit water. It can be seen from these tables that this process would not be economical from a strictly recovery perspective because the net loss would be $\$ 9.22 / 1000$ gal. However, when costs of disposal are considered, the total net cost of resource recovery would still be $\$ 9.22 / 1000$ gal, whereas simple treatment and disposal would be $\$ 23.70 / 1000 \mathrm{gal}$, as was discussed in the previous section. Thus, the value added by resource recovery is $\$ 14.48 / 1000$ gal.

An important observation of the income from resource recovery is that only about $29 \%$ of the income is derived from zinc and copper. In the case of the Berkeley Pit, it is not certain that a large market for the other products is sufficiently close to justify the added transportation costs. However, in a bettersituated location, these products may be readily marketed. If a market for all of these lower value products cannot be found, then they would need to be disposed, thereby creating a sludge disposal cost of $\$ 14.63 / 1000$ gal (total disposal cost accounting for sludge reduction by recovery of zinc and copper sulfate equivalent) and an income of only $\$ 4.14 / 1000 \mathrm{gal}$. In this case, the net cost of resource recovery is $\$ 35.48$, which is more than the cost of simpler treatment and disposal. 
Table 4. Preliminary Process Costs of Flowsheet Illustrating Series Separation of Individual Components

\begin{tabular}{||l|c|c|c||}
\hline \multicolumn{1}{|c|}{ Process } & Process Feedrate & Assumed Process Cost & $\begin{array}{c}\text { Cost } / 1000 \text { gal of BP } \\
\text { Water Treated }\end{array}$ \\
\hline Copper Cementation & $1000 \mathrm{gal}$ & $\$ 3.00 / 1000 \mathrm{gal}$ & $\$ 3.00$ \\
\hline Ion Exchange & $1010 \mathrm{gal}$ & $\$ 9.00 / 1000 \mathrm{gal}$ & $\$ 9.11$ \\
\hline Aluminum Precipitation & $1012 \mathrm{gal}$ & $\$ 3.00 / 1000 \mathrm{gal}$ & $\$ 3.04$ \\
\hline Aluminum Leaching & $1.13(10)^{-3}$ ton & $\$ 61 /$ ton feed solids & $<\$ 0.07$ \\
\hline Aluminum Dissolution & $9.91(10)^{-4}$ ton & $\$ 61 /$ ton feed solids & $<\$ 0.06$ \\
\hline Zinc Precipitation & $1130 \mathrm{gal}$ & $\$ 3.00 / 1000 \mathrm{gal}$ & $\$ 3.39$ \\
\hline Zinc Dissolution & $4.36(10)^{-3}$ ton & $\$ 61 / \mathrm{ton}$ feed solids & $\$ 0.27$ \\
\hline Zinc Electrowinning & $33.9 \mathrm{gal}$ & $\$ 3.00 / 1000 \mathrm{gal}$ & $\$ 0.10$ \\
\hline Manganese Neutralization & $<38.8 \mathrm{gal}$ & $\$ 1.00 / 1000 \mathrm{gal}$ & $<\$ 0.01$ \\
\hline Treated Water & $1148 \mathrm{gal}$ & $\$ 1.00 / 1000 \mathrm{gal}$ & $\$ 1.15$ \\
\hline Neutralization & $1195 \mathrm{gal}$ & $\$ 1.00 / 1000 \mathrm{gal}$ & $\$ 1.20$ \\
\hline Electrodialysis & $1195 \mathrm{gal}$ & $\$ 3.00 / 1000 \mathrm{gal}$ & $\$ 3.59$ \\
\hline Reverse Osmosis & & $\cdot$ & $\$ 24.99$ \\
\hline Total Treatment Cost & & & \\
\hline
\end{tabular}

Table 5. Preliminary Value of Recovered Resources from Flowsheet Illustrating Series Separation of Individual Components

\begin{tabular}{|l|l|l|l||}
\hline \multicolumn{1}{|c|}{ Product } & Price & $\begin{array}{l}\text { Production/1000 } \\
\text { gal Feedwater }\end{array}$ & Income \\
\hline Cement Copper $(80 \% \mathrm{Cu})$ & $\$ 0.97 / \mathrm{lb}$ & $1.47 \mathrm{lb}$ & $\$ 1.42$ \\
\hline $\begin{array}{l}\text { Aluminum Sulfate } \\
\left(45 \% \mathrm{Al}_{2}\left(\mathrm{SO}_{4}\right)_{3}\right)\end{array}$ & $\$ 230 /$ ton & 0.0110 tons & $\$ 3.36$ \\
\hline Zinc & $\$ 0.62 / \mathrm{lb}$ & $4.38 \mathrm{lb}$ & $\$ 2.72$ \\
\hline $\begin{array}{l}\text { Manganese Sulfate }(29.5 \% \\
\left.\mathrm{MnSO}_{4}\right)\end{array}$ & $\$ 475 /$ ton & .00672 tons & $\$ 3.20$ \\
\hline Ferric Chloride & $\$ 410 /$ ton & 0.0124 tons & $\$ 5.07$ \\
\hline \hline Total & & & $\$ 15.77$ \\
\hline
\end{tabular}


Tables 6 and 7 summarize the costs and income for the flowsheet in Figure 5 (a simplification of the previous flowsheet) to recover only copper and zinc. In this case, the treatment cost is $\$ 12.72 / 1000$ gal. However, this process still produces a large quantity of sludge. There is insufficient data to calculate the volume of sludge requiring disposal because the dry weight of the leached solids is not known. A comparison of data for lime and sodium precipitation of nonaerated sludge (Canonie Environmental Services 1993) suggests that there would be a much smaller dry weight of solids produced from sodium precipitation (almost 60\% less for precipitation of nonaerated sludge). However, according to data reported by Teringo 1987 , sodium hydroxide sludge can be pressure filtered to only about $30 \%$ solids (about $17 \%$ greater volume for equal dry weights of sludge). For purposes of this analysis, it is assumed that the amount of sludge generated is proportional to the weight of the constituents in the leached precipitate. Using this assumption, this process would remove zinc and copper from the precipitate, which accounts for about $6.7 \%$ of the TDS in the Berkeley Pit water. This would reduce the sludge disposal cost by a corresponding amount to about $\$ 15.60 / 1000$ gal of water treated precipitate resulting in a net resource recovery and disposal cost of $\$ 28.32$, as opposed to $\$ 23.70 / 1000$ gal for simple treatment and disposal, while much less than the cost required for recovery of the other constituents in the previous flowsheet, it is still not competitive with simple treatment and disposal.

Recovery and sale of manganese as a sulfate for this flowsheet would improve revenue by about $\$ 3.00 / 1000$ gal and reduce disposal costs by about $\$ 0.80 / 1000$ gal. Further research would need to be conducted to determine whether the total sludge produced is less than that assumed in this analysis.

Table 6. Preliminary Process Costs from Flowsheet Illustrating Semiselective Separation of Constituents Using Precipitation

\begin{tabular}{|l|l|l|l||}
\hline \multicolumn{1}{|c|}{ Process } & Process Feedrate & Assumed Process Cost & $\begin{array}{l}\text { Cost/1000 gal of BP } \\
\text { Water Treated }\end{array}$ \\
\hline \hline Copper Cementation & $1000 \mathrm{gal}$ & $\$ 3.00 / 1000 \mathrm{gal}$ & $\$ 3.00$ \\
\hline $\begin{array}{l}\text { Hydroxide } \\
\text { Precipitation }\end{array}$ & $1100 \mathrm{gal}$ & $\$ 3.00 / 1000 \mathrm{gal}$ & $\$ 3.30$ \\
\hline Neutral Leach & $.037 \mathrm{ton}$ & $\$ 61 /$ ton feed solids & $\$ 2.26$ \\
\hline Acid leach & $.037 \mathrm{ton}$ & $\$ 61 /$ ton feed solids & $\$ 2.26$ \\
\hline Zinc Electrowinning & $38.8 \mathrm{gal}$ & $\$ 3.00 / 1000$ gal & $\$ 0.12$ \\
\hline $\begin{array}{l}\text { Treated Water } \\
\text { Neutralization }\end{array}$ & $1150 \mathrm{gal}$ & $\$ 1.00 / 1000 \mathrm{gal}$ & $\$ 1.15$ \\
\hline Electrodialysis & $1180 \mathrm{gal}$ & $\$ 1.00 / 1000 \mathrm{gal}$ & $\$ 1.18$ \\
\hline Reverse Osmosis & $1180 \mathrm{gal}$ & $\$ 3.00 / 1000 \mathrm{gal}$ & $\$ 3.54$ \\
\hline \hline Total Cost & & & $\$ 16.86$ \\
\hline
\end{tabular}


Table 7. Preliminary Value of Recovered Resources from Flowsheet Illustrating Semiselective Separation of Constituents Using Precipitation

\begin{tabular}{||l|l|l|l||}
\hline \multicolumn{1}{|c|}{ Product } & Price & $\begin{array}{l}\text { Production/1000 } \\
\text { gal Feedwater }\end{array}$ & Income \\
\hline Cement Copper $(80 \% \mathrm{Cu})$ & $\$ 0.97 / \mathrm{lb}$ & $1.47 \mathrm{lb}$ & $\$ 1.42$ \\
\hline Zinc & $\$ 0.62 / \mathrm{lb}$ & $4.38 \mathrm{lb}$ & $\$ 2.72$ \\
\hline \hline Total & & & $\$ 4.14$ \\
\hline
\end{tabular}

Tables 8 and 9. summarize costs and income for the flowsheet in Figure 3, which preceded series separation by a nonselective concentration step using nanofiltration. In this case, solvent extraction is used exclusively for series separation of each component from Pit water, even though it is a more expensive process than precipitation. However, processing costs, which are based on feedrate are effectively reduced by a factor of nearly 2 by preconcentrating the feed using nanofiltration by a factor of 2 . Consequently, the total treatment cost is $\$ 29.99$. Because this flowsheet also produces two sludge streams (streams 14 and 36 ), there is an added sludge disposal cost of $\$ 8.42$. Net resource recovery and disposal costs for this flowsheet are $\$ 24.36$, if all products can be marketed and are comparable to simple treatment and disposal. However, total costs increase to $\$ 32.59$ if only markets for zinc and copper sulfates can be found.

Even though costs associated with the above process are not favorable, the advantages of preconcentration are evident, and if a greater degree of preconcentration could be achieved, treatment costs could be further reduced. Achieving a volume reduction of 3 times, the treatment costs would be reduced to about $\$ 21$ and a total cost of recovery and disposal of about $\$ 15.4$ to 23.5 depending on the availability of markets for ferric and manganese sulfates.

The application of a preconcentration strategy using nanofiltration or RO is not considered proven because of the low pH of the feedwater and because of the potential for fouling of membranes due to calcium, magnesium, and silica in the water at or near saturation conditions and requires experimental verification. However, the flowsheet in Figure 5 uses solvent extraction to separate all of the desired constituents from the feedwater, leaving behind principally the calcium, silica, and sulfate. Tables 10 and 11 show the approximate costs and income associated with this flowsheet. In this example, the solvent extraction costs are assumed to be double the average cost due to the increased complexity of applying six low-volume stripping steps in the solvent extraction step. This assumption is made for illustration purposes only, since there is no specific data to make this claim. Treatment costs total $\$ 22.52 / 1000$ gal with no sludge produced from the constituents of interest. Income for the process is $\$ 14.05 / 1000$ gal for a net total recovery and disposal cost of $\$ 8.47$ I 1000 gal. The net value added over simple treatment and disposal for this process flowsheet is $\$ 15.23$. 
Table 8. Preliminary Costs for Flowsheet Showing Preconcentration of Feedwater

\begin{tabular}{||l|l|l|l||}
\hline \multicolumn{1}{|c|}{ Process } & Process Feedrate & Assumed Process Cost & $\begin{array}{l}\text { Cost/1000 gal of BP } \\
\text { Water Treated }\end{array}$ \\
\hline Nanofiltration & $1000 \mathrm{gal}$ & $\$ 3.00 / 1000 \mathrm{gal}$ & $\$ 3.00$ \\
\hline Reverse Osmosis & $495 \mathrm{gal}$ & $\$ 3.00 / 1000 \mathrm{gal}$ & $\$ 1.49$ \\
\hline Iron Solvent Extraction & $505 \mathrm{gal}$ & $\$ 8.00 / 1000 \mathrm{gal}$ & 4.04 \\
\hline Aluminum Precipitation & $522 \mathrm{gal}$ & $\$ 3.00 / 1000 \mathrm{gal}$ & $\$ 1.58$ \\
\hline Copper Solvent Extraction & $508 \mathrm{gal}$ & $\$ 8.00 / 1000 \mathrm{gal}$ & $\$ 4.06$ \\
\hline Zinc Solvent Extraction & $514 \mathrm{gal}$ & $\$ 8.00 / 1000 \mathrm{gal}$ & $\$ 4.11$ \\
\hline $\begin{array}{l}\text { Manganese Solvent } \\
\text { Extraction }\end{array}$ & $530 \mathrm{gal}$ & $\$ 8.00 / 1000 \mathrm{gal}$ & $\$ 4.24$ \\
\hline $\begin{array}{l}\text { Ion Exchange } \\
\text { Electrodialysis }\end{array}$ & $536 \mathrm{gal}$ & $\$ 9.00 / 1000 \mathrm{gal}$ & $\$ 4.82$ \\
\hline Lime Precipitation & $536 \mathrm{gal}$ & $\$ 1.00 / 1000 \mathrm{gal}$ & $\$ 0.54$ \\
\hline Treated Water Neutralization & $519 \mathrm{gal}$ & $\$ 3.00 / 1000 \mathrm{gal}$ & $\$ 1.59$ \\
\hline \hline Total Cost & & $\$ 1.00 / 1000 \mathrm{gal}$ & $\$ 0.52$ \\
\hline
\end{tabular}

Table 9. Preliminary Value of Recovered Resources from Flowsheet Illustrating Preconcentration of Feedwater

\begin{tabular}{||l|l|l|l||}
\hline \multicolumn{1}{|c|}{ Product } & Price & $\begin{array}{l}\text { Production/1000 } \\
\text { gal feedwater }\end{array}$ & Income \\
\hline \hline Ferric Sulfate (12\% Fe Solution) & $\$ 160 /$ ton & 0.0303 tons & $\$ 4.85$ \\
\hline Copper Sulfate pentahydrate & $\$ 0.58 / \mathrm{lb}$ & $5.81 \mathrm{lb}$ & $\$ 3.37$ \\
\hline Zinc Sulfate & $\$ 480 /$ ton & 0.00524 tons & $\$ 2.52$ \\
\hline Manganese Sulfate (29.9\% MnSO $)$ & $\$ 475 /$ ton & .00698 tons & $\$ 3.31$ \\
\hline \hline Total & & & $\$ 14.05$ \\
\hline
\end{tabular}


Table 10. Preliminary Costs of Recovered Resources from Flowsheet Illustrating Semiselective Separation of Constituents from the Feedwater Using Solvent Extraction

\begin{tabular}{|l|l|l|l|}
\hline \multicolumn{1}{|c|}{ Process } & Process Feedrate & Assumed Process Cost & $\begin{array}{l}\text { Cost/1000 gal of BP } \\
\text { Water Treated }\end{array}$ \\
\hline \hline Solvent Extraction & $1000 \mathrm{gal}$ & $\$ 14.00 / 1000 \mathrm{gal}$ & $\$ 14.00$ \\
\hline Hydroxide Precipitation & $999 \mathrm{gal}$ & $\$ 3.00 / 1000 \mathrm{gal}$ & $\$ 3.00$ \\
\hline Carbonate Precipitation & $1005 \mathrm{gal}$ & $\$ 3.00 / 1000 \mathrm{gal}$ & 3.01 \\
\hline Sulfate Precipitation & $6.26 \mathrm{gal}$ & $\$ 3.00 / 1000 \mathrm{gal}$ & $\$ 0.19$ \\
\hline Neutralization & $1096 \mathrm{gal}$ & $\$ 1.00 / 1000 \mathrm{gal}$ & $\$ 1.10$ \\
\hline Electrodialysis & $1096 \mathrm{gal}$ & $\$ 1.00 / 1000 \mathrm{gal}$ & $\$ 1.10$ \\
\hline \hline Total Cost & & & $\$ 22.22$ \\
\hline
\end{tabular}

Table 11. Preliminary Value of Recovered Resources from Flowsheet Illustrating Semiselective Separation of Constituents from the Feedwater Using Solvent Extraction

\begin{tabular}{|l|l|l|l|}
\hline \multicolumn{1}{|c|}{ Product } & Price & $\begin{array}{l}\text { Production/1000 } \\
\text { gal feedwater }\end{array}$ & Income \\
\hline \hline Ferric Sulfate (12\% Fe Solution) & $\$ 160 /$ ton & 0.0132 tons & $\$ 4.85$ \\
\hline Copper Sulfate Pentahydrate & $\$ 0.58 / \mathrm{lb}$ & $5.81 \mathrm{lb}$ & $\$ 3.37$ \\
\hline Zinc Sulfate & $\$ 480 /$ ton & 0.00524 tons & $\$ 2.52$ \\
\hline Manganese Sulfate (29.9\% MnSO $)$ & $\$ 475 /$ ton & .00698 tons & $\$ 3.31$ \\
\hline \hline Total & & & $\$ 14.05$ \\
\hline
\end{tabular}

\section{Conclusions}

In developing the four flowsheets for analysis, it was apparent that a number of technologies would be suitable for specific operations and alternate flowsheets could be prepared simply by substituting comparable technologies for specific unit operations where practical alternatives exist. On the other hand, the four flowsheets illustrate alternative ways for applying the key elements in a treatment strategy: 1) concentration of desired constituents to be recovered, 2) selective separation and purification of desired constituents, and 3) water treatment.

The economic analyses of the flowsheets are both preliminary in nature and specific to the water composition of the Berkeley Pit, and should not be considered as accurate costs for either the Berkeley Pit or other sites. However, the economic analyses provide a basis for comparing the different strategies and identifying those elements that would be applicable to any acid mine drainage because of similarities to the composition of water at other sites. Differences in key constituents at other sites would primarily affect the optimal resource recovery process and site-specific economics. 
In the specific case of the Berkeley Pit water, it is apparent that none of the individual flowsheets evaluated can generate a net profit through resource recovery. However, it is possible to significantly reduce the cost of treatment and disposal primarily by reducing the amount of sludge requiring disposal in a Resource Conservation and Reclamation Act (RCRA) landfill. Furthermore, by combining the best elements of the flowsheets, it may be possible to achieve a net profit for resource recovery.

Preconcentration of water requiring further treatment to remove constituents is important to reducing water treatment costs because it reduces both the capital and O\&M costs for subsequent unit operations. A preferred way to accomplish this is by nonselective separation of constituents from the feedwater using nanofiltration in tandem with $\mathrm{RO}$. This would produce a large volume of treated water that would be neutralized and treated using $\mathrm{RO}$ to remove any trace contaminants before discharge, and a smaller volume of contaminated water. However, the feasibility of nanofiltration to acid mine drainage needs to be demonstrated because of possible adverse effects resulting from membrane fouling, and degradation due to longterm exposure to low $\mathrm{pH}$. Solvent extraction can also be used to remove the desired constituents in a single stage, thereby concentrating them in the solvent phase for subsequent separation into desired product streams. Sodium hydroxide precipitation could also be applied as a concentration step followed by selective leaching of desired constituents from the resultant precipitate. In this case, the use of sodium hydroxide instead of lime not only reduces the sludge volume but also maximizes the concentration of each constituent in the sludge by minimizing the calcium sulfate inventory. Evaporation of the feedwater may also be feasible if the volume of acid mine drainage is modest. In the case of the Berkeley Pit, evaporation is not practical.

Waste minimization through the use of sodium hydroxide as a neutralizing reagent is also an important key to favorable economics because it can eliminate the addition of lime. Lime adds calcium to the water and ultimately leads to a significant increase in the amount of sludge generated. Recovery of sodium hydroxide and sulfuric acid using electrodialysis for recycle also minimizes the amount of sodium and sulfate remaining in the treated water. This approach also produces excess sulfuric acid from acid waste streams that could be sold if a market exists, even though its sale does not contribute significantly to overall economics.

Recovery of iron, aluminum, and manganese sulfate salts in addition to the higher valued copper and zinc concentrates are important to the overall economics of resource recovery because their recovery provides both a significant source of revenue as well as a way for reducing the amount of sulfate being converted to sludge. However, it may not be practical to recover iron and aluminum salts from acid mine drainage if there is no market. Recovery of zinc and copper may still be justified if their values are sufficiently high; they not only provide a source of revenue with readily available markets to reduce treatment costs, but they also provide for a modest reduction in the amount of sludge requiring disposal. While copper can be readily recovered in a relatively pure form using precipitation or cementation, zinc is less readily recovered because of interference from iron, which adversely affects subsequent zinc purification. Removal of iron can be achieved by either selective separation using ion exchange, solvent extraction before zinc recovery, or by precipitation of zinc, aluminum, and iron at a relatively neutral $\mathrm{pH}$ followed by selective leaching of the zinc-rich concentrate, as is currently practiced by industry for zinc ore.

The treatment strategies developed in this study should be capable of meeting the Clean Option discharge water performance criteria for all contaminants except sulfate, which does not achieve the Secondary MCLs of the Safe Water Drinking Water Act. Several treatment options exist that can be applied to meet this limit if it is applicable at a specific site. These options include further concentration of the treated water followed by lime precipitation, sodium carbonate precipitation with electrodialysis of the filtrate, or evaporation. Bioreduction of the treated water could be applied with or without prior concentration of the water. 


\section{References}

40 CFR 141. 1991. U.S. Environmental Protection Agency "National Primary Drinking Water Regulations." U.S. Code of Federal Regulations.

40 CFR 143. 1991. U.S. Environmental Protection Agency "National Secondary Drinking Water Regulations." U.S. Code of Federal Regulations.

ARCO. 1994. Butte Mine Flooding Operable Unit Remedial Investigation/Feasibility Study, Draft Feasibility Study Report. ARCO, Anaconda, Montana.

Canonie Environmental Services Corp. 1993. Treatability Sampling and Bench-Scale Testing Report Butte Mine Flooding Operable Unit Butte, Montana. Canonie Environmental Services Corp., Englewood, Colorado.

Cartwright, P. 1994. "Pollution Prevention Drives Membrane Technologies," Chemical Engineering. September, 1994.

DeRenzo, D. J., ed. 1978. Unit Operations for Treatment of Hazardous Industrial Wastes. Noyes Data Corporation, Park Ridge, New Jersey.

Lo, T. C., M. H. I. Baird, and C. Hanson. 1983, Handbook of Solvent Extraction. Wiley-Interscience, New York.

MSE, Inc. 1993a. Resource Recovery Project Berkeley Pit Water Characterization Interim Report. NEWTTEC-9, MSE, Inc., Butte, Montana.

MSE Inc. 1993b. Resource Recovery Issue Identification and Analysis Interim Report. MSE Inc., Butte, Montana.

MSE Inc. 1994. Resource Recovery Project Preliminary Marketing Analysis for Potentially Recoverable Products. RR5, MSE Inc., Butte, Montana.

Ritcey, C. M. and A. W. Ashbrook. 1979. Solvent Extraction Principles and Applications to Process Metallurgy Part II. Elsevier Scientific, New York.

Rosenqvist, T. 1974. Principles of Extractive Metallurgy. McGraw-Hill, Inc., New York.

Teringo, J. III. 1987. "Magnesium Hydroxide Reduces Sludge/Improves Filtering," Pollution Engineering, 19(4):78-83.

TETRA Technologies, Inc. Undated. Resource Recovery Project Technology Demonstration Final Report for Demonstration \#1 TETRA Technologies, Inc. 's High Density Solids $\left(H D S^{\text {tm }}\right)$ Process. RR-12, MSE Inc., Butte, Montana.

U.S. Environmental Protection Agency (EPA). 1986. Quality Criteria for Water - 1986. EPA 440/5-860001 , Office of Water Regulations and Standards, U.S. Environmental Protection Agency, Washington, D.C. 
Appendix A

Physical and Chemical Characteristics of the Berkeley Pit Water 


\section{Appendix A}

\section{Physical and Chemical Characteristics of the Berkeley Pit Water}

According to the analysis of water samples taken from the Berkeley Pit in May 1991 (MSE 1993), some variation of the water chemical composition is evident, depending on both the depth of the sample and the time at which the sample was taken. Table A.1 provides data on the chemical composition of the water as a function of depth. These data show that there is a pronounced increase in the iron ( $66 \%$ ), potassium $(30 \%)$, and arsenic (400\%), and a slight increase in sulfate (11\%) and zinc (9\%) between measurements taken near the surface and those taken at depths of $225 \mathrm{ft}$ or greater. Similarly, there is a pronounced decrease in fluoride $(-27 \%)$, chloride $(-17 \%)$, and cadmium $(-17 \%)$. The remainder of the constituents vary over a range of $\pm 7 \%$ and may be within the experimental error of the measurements.

The average of the values for each constituent at the four depths listed in Table A.1 serve as a baseline for developing resource recovery strategies. These values in Table A.2 are shown to be within $\pm 25 \%$ of the maximum and minimum values measured in 1991 for the various depths (Table A.1).

In addition to spacial variation in the Berkeley Pit water chemistry, changes also occur with time, as suggested by the trends shown in Table A.3, and should be considered another area of uncertainty in using the baseline values. Historical data for selected constituents for water samples taken from various depths during 1986, 1987, and 1991 (Table A.2) show a consistent increase in concentration over time for samples taken near the surface. This effect is less consistent for greater depths, although several continue to show a modest increase between 1987 and 1991 including sulfate $(19 \%$ - 21\%), manganese (24\% $27 \%$ ), zinc $(14 \%-18 \%)$ and iron ( $8 \%-11 \%)$. Copper and cadmium, however, show a slight decrease, and arsenic shows no consistent trend.

The variations in the concentration with depth and time may be a manifestation of changes in the relative contributions of the various water sources over time. In particular, the surface waters and the clean groundwater enter above the pit water level, whereas the groundwater from the underground mines must flow against a hydraulic head that has increased by as much as $700 \mathrm{ft}$ of water over time.

Variations may also be attributed in part to the precipitation of ferric hydroxide near the water surface that is caused by oxidation of the ferrous cation in the water. MSE (1993) reports that the oxidation state of the iron changes from predominantly $(+2)$ at depths greater than $10 \mathrm{ft}$ to predominantly $(+3)$ at the surface, except when the surface is covered with ice. This is attributed to the diffusion of oxygen from the air into the water near the surface, which is supported by a 90 -fold decrease in the dissolved oxygen of the water between $3 \mathrm{ft}$ and $>400 \mathrm{ft}$ of depth, as shown in Table A.1. Associated with this change in oxidation state is the reported formation of ferric hydroxide precipitate. 
Table A.1. Variation in the Berkeley Pit Water Chemistry with Depth (MSE Inc. 1993; ARCO 1994)

\begin{tabular}{|c|c|c|c|c|}
\hline \multirow[b]{2}{*}{ Depth } & \multicolumn{4}{|c|}{ Concentration (mg/L) } \\
\hline & $3 \mathbf{f t}$ & $>3.4 \mathrm{ft}$ & $225 \mathrm{ft}$ & $>400 \mathrm{ft}$. \\
\hline $\mathrm{Ag}$ & 0.006 & 0.006 & 0.006 & 0.006 \\
\hline $\mathrm{Al}$ & 274.2 & 268.7 & 288 & 284.9 \\
\hline As & 0.209 & 0.209 & 0.83 & 0.88 \\
\hline B & 0.41 & 0.38 & 0.4 & 0.42 \\
\hline $\mathrm{Ca}$ & 473 & 460 & 492 & 488 \\
\hline $\mathrm{Cd}$ & 1.807 & 1.708 & 1.572 & 1.573 \\
\hline $\mathrm{Cl}$ & 15.1 & 10.8 & 10.9 & 11.1 \\
\hline $\mathrm{Co}$ & 1.68 & 1.69 & 1.8 & 1.83 \\
\hline $\mathrm{Cr}$ & 0.054 & 0.056 & 0.055 & 0.054 \\
\hline $\mathrm{Cu}$ & 177.8 & 178.8 & 191.3 & 186.6 \\
\hline$F$ & 32.9 & 14.3 & 19.2 & 18 \\
\hline $\mathrm{Fe}$ & 649 & 666 & 1088 & 1095 \\
\hline $\mathbf{K}$ & 15.7 & 15.4 & 20.3 & 20.9 \\
\hline $\mathrm{Li}$ & 0.262 & 0.251 & 0.266 & 0.269 \\
\hline Mg & 422 & 411 & 418 & 420 \\
\hline Mn & 190 & 190.1 & 182 & 182 \\
\hline Mo & 0.06 & 0.05 & 0.05 & 0.07 \\
\hline $\mathrm{Na}$ & 71.2 & 66.1 & 68.3 & 69.7 \\
\hline $\mathrm{Ni}$ & 1.11 & 1.03 & 1.05 & 1.06 \\
\hline $\mathrm{NO}_{3}$ & 0.2 & 0.2 & 0.2 & 0.5 \\
\hline $\mathrm{O}_{2}$ & & 5.34 & & 0.06 \\
\hline $\mathbf{P b}$ & 0.05 & 0.08 & 0.08 & 0.05 \\
\hline $\mathrm{pH}$ & 2.73 & 2.47 & 2.84 & 2.69 \\
\hline $\mathrm{SiO}_{2}$ & 100 & 94.4 & 97 & 98.5 \\
\hline $\mathrm{SO}_{4}$ & 7217 & 7261 & 8010 & 8084 \\
\hline Sr & 1.42 & 1.33 & 1.34 & 1.35 \\
\hline $\mathrm{Ti}$ & 0.076 & 0.08 & 0.075 & 0.08 \\
\hline V & 0.019 & 0.041 & 0.18 & 0.178 \\
\hline $\mathrm{Zn}$ & 505.4 & 506.3 & 552.4 & 546.6 \\
\hline $\mathrm{Zr}$ & 0.006 & 0.006 & 0.006 & 0.006 \\
\hline
\end{tabular}


Table A.2. Baseline Water Chemistry of Berkeley Pit

\begin{tabular}{|c|c|c|c|}
\hline Element & $\begin{array}{c}\text { Average } \\
\text { Concentration (mg/L) }\end{array}$ & Element & $\begin{array}{c}\text { Average } \\
\text { Concentration }(\mathrm{mg} / \mathrm{L})\end{array}$ \\
\hline $\mathrm{Ca}$ & 478.25 & $\mathrm{Sr}$ & 1.36 \\
\hline $\mathrm{Mg}$ & 417.75 & $\mathrm{Ti}$ & 0.07775 \\
\hline $\mathrm{Na}$ & 68.825 & V & 0.1045 \\
\hline $\mathrm{K}$ & 18.075 & $\mathrm{Zn}$ & 527.675 \\
\hline $\mathrm{SiO}_{2}$ & 97.475 & $\mathrm{Zr}$ & 0.006 \\
\hline $\mathrm{Fe}$ & 874.5 & As & 0.532 \\
\hline $\mathrm{Mn}$ & 186.025 & Co & 1.75 \\
\hline $\mathrm{Al}$ & 278.95 & $\mathrm{Cr}$ & 0.05475 \\
\hline $\mathrm{Ag}$ & 0.006 & $\mathrm{Cl}$ & 11.975 \\
\hline B & 0.4025 & $\mathrm{SO}_{4}$ & 7643 \\
\hline $\mathrm{Cd}$ & 1.665 & $\mathrm{NO}_{3}$ & 0.275 \\
\hline $\mathrm{Cu}$ & 183.625 & F & 21.1 \\
\hline $\mathrm{Li}$ & 0.262 & $\mathrm{Br}$ & 0 \\
\hline Mo & 0.0575 & $\mathrm{~Pb}$ & 0.065 \\
\hline $\mathrm{Ni}$ & 1.0625 & $\mathrm{O}_{2}$ & 1.35 \\
\hline $\mathrm{PO}_{4}$ & 0 & & \\
\hline
\end{tabular}


Table A.3. Variation in the 1991 Berkeley Pit Water Chemistry with Time (MSE 1993)

\begin{tabular}{|c|c|c|c|c|c|c|}
\hline Element, Depth & $\begin{array}{c}\text { October } \\
1986 \\
\end{array}$ & $\begin{array}{c}\text { October } \\
1987 \\
\end{array}$ & $\begin{array}{l}\text { May } \\
1991 \\
\end{array}$ & $\begin{array}{l}\% \text { Change } \\
1986-1987 \\
\end{array}$ & $\begin{array}{l}\% \text { Change } \\
1987-1891 \\
\end{array}$ & $\begin{array}{c}\text { Annual } \\
\% \text { Change } \\
1987-1991 \\
\end{array}$ \\
\hline \multicolumn{7}{|l|}{ Iron } \\
\hline $0-3 \mathrm{ft}$ & 117 & 231 & 649 & $97 \%$ & $181 \%$ & $33 \%$ \\
\hline $200-225 \mathrm{ft}$ & 918 & 983 & 1088 & $7 \%$ & $11 \%$ & $3 \%$ \\
\hline $390-400 \mathrm{ft}$ & 1020 & 1010 & 1095 & $-1 \%$ & $8 \%$ & $2 \%$ \\
\hline \multicolumn{7}{|l|}{ Zinc } \\
\hline $0-3 \mathrm{ft}$ & 178 & 214 & 505 & $20 \%$ & $136 \%$ & $27 \%$ \\
\hline $200-225 \mathrm{ft}$ & 460 & 469 & 552 & $2 \%$ & $18 \%$ & $5 \%$ \\
\hline $390-400 \mathrm{ft}$ & 477 & 478 & 547 & $0 \%$ & $14 \%$ & $4 \%$ \\
\hline \multicolumn{7}{|l|}{ Copper } \\
\hline $0-3 \mathrm{ft}$ & 14 & 134 & 178 & $857 \%$ & $33 \%$ & $8 \%$ \\
\hline $200-225 \mathrm{ft}$ & 204 & 199 & 191 & $-2 \%$ & $-4 \%$ & $-1 \%$ \\
\hline $390-400 \mathrm{ft}$ & 213 & 196 & 187 & $-8 \%$ & $-5 \%$ & $-1 \%$ \\
\hline \multicolumn{7}{|l|}{ Manganese } \\
\hline $0-3 \mathrm{ft}$ & 64 & 70.8 & 190 & $11 \%$ & $168 \%$ & $32 \%$ \\
\hline $200-225 \mathrm{ft}$ & 144 & 143 & 182 & $-1 \%$ & $27 \%$ & $7 \%$ \\
\hline $390-400 \mathrm{ft}$ & 156 & 147 & 182 & $-6 \%$ & $24 \%$ & $6 \%$ \\
\hline \multicolumn{7}{|l|}{ Cadmium } \\
\hline $0-3 \mathrm{ft}$ & 1.00 & 1.45 & 1.81 & $45 \%$ & $25 \%$ & $6 \%$ \\
\hline $200-225 \mathrm{ft}$ & 1.74 & 1.76 & 1.57 & $1 \%$ & $-11 \%$ & $-3 \%$ \\
\hline $390-400 \mathrm{ft}$ & 1.69 & 1.78 & 1.57 & $5 \%$ & $-12 \%$ & $-3 \%$ \\
\hline \multicolumn{7}{|l|}{ Arsenic } \\
\hline $0-3 \mathrm{ft}$ & 0.016 & 0.004 & 0.209 & $-75 \%$ & $5125 \%$ & $200 \%$ \\
\hline $200-225 \mathrm{ft}$ & 0.041 & 0.755 & 0.83 & $1741 \%$ & $10 \%$ & $3 \%$ \\
\hline $390-400 \mathrm{ft}$ & 0.123 & 1.01 & 0.88 & $721 \%$ & $-13 \%$ & $-4 \%$ \\
\hline \multicolumn{7}{|l|}{ Sulfate } \\
\hline $0-3 \mathrm{ft}$ & NA & 3670 & 7217 & NA & $97 \%$ & $21 \%$ \\
\hline $200-225 \mathrm{ft}$ & NA & 6600 & 8010 & NA & $21 \%$ & $6 \%$ \\
\hline $390-400 \mathrm{ft}$ & NA & 6780 & 8084 & NA & $19 \%$ & $5 \%$ \\
\hline
\end{tabular}

\section{References}

MSE, Inc., 1993. Resource Recovery Project Berkeley Pit Water Characterization Interim Report. NEWTTEC-9, MSE, Inc., Butte, Montana.

ARCO. 1994. Butte Mine Flooding Operable Unit Remedial Investigation/Feasibility Study, Draft Remedial Investigation Report. ARCO, Anaconda, Montana. 
Appendix B

Constituent Disposition as Potentially Marketable Products 


\section{Appendix B}

\section{Constituent Disposition as Potentially Marketable Products}

Potential markets for the major constituents in the Berkeley Pit water were investigated for various metals and chemical compounds containing aluminum, copper, iron, magnesium, manganese, and zinc. These elements constitute about $25 \%$ of the total inventory of soluble solids in the Berkeley Pit water. . Marketable forms range from concentrates as feedstock to smelters to specialty chemicals. Over 75 contacts were made within industry during this evaluation including refiners, potential end-users, and distributors. The results of this evaluation are summarized in Table B.1.

Most of the remaining dissolved solids are accounted for by sulfate anions, so the incorporation of sulfate into some of these compounds as well as the possible recovery and reuse of sulfate as calcium sulfate and sulfuric acid were also considered because of the potential for waste minimization due to the disposal of excess low-value sulfate compounds.

It is apparent that markets exist for most of the major constituents in the Berkeley Pit water. Most of the interest appears to be in specialty chemical markets rather than base metal producers (smelters), and the specialty chemical markets are relatively large. These specialty markets will likely be the focus of flowsheet development for the Clean Option strategy. The following is a discussion of each of the potential markets for they various constituents.

\section{Aluminum}

A number of contacts were made within the aluminum refining and processing industry to determine whether there is a potential market for the aluminum recovered from Berkeley Pit. A summary of this evaluation is also given inTable B.1. A number of aluminum refiners were contacted but they indicated little interest in purchasing the recovered aluminum as a synthetic bauxite. Bauxite is typically $50-60 \%$ $\mathrm{Al}_{2} \mathrm{O}_{3}$, and the principal impurities are $\mathrm{SiO}_{2}(1-7 \%), \mathrm{Fe}_{2} \mathrm{O}_{3}(5-20 \%), \mathrm{TiO}_{2}(2-4 \%)$. The other potential aluminum source, as feed to a refinery, would be as high-grade alumina; however, stringent impurity levels would need to be met and numerous energy-intensive processing steps would be required to produce alumina at the Berkeley Pit site.

There was much more interest expressed by end-users in obtaining aluminum salts and solutions as products. In particular, one company indicated interest in purchasing aluminum salts and possibly even aluminum salt solutions. The end use would be in the pulp and paper industry and sewage treatment. Two grades of aluminum sulfate were identified as marketable: The anhydrous grade contains at least $26 \% \mathrm{Al}$ and the dry grade contains $45 \% \mathrm{Al}_{-} \mathrm{SO}_{4}$. In addition, a higher value is placed on iron-free aluminum sulfate, which contains $<50 \mathrm{ppm}$ iron. In addition to the end-product aluminum sulfate products, some companies were interested in obtaining $\mathrm{NaAlO}_{2}$ as a feed source for producing aluminum salts and salt solutions. 
Table B.1. Potential Markets for Constituents Recovered from Berkeley Pit

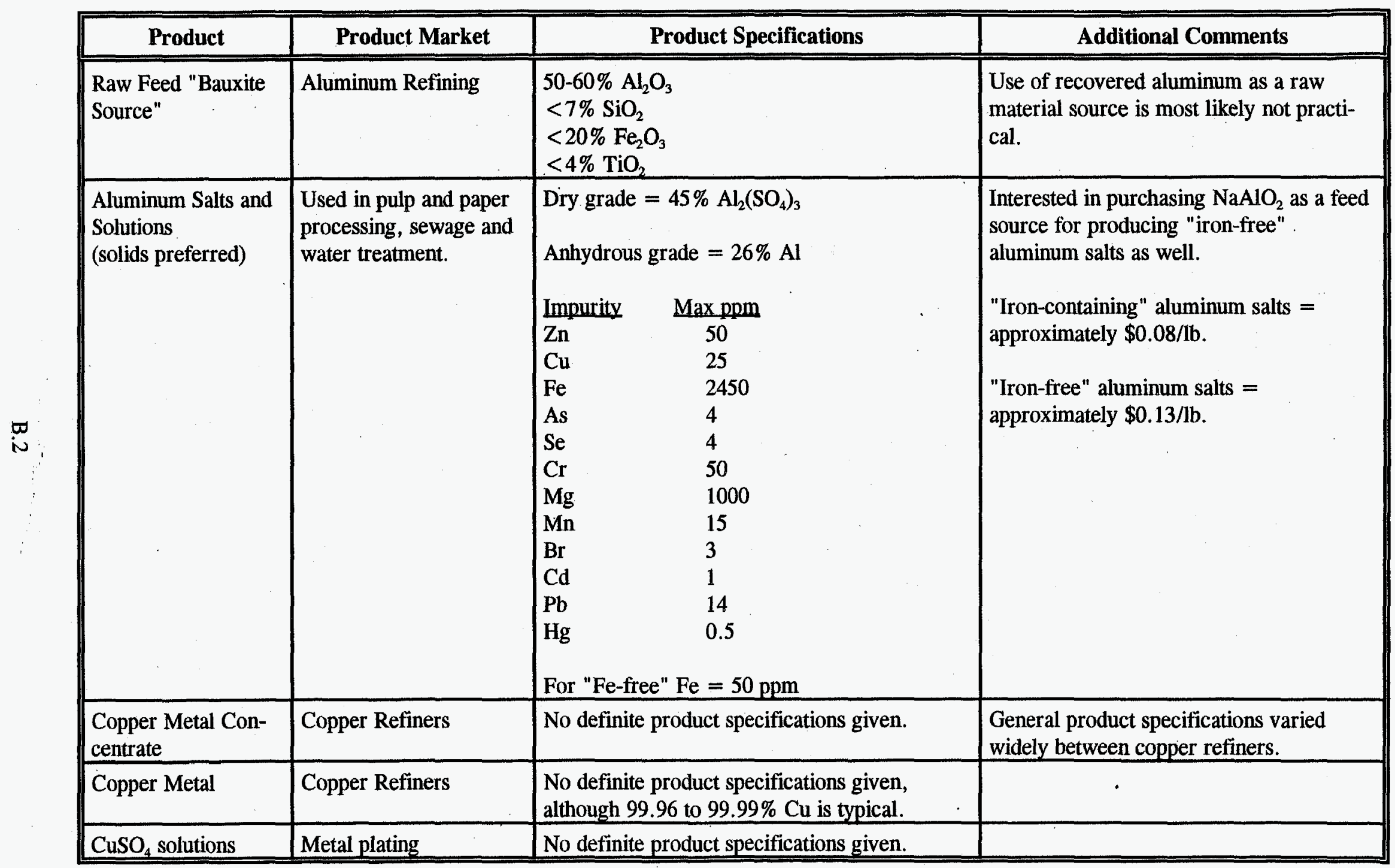


Table B.1. (Contd)

\begin{tabular}{|c|c|c|c|}
\hline Product & Product Market & Product Specifications & Additional Comments \\
\hline $\mathrm{CuSO}_{4}-5 \mathrm{H}_{2} \mathrm{O}$ crystals & End-use & $\begin{array}{lc}99.95 \% \mathrm{CuSO}_{4} & \mathbf{5 H}_{2} \mathrm{O} \\
\text { Impurity } & \mathrm{Max} \mathrm{ppm} \\
& \\
\mathrm{Pb} & 20 \\
\mathrm{As} & 0.1 \\
\mathrm{Cd} & 0.1 \\
\mathrm{Cr} & 1.4 \\
\mathrm{Zn} & 120 \\
\mathrm{Ni} & 14 \\
& \\
\mathrm{Al} \text { and Fe low enough to maintain } 99.95 \% \\
\text { purity spec. }\end{array}$ & \\
\hline Hematite & Iron Smelters & $\begin{array}{l}\text { No definite product specifications given, } \\
\text { although }<100 \mathrm{ppm} \mathrm{Zn} \text { is required. }\end{array}$ & \\
\hline $\begin{array}{l}\text { Iron Salts and Solu- } \\
\text { tions }\end{array}$ & $\begin{array}{l}\text { Primarily water treat- } \\
\text { ment }\end{array}$ & $\begin{array}{lc}\text { Impurity } & \text { Max ppm } \\
& \\
\mathrm{As} & 50 \\
\mathrm{Cd} & 10 \\
\mathrm{Cr} & 50 \\
\mathrm{~Pb} & 50 \\
\mathrm{Hg} & 2 \\
\mathrm{Se} & 10 \\
\mathrm{Ag} & 50 \\
& \\
\text { Low Al, Mg, Mn, Zn (to maintain } 99.9 \% \\
\text { purity spec) }\end{array}$ & $\begin{array}{l}\text { Iron-chloride or sulfate salts in the } \\
\text { form of crystals is preferred, al- } \\
\text { though iron salt solutions are also } \\
\text { marketable. }\end{array}$ \\
\hline
\end{tabular}


Table B.1. (Contd)

\begin{tabular}{|c|c|c|c|}
\hline Product & Product Market & Product Specifications & Additional Comments \\
\hline Ferric Chloride & Waste water treatment & $\begin{array}{ll}\text { 12-14\% } \mathrm{Fe} \text { (needed for shipping, 38-42\% } \\
\mathrm{FeCl}_{3} \text { ) } \\
\text { Impurity } & \text { Max ppm } \\
& \\
\mathrm{As} & 80\left(50 \text { for } \mathrm{SO}_{4}{ }^{\circ}\right) \\
\mathrm{Ni} & \text { To be determine } \\
\mathrm{Cd} & 20 \\
\mathrm{Cr} & 80 \\
\mathrm{~Pb} & 80 \\
\mathrm{Hg} & 3 \\
\mathrm{Se} & 20 \\
\mathrm{Ag} & 80 \\
\end{array}$ & $\begin{array}{l}\text { Market is large enough that all of the iron } \\
\text { recovered from Berkeley Pit could } \\
\text { potentially be sold on this market. }\end{array}$ \\
\hline Magnesium Oxide & Refractories & No definite product specifications given. & $\begin{array}{l}\text { Some companies showed interest in a } \\
\text { magnesium oxide product, however they } \\
\text { required specifications. }\end{array}$ \\
\hline Manganese Sulfate & - & No definite product specifications given. & $\begin{array}{l}\text { Some companies showed interest in a } \\
(29.5 \%) \text { manganese sulfate product. }\end{array}$ \\
\hline
\end{tabular}


Table B.1. (Contd)

\begin{tabular}{|c|c|c|c|c|}
\hline Product & Product Market & & Product Specifications & Additional Comments \\
\hline \multirow{12}{*}{$\begin{array}{l}\text { Zinc Chloride and } \\
\text { Zinc Ammonium } \\
\text { Chloride Solutions }\end{array}$} & \multirow{12}{*}{$\begin{array}{l}\text { Wood preservatives, } \\
\text { galvanizing and metal } \\
\text { plating. }\end{array}$} & \multicolumn{2}{|c|}{ For $45 \% \mathrm{ZnCl}_{2}$ and $\mathrm{Zn}-\mathrm{NH}_{3}-\mathrm{Cl}$} & \multirow{12}{*}{$\begin{array}{l}\text { Very large markets for both } \mathrm{ZnCl}_{2} \text { and } \\
\mathrm{Zn}-\mathrm{NH}_{3}-\mathrm{Cl} \text {. }\end{array}$} \\
\hline & & Impurit & Maxppm & \\
\hline & & & 10 & \\
\hline & & & & \\
\hline & & & & \\
\hline & & & & \\
\hline & & & 350 & \\
\hline & & & 50 & \\
\hline & & & low & \\
\hline & & & low & \\
\hline & & & low & \\
\hline & & & low & \\
\hline Zinc Oxide & $\begin{array}{l}\text { primary metals, salt } \\
\text { production }\end{array}$ & \multicolumn{2}{|c|}{$\begin{array}{l}99.9 \% \mathrm{ZnO} \text {, major concerns are } \mathrm{Pb}, \mathrm{Cd}, \mathrm{Fe} \text {; } \\
\text { all typically }<10 \mathrm{ppm} \text {. }\end{array}$} & \\
\hline Zinc Concentrate & Zinc Refiners & \multicolumn{2}{|c|}{ No definite product specifications given. } & \\
\hline
\end{tabular}




\section{Copper}

There was interest in obtaining copper in a variety of forms, ranging from concentrate for use in copper smelters to high-purity copper and copper salts.

Markets within copper metal producing companies were investigated for two general types of copper products: 1) Refined copper metal such as that obtained from electrowinning, and 2) impure copper products such as those obtained from cementation or precipitation. In general, none of the companies would give specific price estimates. They wanted to know much more about the copper product (availability and purity) before discussing price. Copper scrap companies expressed interest in obtaining copper metal and indicated that better prices would be obtained for selling copper as scrap than by selling it as feedstock to a smelter, even considering the higher processing costs to obtain higher purity copper metal.

Representatives from several copper producing companies (smelters) were contacted regarding potential interest in obtaining various copper concentrates. Responses regarding buying copper compounds for use as feedstocks in their smelting operations varied widely. One company representative said they would probably take copper in nearly any form. In fact, they frequently buy small amounts of nonsulfide copper compounds to blend with and dilute the sulfide concentrates because of the excessive fuel value of the sulfur. Other companies indicated that copper hydroxide concentrates would need to be upgraded by blending with other copper concentrates. Still others indicated that they wouldn't accept copper concentrates coming from a Superfund site because of uncertain liabilities associated with it.

Several companies expressed interest in obtaining copper as a copper sulfate solution, primarily for use in metal plating. The product specifications were not given, however. One company expressed interest in obtaining the entire amount of Berkeley Pit copper as copper sulfate crystals. They indicated that the national market is approximately $120 \mathrm{M} \mathrm{lb} / \mathrm{yr}$, and that $12 \mathrm{M} \mathrm{lb} / \mathrm{yr}$ could be placed into the market from Berkeley Pit. They also provided product specifications. Basically a $99.95 \%$ pure $\mathrm{CuSO}_{4}-5 \mathrm{H}_{2} \mathrm{O}$ product is required, with maximum impurity levels for lead $(20 \mathrm{ppm})$, arsenic $(0.1 \mathrm{ppm})$, cadmium $(0.1$ $\mathrm{ppm})$, chromium (1.4 ppm), zinc (120 ppm), and nickel (14 ppm). Combined aluminum and iron levels need to be low enough to allow for the $99.95 \%$ pure product. Two different grades were identified: low grade (20 to $80 \mathrm{ppm}$ iron and aluminum), and high grade (1 to $10 \mathrm{ppm}$ iron and aluminum).

Although not included in Table B.1, another noteworthy project, Summitville Project, is currently operating in southern Colorado. The EPA has taken control this abandoned gold mining site and have hired a contractor (Environmental Chemical Corp) to install and operate a water treatment system to treat acid mine drainage (AMD) and cyanide-contaminated water at the site. They are currently precipitating copper and iron as a hydroxide sludge, then passing the effluent through activated carbon beds to extract gold and silver. The sludge ( $\sim 40 \mathrm{wt} \%$ copper) is sent to a permitted treatment facility. where the copper is recovered. The gold/silver-bearing carbon is also sent offsite to another firm for gold and silver recovery. EPA anticipates that the process will eventually become economically selfsustaining.

In conversations with the permitted treatment facility, the EPA indicated that wastes are accepted for a fee. In the case of a sludge such as that from the Summitville project, the fee is adjusted downward: based on the value of recovered metals in the sludge. The facility treats the sludge, recovers various metals, and in turn sells them (e.g., copper) to a metal producer. 
When the Berkeley Pit project was discussed, the treatment facility representative said that, from experience, it would be most economical to precipitate everything into one sludge, dewater it as much as possible to avoid paying to ship water, load the sludge on rail cars and send it to a treatment facility for processing. He felt that a process to recover and market separate constituents, such as a copper concentrate, could not be operated for a lower overall cost.

\section{Iron}

The potential iron market includes the use of iron as a source of hematite for steel mills and as iron salts. Iron in the form of hematite can potentially be used as feedstock to steel mills. For this use, the zinc concentration must be less than $100 \mathrm{ppm}$.

Iron salts that were of interest to companies were sulfates or chlorides. A $99.9 \%$ pure iron chloride or iron sulfate crystal product was required by one company. The product impurity specifications were also given and are included in Table B.1. Another company expressed interest in obtaining a ferric chloride product, containing between $12-14 \%$ iron. Product specifications were also given for the ferric chloride product and are included in Table B.1. Companies indicated that the market for iron chloride and sulfate crystals and solutions was large enough so that the entire amount of iron obtained from Berkeley Pit could be placed into this market. The major uses for these products would be in water treatment and purification.

\section{Magnesium}

There was some interest expressed in obtaining a magnesium oxide product. However, product specifications were not readily available from any of the companies contacted. In addition to magnesium oxide, markets for magnesium carbonate and magnesium chloride were investigated. The interest for such products was not as great as that for magnesium oxide.

\section{Manganese}

Several companies were interested in obtaining manganese as a manganese metal concentrate, metal flakes, sulfate salt, or as manganese dioxide. One company interested in manganese metal flakes indicated that they may be willing to purchase 2000-5000 ton/year and possibly more, depending on product quality. The production of a manganese metal flake, however, may be too energy-intensive and require too many additional processing steps to be feasible in a resource recovery strategy for the Berkeley Pit. Product specifications were requested for all of the potential manganese products; however, no definite product specifications were obtained.

\section{Zinc}

There are large markets for zinc chloride and zinc-ammonium-chloride salt products. Zinc oxide, a precursor to these salts, was also identified as a potential zinc product. Product specifications for all of these zinc products were provided by companies, and are included in Table B.1. Cadmium, lead, and iron impurities are of major concern in all of these zinc products. 
One company indicated that the market for zinc chloride and zinc-ammonium-chloride salts is large enough that we could expect to sell the entire amount of zinc from Berkeley Pit as these end products. The primary markets for all of these zinc products are as wood preservatives and in galvanizing and metal plating solutions.

In addition to final zinc products, zinc may also be used as a feedstock to zinc smelters. Zinc smelter companies were contacted by MSE (1994) and two expressed interest. One smelter currently accepted zinc concentrates containing $40 \%$ zinc, and was expected to accept concentrates containing as little as $20 \%$ zinc. The other smelter accepted zinc concentrates containing as little as $2 \%$ and as much as $80 \%$ zinc. Both companies charge a fixed fee for accepting the concentrates providing a credit for a fraction of the zinc values. Penalties were assessed for concentrates containing deleterious constituents including iron, cadmium, lead, and moisture. These penalties are described in the next section.

\section{Other Constituents}

Calcium is the only other major cation in the Berkeley Pit water that is at a sufficient concentration to be considered a significant resource compared to those previously discussed, and it is most likely to be recovered from the water in the from of calcium sulfate, in order to reduce sulfate levels to acceptable levels. MSE (1994), prepared a market assessment for calcium sulfate (gypsum) in the Butte area. The two most likely markets for gypsum are in cement production and wallboard manufacturing. Two local cement manufacturers expressed interest in evaluating Berkeley Pit-derived gypsum as a feedstock. However, they would only consume about 50 ton/day of gypsum from treatment of the Berkeley Pit water, which would account for only about $10 \%$ of the anticipated supply. Wallboard manufacturing, a major consumer of gypsum, does not exist within 200 miles of Butte, Montana, the maximum practical shipping radius for gypsum. However, a ready supply of synthetic gypsum from the pit might be sufficient to warrant construction of a wallboard manufacturing plant in Butte, particularly if the alternative is to dispose of the gypsum in a landfill.

The sulfate anion is the major constituent in the Berkeley Pit water, accounting for over $70 \%$ of the TDS in the water. The purified metal sulfate salts (aluminum sulfate, copper sulfate, manganese sulfate, and iron sulfate) previously described also provide a market for sulfate in the Berkeley Pit water. In some cases this would require recovery of the sulfate as purified sulfuric acid to use as a reagent in resource recovery. Another possible resale product for sulfate would be as an ammonium sulfate product, which is widely used as an agricultural fertilizer.

None of the remaining constituents in the water are at concentrations to warrant recovery. Instead, a portion of these constituents, along with residual levels of the constituents previously described, will be disposed as impurities in the various products subject to the purity requirements of the various products.

A portion also will be discharged to the environment in the treated water, subject to criteria for discharged water. The remainder will be disposed in a landfill.

\section{References}

MSE Inc., 1994. Resource Recovery Project Preliminary Marketing Analysis for Potentially Recoverable Products. RR5, MSE Inc., Butte, Montana. 


\section{Appendix C}

Identification of Technologies Suitable for Treating Berkeley Pit Water 


\section{Appendix C}

\section{Identification of Technologies Suitable for Treating Berkeley Pit Water}

The suitability for a specific technology to treat contaminated water depends on three factors: 1) applicability to one or more of the contaminants of interest and satisfactory performance in a unit operation at the contaminant concentrations encountered; 2) achievable pre- and post-treatment requirements for the technology through other unit operations; and 3) reasonable cost of the unit operation (must not be so high that it renders the entire resource recovery option uneconomical). Each of these factors affect the complexity of resource recovery and water treatment because no single technology is expected to be amenable to all of the constituents from both resource recovery and water treatment perspectives.

Technology applicability for the Berkeley Pit water is simplified somewhat because all of the contaminants and potentially recoverable constituents are inorganic. If there were organic contaminants also present, processing complexity and cost would be greater. However, the range of types and concentrations of the various constituents in the Berkeley Pit water adds to the complexity of resource recovery and water treatment. The concentration of inorganic constituents varies from hundreds of $\mathrm{ppm}$ to less than $1 \mathrm{ppm}$. In addition, their solubilities vary from less than $1 \mathrm{ppm}$ to $>1000 \mathrm{ppm}$. The contaminants are also divided between cations, with different oxidation states (heavy metals) and anions (sulfate, arsenate). Similarly, the concentration goals for some of the constituents in the treated water range from $250 \mathrm{ppm}$ for sulfates to $0.12 \mathrm{ppb}$ for silver.

The costs for different technologies and their sensitivities to process scale vary widely for both capital and operation and maintenance. This variance is due to several factors including process complexity, material and energy requirements, minimum and maximum processing scale, and efficiency requirements. An important caveat to interpreting process costs for an individual unit operation is whether or not the entire feedwater stream from the pit is being treated. Process costs are usually based on the volume of water passing through it. However, overall resource recovery costs are based on the volume of treated water from the Berkeley Pit; therefore, an expensive unit operation would have a.major impact if it is used to treat the entire feed stream, but only a minor impact if it is used to treat a much smaller volume. For example, by concentrating the feed by a factor of $4 \mathrm{X}$ using evaporation subsequent processing costs for the pit water would effectively be a quarter of the cost based on the concentrated stream.

Technologies applicable to a resource recovery strategy have been divided into two groups: primary unit operations and secondary unit operations. The primary unit operations for treating the Berkeley Pit water would be used to separate and purify the desired constituents in the feedwater and to process the water to meet the target purity for discharge. Secondary unit operations would be needed to pre- and/or post-treat the process stream of a primary unit operation and to recover and recycle chemical reagents used in treatment. Several technologies fall into more than one group or category within a group. 


\section{Primary Unit Operations}

The primary unit operations for treating the Berkeley Pit water can be divided into three broad categories: concentration, selective separation and purification, and secondary water treatment. These processes are identified in Table C.1.

\section{Concentration}

The processes in the concentration category are unit operations that can non- or semiselectively concentrate the dissolved solids in the feed. It is envisioned that one of these operations would be used to reduce the volume of material requiring subsequent processing to recover the heavy metals of interest for resource recovery. Evaporation and freeze crystallization processes are very nonselective by nature, producing a pure, treated water stream. Precipitation, reverse osmosis, nanofiltration, and electrodialysis processes are also used to purify water by removing most of the dissolved solids, although some selectivity occurs.

Solvent extraction and ion exchange/adsorption processes are usually used to selectively remove a specific constituent, but can be used in many cases to remove several constituents at once to achieve the necessary concentration. When comparing the two, ion exchange is typically used to treat more dilute streams and can result in more concentrated elution streams.

Recently developed facilitated transport membrane technologies (such as liquid emulsion membranes and coupled transport membranes) are hybrid solvent extraction systems that show promise for treating more dilute streams. In a facilitated membrane system, the feed and stripping streams are separated by a liquid membrane consisting of solvent and/or surfactant. These systems offer advantages of lower solvent losses and higher concentrations in the elution stream compared to conventional solvent extraction.

Selective separation/purification processes are typically used to separate one constituent from the others and thereby effect an increase in purity. In most cases, this also results in an increase in the concentration of that constituent for all subsequent processing. Selective precipitation works in those instances where the addition of a reagent can cause one or two of the constituents to precipitate. In the case of sulfide and hydroxide, precipitation selectivity is achieved by varying $\mathrm{pH}$. Phosphate precipitation selectively removes trivalent cations such as $\mathrm{Fe}^{+3}$ and $\mathrm{Al}^{+3}$ from divalent and monovalent cations. In the specific case of the Berkeley Pit water, aeration of the water causes the $\mathrm{Fe}^{+2}$ to oxidize to $\mathrm{Fe}^{+3}$, which is above its solubility limit. The addition of an $\mathrm{M}^{+1}$ cation such as potassium can lead to the precipitation of $\mathrm{Fe}^{+3}$ as jarosite without coprecipitating +2 metal cations. Insoluble complexes, such as zinc and copper ferrocyanide, can also be formed from water containing these dissolved metals by adding potassium ferrocyanide to form insoluble zinc and copper ferri- and ferrocyanide complexes. Cementation is a redox process where reduced metal iron is oxidized by copper cations, resulting in the precipitation of the copper as a reduced metal. Cementation works in principle for the cation of any metal more noble than the reduced metal being used.

Ion flotation can be used to selectively remove anions and cations from solution by the addition of a surfactant that forms an insoluble salt with the ion of interest. Solvent extraction and ion-exchange/ adsorption processes are frequently used to selectively separate and concentrate constituents from an aqueous mixture. In addition, selective separation can be achieved during nonselective extraction of several constituents from a mixture through selective stripping, typically achieved by a sequence of stripping steps at different $\mathrm{pH}$ values. 
Table C.1. Primary Unit Operations for Resource Recovery

\begin{tabular}{|c|c|c|}
\hline Concentration & Selective Separation/Purification & Secondary/Water Treatment \\
\hline $\begin{array}{l}\text { Precipitation } \\
\text { - Lime Precipitation } \\
\text { - Carbonate Precipitation } \\
\text { - Sulfide Precipitation } \\
\text { - Hydroxide Precipitation } \\
\text { Membrane Separation } \\
\text { - Reverse Osmosis } \\
\text { - Nanofiltration } \\
\text { - Facilitated Transport Membranes } \\
\text { - Electrodialysis } \\
\\
\text { Evaporation } \\
\text { Freeze Crystallization } \\
\text { Solvent Extraction } \\
\text { Ion Exchange/Adsorption }\end{array}$ & $\begin{array}{l}\text { Precipitation } \\
\text { - Jarosite Precipitation } \\
\text { - Redox Precipitation ( } \mathrm{Fe}^{+2} \text { Oxidation) } \\
\text { - Sulfide Precipitation } \\
\text { - Phosphate Precipitation } \\
\text { - Insoluble Complex Formation } \\
\text { - Cementation } \\
\text { Ion Flotation } \\
\text { Solvent Extraction } \\
\text { Ion Exchange/Adsorption } \\
\text { Electrolytic Separation } \\
\text { - Electrodialysis } \\
\text { - Electrowinning } \\
\text { High Gradient Magnetic Separation } \\
\text { Leaching }\end{array}$ & $\begin{array}{l}\text { Ion Exchange/Adsorption } \\
\text { Membrane Separation } \\
\text { - Reverse Osmosis } \\
\text { - Nano Filtration } \\
\\
\text { Bioacumulation } \\
\text { Biochemical Redox } \\
\text { Neutralization } \\
\text { Precipitation }\end{array}$ \\
\hline
\end{tabular}




\section{Selective Separation/Purification}

Electrowinning is an electrolytic process that achieves selective separation by adjusting the voltage potential applied across two electrodes. In practice, electrowinning solutions usually contain at least $20-50 \mathrm{~g} / 1$ of the metal of interest (or more). Therefore, electrowinning is usually preceded by a concentration process such as solvent extraction.

High gradient magnetic separation can be used to separate precipitated ferro ( $\mathrm{Fe}, \mathrm{Ni}$, and $\mathrm{Mn}$ compounds) and paramagnetic $(\mathrm{Cu}, \mathrm{Zn})$ solid particles from diamagnetic ( $\mathrm{Al}, \mathrm{Mg}$, and $\mathrm{Ca}$ compounds) particles suspended in aqueous solutions.

Leaching is used to extract constituents from precipitates. Once solids are precipitated; they may be selectively leached to extract a specific metal(s) into solution, thus further purifying the precipitate or leachate; or nonselectively leached to dissolve the entire precipitate into solution so that further purification can take place downstream (e.g., via solvent extraction, ion exchange, etc.). One example of selective leaching practiced in industry is the leaching of copper-nickel matte with sulfuric acid. From a thermodynamic viewpoint, both metals are soluble in sulfuric acid, however the copper oxide dissolution kinetics are faster, thus making a separation possible. Acid leaching of valuable minerals from gangue material is more prevalent in industry.

\section{Secondary Water Treatment}

Secondary water treatment unit operations are used to treat process streams containing treated waste water from unit operations that concentrate, separate, and purify constituents to be recovered as products. Secondary water treatment involves removing any remaining constituents in the water that exceed treatment goals for water to be discharged.

Most of the technologies for secondary water treatment are specifically suited for treating very dilute concentrations of contaminants. These are ion exchange/adsorption, reverse osmosis, nanofiltration, precipitation, bioaccumulation, and biochemical redox. The principles behind the first three technologies were previously discussed. Bioaccumulation is similar to adsorption, except that living or dead organisms, propagated in the water through the addition of nutrients, serve as the adsorbent. Biochemical reduction usually involves the consumption of the oxygen in an oxygen containing anion. In the case of sulfate anions, the sulfur is reduced to sulfide, which in turn may precipitate one or more of the cations in the water. Neutralization is accomplished through the addition of an acid or base to adjust the water $\mathrm{pH}$ to the target range $(4>\mathrm{pH}<10)$ if necessary.

\section{Secondary Unit Operations}

Secondary unit operations treat process streams entering or leaving a primary unit operation to meet feed requirements, achieve a saleable product, produce an acceptable disposal form for process wastes, or to recover and recycle chemical reagents used in treatment. These unit operations are divided into the general categories of physical, chemical, and thermochemical technologies (see Table C.2).

Physical separation processes include liquid-solid separation and evaporation/distillation technologies. Liquid-solid separation technologies are those that do not rely on a phase change to achieve separation, whereas evaporation and distillation rely on a phase change of the liquid to achieve the separation. 
Table C.2. Secondary Unit Operations for Treating Process Streams

\begin{tabular}{||l|l|l||}
\hline \multicolumn{1}{|c|}{ Physical Processes } & \multicolumn{1}{|c|}{ Chemical Processes } & Thermochemical Processes \\
\hline \hline Liquid-Solid Separation & Electrochemical Salt Splitting & Calcination \\
- Media Filtration & Chemical Redox & Roasting \\
- Flotation & Geutralization & \\
- Ultra/micro filtration & & \\
- Centrifugation & & \\
- Coagulation/Flocculation & & \\
- Sedimentation & & \\
Pressure/Vacuum Filtration & & \\
Evaporation/distillation & & \\
\hline
\end{tabular}

Chemical processes include electrochemical salt splitting, chemical redox, and neutralization. Electrochemical salt splitting is an electrodialysis separation technique for removing the cations and anions from a process feed stream and separating them into acidic and basic product streams. For example, an aqueous stream containing sodium sulfate could be split into a caustic stream that is recycled to neutralize the acid waste and a sulfuric acid stream that would be either concentrated and sold or neutralized and disposed. The treated feedwater is depleted in dissolved salts and would be either discharged or sent to a secondary water treatment process. Neutralization is used to vary the $\mathrm{pH}$ of a process stream as a pretreatment to another process or as a post treatment process before discharging water to the environment.

Thermochemical processes include calcination, roasting, and gas phase thermal redox. Calcination and roasting are standard mineral processing technologies. Calcination is the thermal decomposition of a solid into a new solid and a gas. For example, calcium carbonate can be calcined to calcium oxide and carbon dioxide. In roasting, the solids are reacted with a gaseous oxidant or reductant to produce a new mineral solid. For example, zinc can be oxidized in air to form zinc oxide. Gas phase thermal redox involves the reaction of two gases to a new gas. For example, sulfur dioxide and hydrogen sulfide can be reacted to produce water vapor and elemental sulfur. 


\section{Appendix D}

\section{Stream Flow Material Balance for}

Flowsheet Showing Series Separation of

Constituents from Feedwater 


\title{
Appendix D
}

\section{Stream Flow Material Balance for Flowsheet Showing Series Separation of Constituents from Feedwater}

\begin{abstract}
An integrated process for treating the Berkeley Pit water in a series of separation steps to recover copper as cement copper sponge and zinc metal as the primary constituent, iron as ferric chloride, and manganese dioxide and aluminum sulfate as byproducts are shown in Figure D.1. This process consists of cementation to recover copper, ion exchange to recover iron as ferric chloride, hydroxide precipitation and solid-liquid separation, followed by dissolution/leaching of the solids and electrowinning, to recover zinc metal and manganese dioxide (the latter of which is neutralized to produce manganese sulfate). Electrodialysis is used to recover caustic from the process, which is used as the precipitation reagent for the process flowsheet. Most of the sulfuric acid, also recovered in the electrodialysis, is used in the various neutralization, leach, and dissolution steps. Stream flow rates and compositions are described in Table D.1.
\end{abstract}




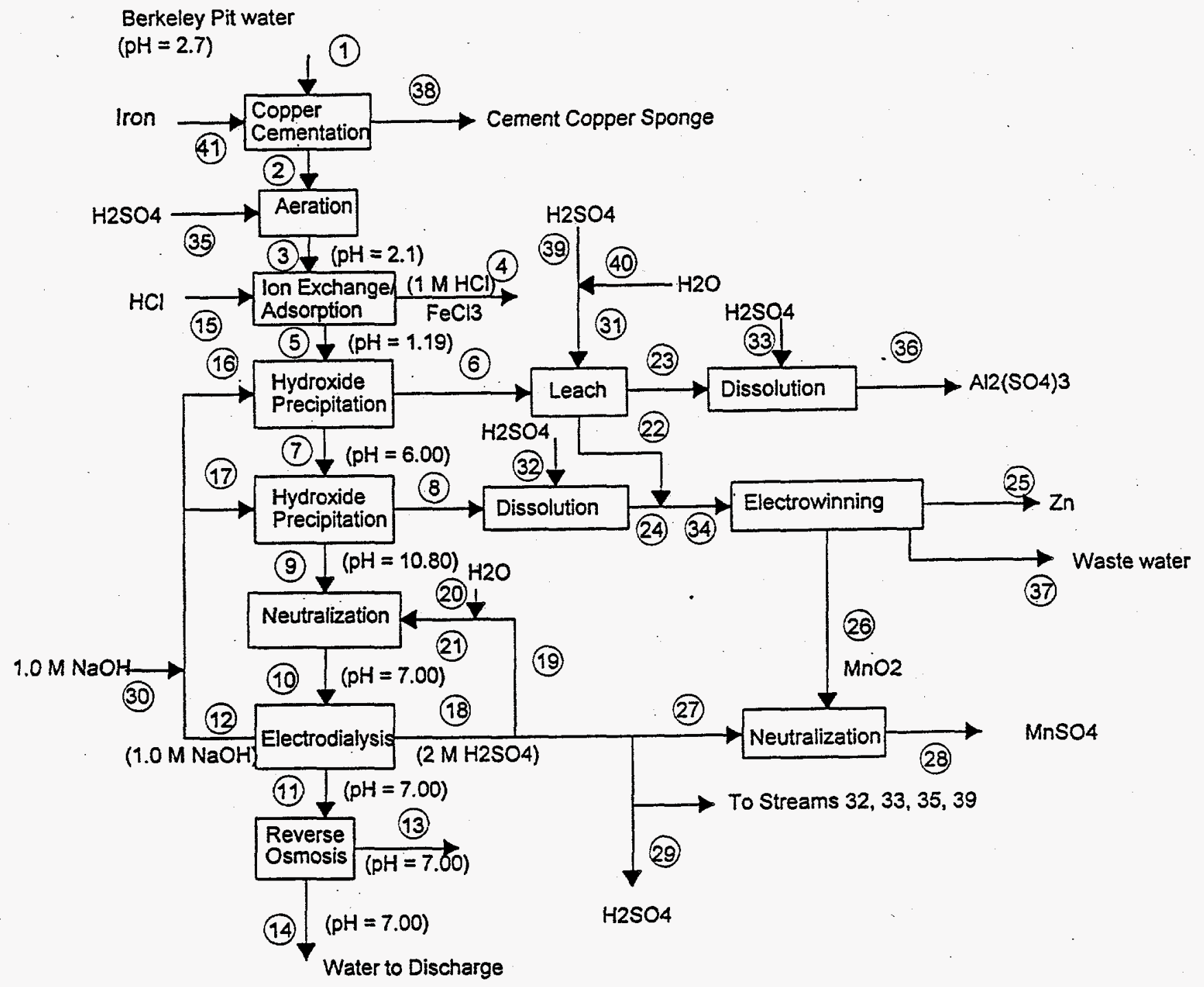

Figure D.1. Flowsheet Showing Series Separation of Constituents from Feedwater 


\begin{tabular}{|c|c|c|c|c|c|c|c|c|c|c|c|}
\hline \multicolumn{12}{|c|}{ Component Material Balance } \\
\hline \multicolumn{12}{|c|}{ Basis: Stream $1=1000 \mathrm{~g}$ (total) } \\
\hline \multicolumn{12}{|c|}{$\begin{array}{l}\text { (All values, except } \mathrm{pH} \text { and } \\
\text { flowrate, are given as } \mathrm{ppm} ; \mathrm{pH} \\
=\mathrm{pH} \text { units; Flowrate = } \mathrm{g} \text { ) }\end{array}$} \\
\hline & STREAM & STREAM & STREAM & STREAM & STREAM & STREAM & STREAM & STREAM & STREAM & STREAM & STREAM \\
\hline Component & 1 & 2 & 3 & 4 & 5 & 6 & 7 & 8 & 9 & 10 & 11 \\
\hline $\mathbf{A g}$ & $6.00 \mathrm{E}-03$ & $6.00 \mathrm{E}-03$ & $5.93 E-03$ & $3.56 \mathrm{E}-04$ & $6.92 \mathrm{E}-03$ & $3.79 E-03$ & $5.42 E-03$ & $3.49 \mathrm{E}-03$ & $4.99 \mathrm{E}-03$ & $4.79 \mathrm{E}-03$ & $4.69 \mathrm{E}-03$ \\
\hline Al & $2.79 E+02$ & $2.79 E+02$ & $2.76 \mathrm{E}+02$ & $8.18 E+02$ & $2.48 E+02$ & $2.69 E+05$ & $1.25 E+01$ & $4.87 E+03$ & $9.21 \mathrm{E}-02$ & $8.85 E-02$ & $8.67 E-02$ \\
\hline As & 5.32E-01 & 5.32E-01 & 5.26E-01 & $3.15 \mathrm{E}-02$ & $5.25 \mathrm{E}-01$ & $3.01 E+02$ & 2.41E-01 & $1.55 E-01$ & 2.21E-01 & $2.12 E-01$ & $2.08 E-01$ \\
\hline$B$ & 4.03E-01 & 4.03E-01 & 3.98E-01 & $0.00 E+00$ & $3.98 \mathrm{E}-01$ & $2.55 \mathrm{E}-01$ & $3.64 E-01$ & 2.34E-01 & 3.35E-01 & $3.22 \mathrm{E}-01$ & 3.15E-01 \\
\hline $\mathrm{Ca}$ & $4.78 E+02$ & $4.78 E+02$ & $4.72 \mathrm{E}+02$ & $2.83 E+01$ & $4.72 \mathrm{E}+02$ & $3.02 E+02$ & $4.32 \mathrm{E}+02$ & $2.78 \mathrm{E}+02$ & $3.97 E+02$ & $3.82 E+02$ & $3.74 \mathrm{E}+02$ \\
\hline Cd & $1.67 \mathrm{E}+00$ & $1.67 \mathrm{E}+00$ & $1.64 E+00$ & $9.87 E-02$ & $1.64 \mathrm{E}+00$ & $1.05 E+00$ & $1.60 E+00$ & $5.78 E+02$ & $2.76 \mathrm{E}-02$ & $2.65 \mathrm{E}-02$ & $2.60 \mathrm{E}-02$ \\
\hline $\mathrm{Cl}$ & $1.20 E+01$ & $1.20 \mathrm{E}+01$ & $1.18 \mathrm{E}+01$ & $9.64 \mathrm{E}+04$ & $1.18 \mathrm{E}+01$ & $7.59 E+00$ & $1.08 \mathrm{E}+01$ & $6.97 \mathrm{E}+00$ & $9.97 E+00$ & $9.58 \mathrm{E}+00$ & 4.79E-01 \\
\hline Co & $1.75 E+00$ & $1.75 E+00$ & $1.73 E+00$ & $1.04 \mathrm{E}-01$ & $1.73 E+00$ & $1.11 \mathrm{E}+00$ & $1.58 \mathrm{E}+00$ & $1.02 \mathrm{E}+00$ & $1.45 E+00$ & $1.40 E+00$ & $1.37 E+00$ \\
\hline $\mathrm{Cr}$ & $5.48 \mathrm{E}-02$ & $5.48 \mathrm{E}-02$ & $5.41 \mathrm{E}-02$ & $3.25 \mathrm{E}-03$ & $5.40 \mathrm{E}-02$ & $3.46 \mathrm{E}-02$ & 4.95E-02 & 3.18E-02 & $4.55 E-02$ & 4.37E-02 & $4.28 \mathrm{E}-02$ \\
\hline $\mathrm{Cu}$ & $1.84 E+02$ & $9.18 E+00$ & $9.07 E+00$ & 5.44E-01 & $9.05 \mathrm{E}+00$ & $5.81 E+00$ & $8.30 E+00$ & $3.24 E+03$ & $3.68 \mathrm{E}-02$ & $3.54 \mathrm{E}-02$ & $3.47 \mathrm{E}-02$ \\
\hline$F$ & $2.11 \mathrm{E}+01$ & $2.11 E+01$ & $2.08 \mathrm{E}+01$ & $0.00 \mathrm{E}+00$ & $2.08 E+01$ & $1.34 \mathrm{E}+01$ & $1.91 \mathrm{E}+01$ & $1.23 E+01$ & $1.76 \mathrm{E}+01$ & $1.69 \mathrm{E}+01$ & $8.44 \mathrm{E}-01$ \\
\hline $\mathrm{Fe}$ & $8.75 E+02$ & $1.03 E+03$ & $1.02 E+03$ & $3.02 E+04$ & $1.02 \mathrm{E}+01$ & $6.51 E+00$ & $9.31 E+00$ & $3.50 E+03$ & $3.36 \mathrm{E}-01$ & $3.23 \mathrm{E}-01$ & $3.17 \mathrm{E}-01$ \\
\hline$K$ & $1.81 \mathrm{E}+01$ & $1.81 E+01$ & $1.79 \mathrm{E}+01$ & $2.68 \mathrm{E}-01$ & $1.78 \mathrm{E}+01$ & $1.14 \mathrm{E}+01$ & $1.64 \mathrm{E}+01$ & $1.05 E+01$ & $1.50 E+01$ & $1.44 \mathrm{E}+01$ & 7.22E-01 \\
\hline $\mathrm{Li}$ & $2.62 \mathrm{E}-01$ & 2.62E-01 & $2.59 \mathrm{E}-01$ & $3.88 \mathrm{E}-03$ & 2.59E-01 & $1.66 \mathrm{E}-01$ & 2.37E-01 & 1.53E-01 & $2.18 \mathrm{E}-01$ & 2.09E-01 & $1.05 \mathrm{E}-02$ \\
\hline $\mathrm{Mg}$ & $4.18 E+02$ & $4.18 E+02$ & $4.13 E+02$ & $0.00 E+00$ & $4.13 E+02$ & $2.65 E+02$ & $3.78 E+02$ & $9.34 E+04$ & $1.29 E+02$ & $1.24 \mathrm{E}+02$ & $1.21 E+02$ \\
\hline $\mathrm{Mn}$ & $1.86 \mathrm{E}+02$ & $1.86 \mathrm{E}+02$ & $1.84 E+02$ & $1.10 \mathrm{E}+01$ & $1.83 \mathrm{E}+02$ & $1.18 E+02$ & $1.68 E+02$ & $6.45 E+04$ & $3.25 E+00$ & $3.12 E+00$ & $3.06 E+00$ \\
\hline Mo & $5.75 \mathrm{E}-02$ & $5.75 E-02$ & $5.68 \mathrm{E}-02$ & $1.69 \mathrm{E}-01$ & $5.12 \mathrm{E}-02$ & $3.28 \mathrm{E}-02$ & $4.69 \mathrm{E}-02$ & $3.02 \mathrm{E}-02$ & $4.31 \mathrm{E}-02$ & $4.14 E-02$ & $4.06 \mathrm{E}-02$ \\
\hline $\mathrm{Na}$ & $6.88 E+01$ & $6.88 E+01$ & $6.80 \mathrm{E}+01$ & $1.02 E+00$ & $6.80 E+01$ & $1.39 \mathrm{E}+03$ & $1.98 E+03$ & $1.92 E+03$ & $2.74 E+03$ & $2.63 E+03$ & $1.32 E+02$ \\
\hline $\mathrm{Ni}$ & $1.06 E+00$ & $1.06 \mathrm{E}+00$ & $1.05 E+00$ & 6.30E-02 & $1.05 E+00$ & $6.72 \mathrm{E}-01$ & $9.60 \mathrm{E}-01$ & $3.49 E+02$ & $6.45 \mathrm{E}-02$ & $6.19 \mathrm{E}-02$ & $6.07 \mathrm{E}-02$ \\
\hline NO3 & $2.75 \mathrm{E}-01$ & 2.75E-01 & $2.72 \mathrm{E}-01$ & $0.00 E+00$ & 2.72E-01 & $1.74 \mathrm{E}-01$ & 2.49E-01 & $1.60 \mathrm{E}-01$ & $2.29 \mathrm{E}-01$ & $2.20 E-01$ & $1.10 \mathrm{E}-02$ \\
\hline $\mathrm{Pb}$ & $6.50 \mathrm{E}-02$ & $6.60 \mathrm{E}-02$ & $6.42 \mathrm{E}-02$ & $3.85 \mathrm{E}-03$ & $6.41 \mathrm{E}-02$ & $4.11 \mathrm{E}-02$ & $5.87 \mathrm{E}-02$ & $3.78 \mathrm{E}-02$ & $5.40 \mathrm{E}-02$ & $5.19 \mathrm{E}-02$ & $5.08 \mathrm{E}-02$ \\
\hline $\mathrm{SiO} 2$ & $9.75 \mathrm{E}+01$ & $9.75 \mathrm{E}+01$ & $9.63 E+01$ & $0.00 E+00$ & $9.63 \mathrm{E}+01$ & $2.99 \mathrm{E}+04$ & $6.45 E+01$ & $2.37 E+04$ & $3.56 \mathrm{E}+00$ & $3.42 E+00$ & $3.35 E+00$ \\
\hline SO4 & $7.38 \mathrm{E}+03$ & $7.38 \mathrm{E}+03$ & $8.45 E+03$ & $0.00 E+00$ & $8.45 E+03$ & $5.42 E+03$ & $7.75 E+03$ & $4.98 \mathrm{E}+03$ & $7.12 \mathrm{E}+03$ & $6.88 E+03$ & $1.66 \mathrm{E}+03$ \\
\hline Sr & $1.36 \mathrm{E}+00$ & $1.36 \mathrm{E}+00$ & $1.34 \mathrm{E}+00$ & $8.06 \mathrm{E}-02$ & $1.34 \mathrm{E}+00$ & $8.60 \mathrm{E}-01$ & $1.23 E+00$ & 7.91E-01 & $1.13 E+00$ & $1.09 \mathrm{E}+00$ & $1.06 E+00$ \\
\hline $\mathrm{Ti}$ & $7.78 \mathrm{E}-02$ & $7.78 \mathrm{E}-02$ & $7.68 \mathrm{E}-02$ & $4.61 \mathrm{E}-03$ & 7.67E-02 & $4.92 \mathrm{E}-02$ & 7.03E-02 & $4.52 E-02$ & $6.46 \mathrm{E}-02$ & $6.21 \mathrm{E}-02$ & $6.08 \mathrm{E}-02$ \\
\hline $\mathrm{v}$ & $1.05 \mathrm{E}-01$ & $1.05 \mathrm{E}-01$ & $1.03 \mathrm{E}-01$ & $6.19 \mathrm{E}-03$ & $1.03 \mathrm{E}-01$ & $6.61 E-02$ & $9.44 E-02$ & 6.07E-02 & $8.68 \mathrm{E}-02$ & $8.34 \mathrm{E}-02$ & $8.17 \mathrm{E}-02$ \\
\hline $2 n$ & $5.28 \mathrm{E}+02$ & $5.28 \mathrm{E}+02$ & $5.21 E+02$ & $3.13 E+01$ & $5.20 \mathrm{E}+02$ & $3.34 E+02$ & $4.77 E+02$ & $1.87 \mathrm{E}+05$ & $2.03 E-01$ & $1.95 \mathrm{E}-01$ & $1.91 \mathrm{E}-01$ \\
\hline $2 r$ & $6.00 \mathrm{E}-03$ & $6.00 \mathrm{E}-03$ & $5.93 \mathrm{E}-03$ & $3.56 \mathrm{E}-04$ & $5.92 E-03$ & $3.79 E-03$ & $5.42 \mathrm{E}-03$ & $3.49 E-03$ & $4.99 \mathrm{E}-03$ & $4.79 \mathrm{E}-03$ & $4.69 \mathrm{E}-03$ \\
\hline $\mathrm{pH}$ & 2.70 & 2.70 & 2.10 & 0.00 & 1.19 & 15.48 & 6.00 & 15.22 & 10.91 & 6.99 & 7.00 \\
\hline FLOWRATE & 1000.00 & 1000.00 & 1012.23 & 33.74 & 1012.23 & 0.88 & 1103.64 & 2.70 & 1148.66 & 1195.81 & 1195.81 \\
\hline TDS & $1.06 \mathrm{E}+04$ & $1.05 E+04$ & $1.16 \mathrm{E}+04$ & $1.27 E+05$ & $1.05 \mathrm{E}+04$ & $3.08 E+05$ & $1.13 E+04$ & $3.88 E+05$ & $1.04 E+04$ & $1.01 E+04$ & $2.30 E+03$ \\
\hline
\end{tabular}




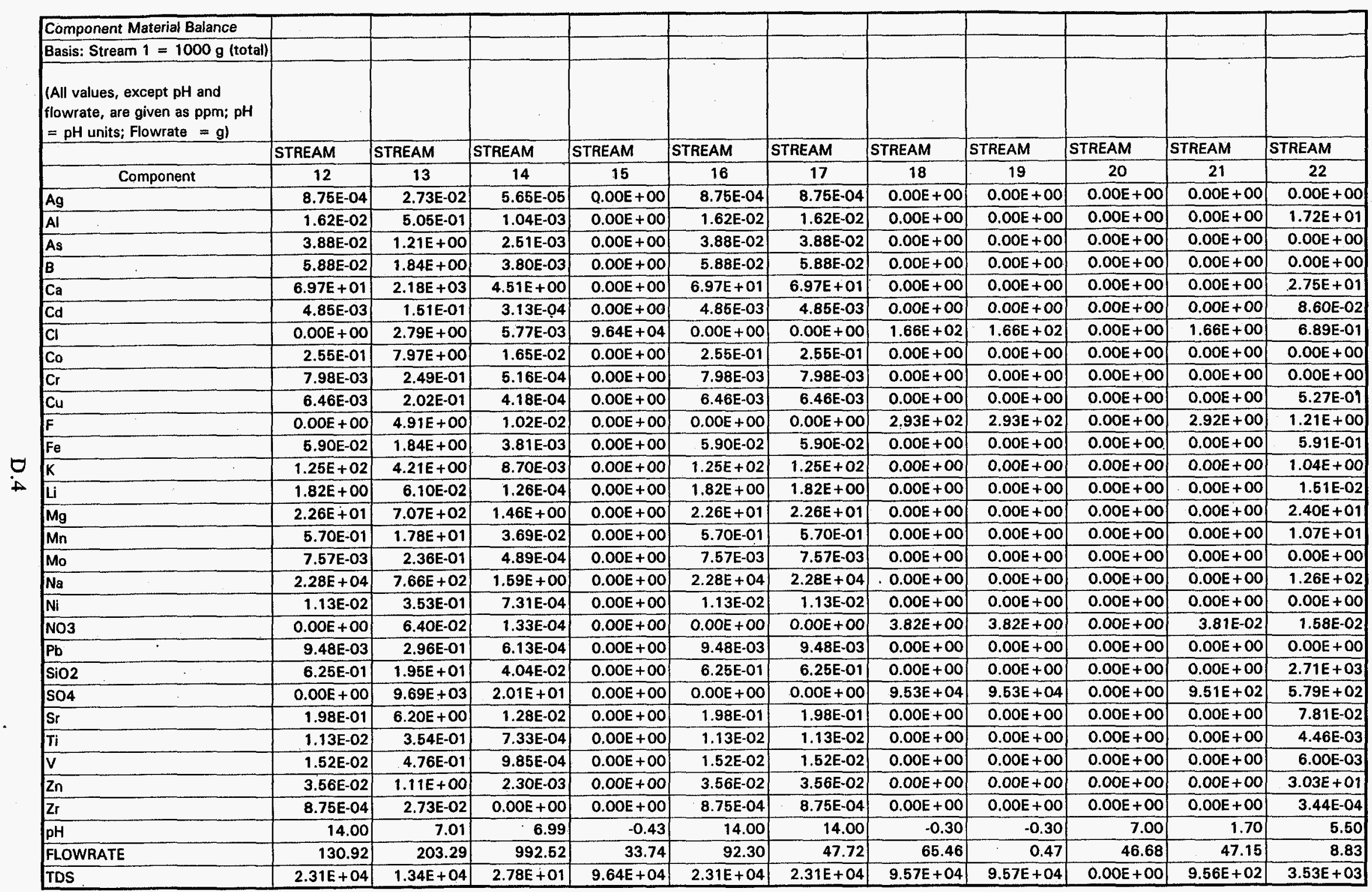









\begin{tabular}{|c|c|c|c|c|c|c|c|c|}
\hline \multicolumn{9}{|c|}{ Component Material Balance } \\
\hline \multicolumn{9}{|c|}{ Basis: Stream $1=1000 \mathrm{~g}$ (total) } \\
\hline \multicolumn{9}{|c|}{$\begin{array}{l}\text { (All values, except pH and } \\
\text { flowrate, are given as ppm; pH } \\
=\text { pH units; Flowrate = g) }\end{array}$} \\
\hline & STREAM & STREAM & STREAM & STREAM & STREAM & STREAM & STREAM & STREAM \\
\hline Component & 34 & 35 & 36 & 37 & 38 & 39 & 40 & 41 \\
\hline$\widehat{\mathrm{Ag}}$ & 2.78E-04 & $0.00 \mathrm{E}+00$ & $2.38 \mathrm{E}-04$ & $0.00 E+00$ & $0.00 E+00$ & $0.00 E+00$ & $0.00 \mathrm{E}+00$ & $0.00 \mathrm{E}+00$ \\
\hline AI & $3.92 \mathrm{E}+02$ & $0.00 E+00$ & $1.69 \mathrm{E}+04$ & $4.00 E+02$ & $0.00 E+00$ & $0.00 E+00$ & $0.00 E+00$ & $0.00 E+00$ \\
\hline As & $1.23 \mathrm{E}-02$ & $0.00 E+00$ & $1.89 \mathrm{E}+01$ & $1.26 \mathrm{E}-02$ & $0.00 E+00$ & $0.00 E+00$ & $0.00 E+00$ & $0.00 E+00$ \\
\hline$B$ & $1.87 \mathrm{E}-02$ & $0.00 E+00$ & $1.60 \mathrm{E}-02$ & $1.90 \mathrm{E}-02$ & $0.00 \mathrm{E}+00$ & $0.00 E+00$ & $0.00 E+00$ & $0.00 E+00$ \\
\hline $\mathrm{Ca}$ & $2.93 E+01$ & $0.00 E+00$ & $0.00 \mathrm{E}+00$ & $2.99 E+01$ & $0.00 E+00$ & $0.00 E+00$ & $0.00 E+00$ & $0.00 E+00$ \\
\hline$\overline{C d}$ & $4.60 \mathrm{E}+01$ & $0.00 E+00$ & $6.60 \mathrm{E}-03$ & $0.00 E+00$ & $0.00 \mathrm{E}+00$ & $0.00 E+00$ & $0.00 E+00$ & $0.00 E+00$ \\
\hline $\mathrm{Cl}$ & $1.10 E+02$ & $1.66 \mathrm{E}+02$ & $1.56 \mathrm{E}+02$ & $1.13 \mathrm{E}+02$ & $0.00 E+00$ & $1.66 \mathrm{E}+02$ & $0.00 E+00$ & $0.00 \mathrm{E}+00$ \\
\hline Co & $8.09 \mathrm{E}-02$ & $0.00 \mathrm{E}+00$ & $6.93 \mathrm{E}-02$ & $8.26 \mathrm{E}-02$ & $0.00 \mathrm{E}+00$ & $0.00 E+00$ & $0.00 E+00$ & $0.00 E+00$ \\
\hline $\mathrm{Cr}$ & 2.53E-03 & $0.00 \mathrm{E}+00$ & $2.17 E-03$ & $2.59 \mathrm{E}-03$ & $0.00 \mathrm{E}+00$ & $0.00 E+00$ & $0.00 E+00$ & $0.00 E+00$ \\
\hline $\mathrm{Cu}$ & $2.58 \mathrm{E}+02$ & $0.00 E+00$ & $0.00 E+00$ & $0.00 E+00$ & $8.00 E+05$ & $0.00 E+00$ & $0.00 E+00$ & $0.00 E+00$ \\
\hline$F$ & $1.95 \mathrm{E}+02$ & $2.93 E+02$ & $2.75 \mathrm{E}+02$ & $1.99 \mathrm{E}+02$ & $0.00 E+00$ & $2.93 E+02$ & $0.00 E+00$ & $0.00 E+00$ \\
\hline $\mathrm{Fe}$ & $2.79 E+02$ & $0.00 E+00$ & $0.00 E+00$ & $0.00 E+00$ & $2.00 E+05$ & $0.00 E+00$ & $0.00 \mathrm{E}+00$ & $1.00 E+06$ \\
\hline$k$ & $1.11 E+00$ & $0.00 E+00$ & $0.00 E+00$ & $1.13 \mathrm{E}+00$ & $0.00 E+00$ & $0.00 E+00$ & $0.00 E+00$ & $0.00 \mathrm{E}+00$ \\
\hline Li & $1.61 \mathrm{E}-02$ & $0.00 \mathrm{E}+00$ & $0.00 E+00$ & $1.64 \mathrm{E}-02$ & $0.00 E+00$ & $0.00 E+00$ & $0.00 E+00$ & $0.00 E+00$ \\
\hline $\mathrm{Mg}$ & $7.44 \mathrm{E}+03$ & $0.00 \mathrm{E}+00$ & $0.00 \mathrm{E}+00$ & $7.59 \mathrm{E}+03$ & $0.00 E+00$ & $0.00 E+00$ & $0.00 E+00$ & $0.00 E+00$ \\
\hline$M n$ & $5.13 E+03$ & $0.00 \mathrm{E}+00$ & $0.0 .0 \mathrm{E}+00$ & $0.00 E+00$ & $0.00 E+00$ & $0.00 E+00$ & $0.00 E+00$ & $0.00 E+00$ \\
\hline Mo & $2.40 \mathrm{E}-03$ & $0.00 E+00$ & $2.06 \mathrm{E}-03$ & $2.45 \mathrm{E}-03$ & $0.00 \mathrm{E}+00$ & $0.00 E+00$ & $0.00 E+00$ & $0.00 E+00$ \\
\hline $\mathrm{Na}$ & $1.85 E+02$ & $0.00 E+00$ & $0.00 E+00$ & $1.89 \mathrm{E}+02$ & $0.00 E+00$ & $0.00 E+00$ & $0.00 E+00$ & $0.00 E+00$ \\
\hline $\mathrm{Ni}$ & $2.78 \mathrm{E}+01$ & $0.00 E+00$ & $4.21 \mathrm{E}-02$ & $0.00 E+00$ & $0.00 E+00$ & $0.00 \mathrm{E}+00$ & $0.00 E+00$ & $0.00 E+00$ \\
\hline NO3 & $2.54 E+00$ & $3.82 E+00$ & $3.58 \mathrm{E}+00$ & $2.59 E+00$ & $0.00 E+00$ & $3.82 E+00$ & $0.00 E+00$ & $0.00 E+00$ \\
\hline $\mathrm{Pb}$ & $3.01 \mathrm{E}-03$ & $0.00 E+00$ & $2.58 \mathrm{E}-03$ & 3.07E-03 & $0.00 E+00$ & $0.00 E+00$ & $0.00 E+00$ & $0.00 E+00$ \\
\hline $\mathrm{SiO2}$ & $2.59 \mathrm{E}+03$ & $0.00 E+00$ & $0.00 E+00$ & $2.65 E+03$ & $0.00 E+00$ & $0.00 E+00$ & $0.00 E+00$ & $0.00 \mathrm{E}+00$ \\
\hline $\mathrm{SO} 4$ & $6.35 E+04$ & $9.53 E+04$ & $8.93 E+04$ & $6.48 \mathrm{E}+04$ & $0.00 E+00$ & $9.53 E+04$ & $0.00 E+00$ & $0.00 E+00$ \\
\hline $\mathrm{Sr}$ & 8.32E-02 & $0.00 E+00$ & $0.00 E+00$ & $8.50 E-02$ & $0.00 E+00$ & $0.00 \mathrm{E}+00$ & $0.00 \mathrm{E}+00$ & $0.00 E+00$ \\
\hline $\mathrm{Ti}$ & $4.76 \mathrm{E}-03$ & $0.00 E+00$ & $0.00 \mathrm{E}+00$ & $4.86 \mathrm{E}-03$ & $0.00 E+00$ & $0.00 E+00$ & $0.00 E+00$ & $0.00 E+00$ \\
\hline $\mathrm{v}$ & $6.39 \mathrm{E}-03$ & $0.00 \mathrm{E}+00$ & $0.00 \mathrm{E}+00$ & $6.53 \mathrm{E}-03$ & $0.00 E+00$ & $0.00 \mathrm{E}+00$ & $0.00 E+00$ & $0.00 E+00$ \\
\hline$\overline{Z n}$ & $1.49 E+04$ & $0.00 E+00$ & $0.00 E+00$ & $0.00 E+00$ & $0.00 E+00$ & $0.00 E+00$ & $0.00 E+00$ & $0.00 E+00$ \\
\hline $2 r$ & 3.67E-04 & $0.00 E+00$ & $0.00 \mathrm{E}+00$ & 3.75E-04 & $0.00 E+00$ & $0.00 E+00$ & $0.00 E+00$ & $0.00 E+00$ \\
\hline $\mathrm{pH}$ & 2.55 & -0.30 & 2.52 & 0.17 & 14.89 & -0.30 & 7.00 & 7.00 \\
\hline FLOWRATE & 33.93 & 12.23 & 14.07 & 33.23 & 0.22 & 0.00 & 8.83 & 0.20 \\
\hline TDS & $9.50 E+04$ & $9.57 E+04$ & $1.07 \mathrm{E}+05$ & $7.60 \mathrm{E}+04$ & NA & $9.57 E+04$ & $0.00 \mathrm{E}+00$ & $1.00 \mathrm{E}+06$ \\
\hline
\end{tabular}




\section{Appendix E}

Stream Flow Material Balance for Flowsheet

Showing Nonselective Concentration of All Constituents from Feedwater 


\section{Appendix E}

\section{Stream Flow Material Balance for Flowsheet Showing Nonselective Concentration of All Constituents from Feedwater}

Figure E.1 is an integrated flowsheet for recovering constituents from Berkeley Pit water that includes a nonselective concentration step, followed by selective separation/ purification of the concentrate, and secondary water treatment steps. Products recovered from the Berkeley Pit water include copper sulfate, ferric sulfate, zinc sulfate, and manganese sulfate. All selective separation processes use solvent extraction. Nanofiltration, reverse osmosis, electrodialysis, and precipitation are used to remove other contaminants from the water. The processing steps and the assumptions made in the performance of those processing steps are given in the flowsheet. A simplified material balance based on ideal splits of constituents to the various streams is provided in Table E.1. This is necessary because experimental testing would be required to determine these splits using solvent extraction. 


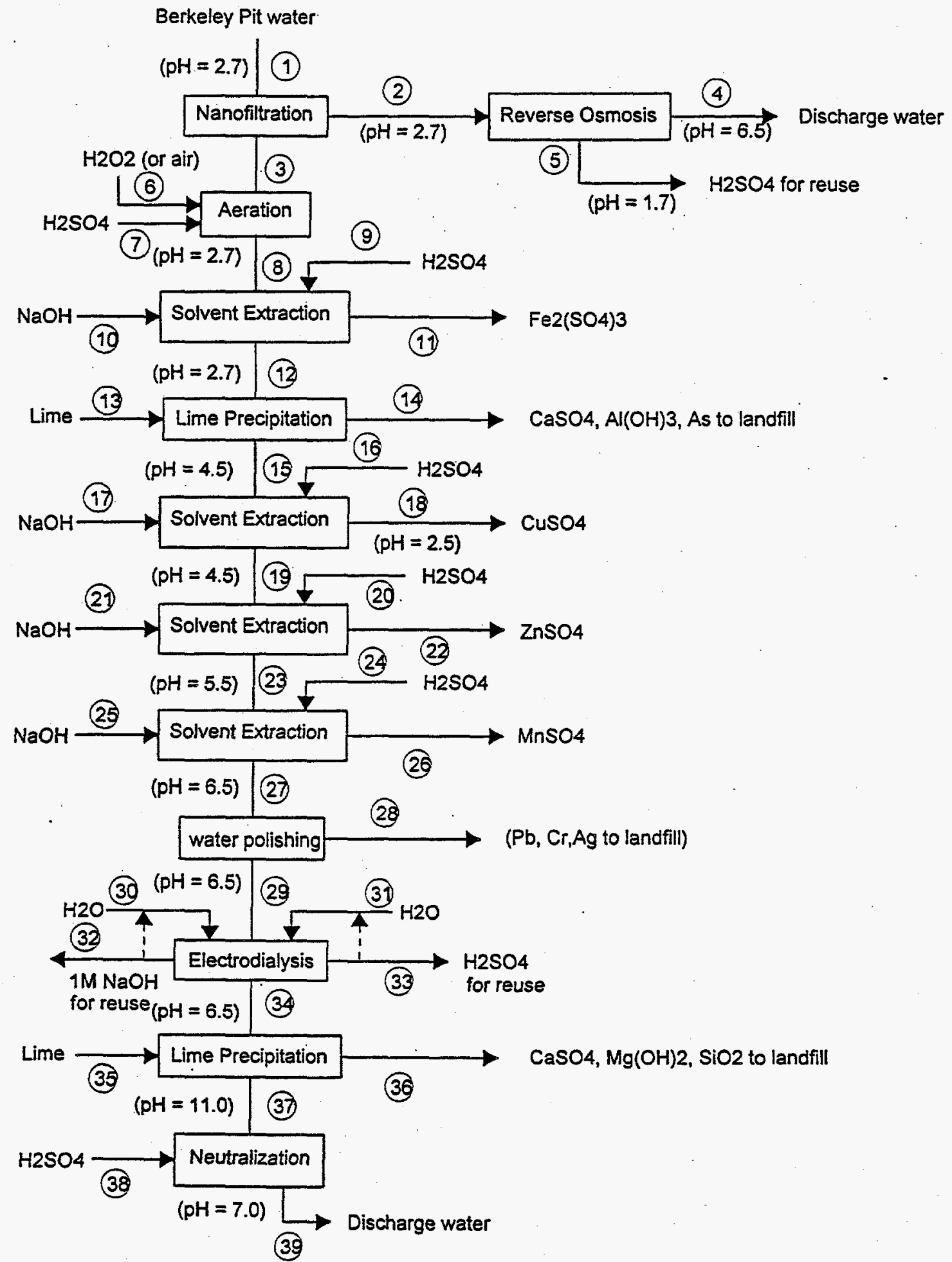

Figure E.1 Flowsheet Showing Nonselective Concentration of All Constituents from Feedwater 
Table E.1. Stream FLow Material Balance Showing Nonselective Concentration of All Constituents from Feedwater

\begin{tabular}{|c|c|c|c|c|c|c|c|c|c|c|}
\hline \multicolumn{11}{|l|}{ Component Material Balance } \\
\hline \\
\hline $\begin{array}{l}\text { (all values, except pH and total } \\
\text { flow are given as ppm); } \mathrm{pH}=\mathrm{pH}\end{array}$ & & & & & & & & & & \\
\hline & STREAM & STREAM & STREAM & STREAM & STREAM & STREAM & STREAM & STREAM & STREAM & STREAM \\
\hline Component & 1 & 2 & 3 & 4 & 5 & 6 & 7 & 8 & 9 & 10 \\
\hline $\mathrm{Ag}$ & 6.00E-03 & $6.06 E-03$ & 5.94E-03 & $0.00 E+00$ & $6.04 E-02$ & $0.00 E+00$ & $0.00 E+00$ & $5.75 \mathrm{E}-03$ & $0.00 E+00$ & $0.00 E+00$ \\
\hline A) & $2.79 E+02$ & $0.00 E+00$ & $5.52 E+02$ & $0.00 E+00$ & $0.00 E+00$ & $0.00 E+00$ & $0.00 E+00$ & $5.34 E+02$ & $0.00 E+00$ & $0.00 E+00$ \\
\hline As & 5.32E-01 & $0.00 E+00$ & $1.05 E+00$ & $0.00 \mathrm{E}+00$ & $0.00 E+00$ & $0.00 E+00$ & $0.00 E+00$ & $1.02 E+00$ & $0.00 E+00$ & $0.00 E+00$ \\
\hline B & 4.02E-01 & $0.00 E+00$ & 7.97E-01 & $0.00 E+00$ & $0.00 E+00$ & $0.00 E+00$ & $0.00 E+00$ & $7.71 E-01$ & $0.00 E+00$ & $0.00 E+00$ \\
\hline $\mathrm{Ca}^{\circ}$ & $4.78 \mathrm{E}+02$ & $0.00 E+00$ & $9.47 E+02$ & $0.00 E+00$ & $0.00 E+00$ & $0.00 E+00$ & $0.00 E+00$ & $9.16 \mathrm{E}+02$ & $0.00 E+00$ & $0.00 E+00$ \\
\hline Cd & $1.66 \mathrm{E}+00$ & $0.00 E+00$ & $3.30 E+00$ & $0.00 E+00$ & $0.00 \mathrm{E}+00$ & $0.00 E+00$ & $0.00 E+00$ & $3.19 E+00$ & $0.00 E+00$ & $0.00 E+00$ \\
\hline c & $1.20 E+01$ & $4.26 \mathrm{E}-01$ & $2.33 E+01$ & 2.45E-05 & $4.24 E+00$ & $0.00 E+00$ & $0.00 E+00$ & $2.25 E+01$ & $0.00 E+00$ & $0.00 E+00$ \\
\hline$C_{0}$ & $1.75 E+00$ & $0.00 E+00$ & $3.46 E+00$ & $0.00 E+00$ & $0.00 E+00$ & $0.00 E+00$ & $0.00 E+00$ & $3.35 \mathrm{E}+00$ & $0.00 E+00$ & $0.00 E+00$ \\
\hline cr & 5.47E-02 & $0.00 E+00$ & $1.08 \mathrm{E}-01$ & $0.00 E+00$ & $0.00 E+00$ & $0.00 E+\infty 0$ & $0.00 E+00$ & $1.05 \mathrm{E}-01$ & $0.00 E+00$ & $0.00 E+00$ \\
\hline $\mathrm{Cu}$ & $1.84 E+02$ & $0.00 E+00$ & $3.64 E+02$ & $0.00 E+00$ & $0.00 E+00$ & $0.00 E+00$ & $0.00 E+00$ & $3.62 E+02$ & $0.00 E+00$ & $0.00 E+00$ \\
\hline$F$ & $2.11 E+01$ & 7.50E-01 & $4.10 E+01$ & $4.32 \mathrm{E}-05$ & $7.47 E+00$ & $0.00 E+00$ & $0.00 E+00$ & $3.97 \mathrm{E}+01$ & $0.00 E+00$ & $0.00 E+00$ \\
\hline $\mathrm{Fe}$ & $8.74 E+02$ & $0.00 E+00$ & $1.73 E+03$ & $0.00 E+00$ & $0.00 E+00$ & $0.00 E+00$ & $0.00 E+00$ & $1.68 E+03$ & $0.00 E+00$ & $0.00 E+00$ \\
\hline$K$ & $1.81 E+01$ & $1.83 E+01$ & $1.79 E+01$ & $0.00 \mathrm{E}+00$ & $1.82 \mathrm{E}+02$ & $0.00 E+00$ & $0.00 E+00$ & $1.73 E+01$ & $0.00 E+00$ & $0.00 E+00$ \\
\hline Li & 2.62E-01 & 2.65E-01 & $2.59 E-01$ & $0.00 \mathrm{E}+00$ & $2.64 E+00$ & $0.00 E+00$ & $0.00 E+00$ & $2.51 \mathrm{E}-01$ & $0.00 E+00$ & $0.00 E+00$ \\
\hline $\mathrm{Mg}$ & $4.18 E+02$ & $0.00 E+00$ & $8.27 E+02$ & $0.00 E+00$ & $0.00 E+00$ & $0.00 E+\infty 0$ & $0.00 E+00$ & $8.00 E+02$ & $0.00 E+00$ & $0.00 E+00$ \\
\hline $\mathrm{Mn}$ & $1.86 E+02$ & $0.00 E+00$ & $3.68 E+02$ & $0.00 E+00$ & $0.00 E+00$ & $0.00 E+00$ & $0.00 \mathrm{E}+00$ & $3.56 \mathrm{E}+02$ & $0.00 E+00$ & $0.00 E+00$ \\
\hline Mo & 5.75E-02 & $0.00 E+00$ & $1.14 E-01$ & $0.00 E+00$ & $0.00 \mathrm{E}+00$ & $0.00 E+00$ & $0.00 E+00$ & $1.10 \mathrm{E}-01$ & $0.00 E+00$ & $0.00 E+00$ \\
\hline $\mathrm{Na}$ & $6.88 \mathrm{EE}+01$ & $6.95 E+01$ & $6.81 . E+01$ & $0.00 E+00$ & $6.93 \mathrm{~B}+02$ & $0.00 E+00$ & $0.00 E+00$ & $6.59 \mathrm{E}+01$ & $0.00 E+00$ & $1.87 E+05$ \\
\hline $\mathrm{Ni}$ & $1.06 \mathrm{E}+00$ & $0.00 E+00$ & $2.10 E+00$ & $0.00 \mathrm{E}+00$ & $0.00 E+00$ & $0.00 E+00$ & $0.00 E+00$ & $2.04 E+00$ & $0.00 E+00$ & $0.00 E+00$ \\
\hline NO3 & $2.75 \mathrm{E}-01$ & 9.77E-03 & $5.35 \mathrm{E}-01$ & $5.63 E-07$ & $9.74 \mathrm{E}-02$ & $0.00 E+00$ & $0.00 \mathrm{E}+00$ & 5.17E-01 & $0.00 E+00$ & $0.00 E+00$ \\
\hline $\mathrm{Pb}$ & $6.50 \mathrm{E}-02$ & $0.00 E+00$ & $1.29 \mathrm{E}-01$ & $0.00 E+00$ & $0.00 E+00$ & $0.00 E+00$ & $0.00 E+00$ & $1.25 \mathrm{E}-01$ & $0.00 E+00$ & $0.00 E+00$ \\
\hline Sio2 & $9.75 E+01$ & $0.00 E+00$ & $1.93 E+02$ & $0.00 E+Q 0$ & $0.00 E+00$ & $0.00 E+00$ & $0.00 E+00$ & $1.87 E+02$ & $0.00 E+00$ & $0.00 E+00$ \\
\hline SO4 & $7.39 E+03$ & $2.63 E+02$ & $1.44 E+04$ & $1.51 E-02$ & $2.62 E+03$ & $0.00 E+00$ & $4.66 \mathrm{E}+04$ & $1.53 E+04$ & $4.62 E+04$ & $0.00 E+00$ \\
\hline Sr & $1.36 E+00$ & $0.00 E+00$ & $2.69 E+00$ & $0.00 E+00$ & $0.00 E+00$ & $0.00 E+00$ & $0.00 E+00$ & $2.60 E+00$ & $0.00 E+00$ & $0.00 E+00$ \\
\hline$T i$ & 7.77E-02 & $0.00 E+00$ & $1.54 \mathrm{E}-01$ & $0.00 E+00$ & $0.00 E+00$ & $0.00 E+00$ & $0.00 E+00$ & $1.49 \mathrm{E}-01$ & $0.00 E+00$ & $0.00 E+00$ \\
\hline v & $1.04 \mathrm{E}-01$ & $0.00 E+00$ & $2.07 \mathrm{E}-01$ & $0.00 E+00$ & $0.00 E+00$ & $0.00 E+00$ & $0.00 E+00$ & $2.00 \mathrm{E}-01$ & $0.00 E+00$ & $0.00 E+00$ \\
\hline$z n$ & $5.28 \mathrm{E}+02$ & $0.00 E+00$ & $1.04 E+03$ & $0.00 E+00$ & $0.00 E+00$ & $0.00 E+00$ & $0.00 E+00$ & $1.01 E+03$ & $0.00 E+00$ & $0.00 E+00$ \\
\hline $\mathrm{zr}$ & 6.00E-03 & $6.06 E-03$ & $5.94 \mathrm{E}-03$ & $0.00 E+00$ & $6.04 \mathrm{E}-02$ & $0.00 E+00$ & $0.00 E+00$ & $5.75 \mathrm{E}-03$ & $0.00 E+00$ & $0.00 E+00$ \\
\hline $\mathrm{H} 2 \mathrm{O} 2$ & $0.00 E+00$ & $0.00 \mathrm{E}+00$ & $0.00 E+00$ & $0.00 E+00$ & $0.00 \mathrm{E}+00$ & $2.31 E+05$ & $0.00 E+00$ & $0.00 E+00$ & $0.00 E+00$ & $0.00 E+00$ \\
\hline $\mathrm{pH}$ & 2.7 & 2.7 & 2.7 & 6.5 & 1.70 & $\mathrm{NA}$ & $(1 \mathrm{MH}+1$ & 2.7 & $(13 \mathrm{MH}+1$ & $11 \mathrm{M} \mathrm{OH}-1$ \\
\hline total flow & 1000.00 & 494.89 & 505.11 & 445.25 & 49.65 & 1.15 & 16.09 & 522.09 & 54.06 & 5.77 \\
\hline TDS & $1.06 E+04$ & $3.52 \mathrm{E}+02$ & $2.06 \mathrm{E}+04$ & $1.52 \mathrm{E}-02$ & $3.51 E+03$ & $2.31 E+05$ & $4.66 \mathrm{E}+04$ & $2.13 E+04$ & $4.62 E+04$ & $1.87 E+05$ \\
\hline
\end{tabular}




\begin{tabular}{|c|c|c|c|c|c|c|c|c|c|c|}
\hline \multicolumn{11}{|l|}{ Component Material Balance } \\
\hline \multicolumn{11}{|l|}{ basis: Stream $1=1000 \mathrm{~g}$ (total) } \\
\hline \multicolumn{11}{|l|}{$\begin{array}{l}\text { (all values, except } \mathrm{pH} \text { and total } \\
\text { flow are given as } \mathrm{ppm}) ; \mathrm{pH}=\mathrm{pH} \\
\text { units, total flow }=\text { grams. }\end{array}$} \\
\hline- & STREAM & STREAM & STREAM & STREAM & STREAM & STREAM & STREAM & STREAM & STREAM & STREAM \\
\hline Component & 11 & 12 & 13 & 14 & 15 & 16 & 17 & 18 & 19 & 20 \\
\hline $\mathrm{Ag}$ & $0.00 E+00$ & $5.69 E-03$ & $0.00 E+00$ & $4.68 \mathrm{E}-03$ & 5.69E-03 & $0.00 E+00$ & $0.00 E+00$ & $0.00 E+00$ & 5.63E-03 & $0.00 \mathrm{E}+00$ \\
\hline AI & $0.00 E+00$ & $5.29 E+02$ & $0.00 \mathrm{E}+00$ & $1.24 \mathrm{E}+04$ & $0.00 \mathrm{E}+00$ & $0.00 E+00$ & $0.00 E+00$ & $0.00 E+00$ & $0.00 E+00$ & $0.00 \mathrm{E}+00$ \\
\hline As & $0.00 \mathrm{E}+00$ & $1.01 E+00$ & $0.00 E+00$ & $2.37 E+01$ & $0.00 E+00$ & $0.00 \mathrm{E}+00$ & $0.00 E+00$ & $0.00 E+00$ & $0.00 E+00$ & $0.00 E+00$ \\
\hline$B$ & $0.00 E+00$ & 7.64E-01 & $0.00 E+00$ & $6.27 \mathrm{E}-01$ & 7.64E-01 & $0.00 E+00$ & $0.00 E+00$ & $0.00 E+00$ & 7.56E-01 & $0.00 E+00$ \\
\hline $\mathrm{Ca}$ & $0.00 \mathrm{E}+00$ & $9.08 E+02$ & $1.67 \mathrm{E}+05$ & $4.90 E+04$ & $3.90 E+01$ & $0.00 \mathrm{E}+00$ & $0.00 E+00$ & $0.00 \mathrm{E}+00$ & $3.86 \mathrm{E}+01$ & $0.00 E+00$ \\
\hline $\mathrm{Cd}$ & $0.00 E+00$ & $3.16 \mathrm{E}+00$ & $0.00 E+00$ & $2.60 \mathrm{E}+00$ & $3.16 \mathrm{E}+00$ & $0.00 E+00$ & $0.00 E+00$ & $0.00 \mathrm{E}+00$ & $3.13 E+00$ & $0.00 E+00$ \\
\hline $\mathrm{Cl}$ & $0.00 E+00$ & $2.23 \mathrm{E}+01$ & $0.00 E+00$ & $1.83 E+01$ & $2.23 E+01$ & $0.00 E+00$ & $0.00 E+00$ & $0.00 E+00$ & $2.21 E+01$ & $0.00 E+00$ \\
\hline Co & $0.00 \mathrm{E}+00$ & $3.32 E+00$ & $0.00 E+00$ & $2.73 E+00$ & $3.32 E+00$ & $0.00 E+00$ & $0.00 E+00$ & $0.00 E+00$ & $3.29 E+00$ & $0.00 E+00$ \\
\hline $\mathrm{Cr}$ & $0.00 E+00$ & 1.04E-01 & $0.00 E+00$ & 8.53E-02 & $1.04 \mathrm{E}-01$ & $0.00 \mathrm{E}+00$ & $0.00 E+00$ & $0.00 E+00$ & $1.03 E-01$ & $0.00 E+00$ \\
\hline $\mathrm{Cu}$ & $0.00 E+00$ & $3.48 \mathrm{E}+02$ & $0.00 E+00$ & $2.86 \mathrm{E}+02$ & $3.49 \mathrm{E}+02$ & $0.00 E+00$ & $0.00 E+00$ & $3.47 \mathrm{E}+03$ & $0.00 \mathrm{E}+00$ & $0.00 E+00$ \\
\hline$F$ & $0.00 E+00$ & $3.93 \mathrm{E}+01$ & $0.00 E+00$ & $3.23 \mathrm{E}+01$ & $3.93 E+01$ & $0.00 E+00$ & $0.00 E+00$ & $0.00 E+00$ & $3.89 E+01$ & $0.00 E+00$ \\
\hline $\mathrm{Fe}$ & $1.59 E+04$ & $0.00 \mathrm{E}+00$ & $0.00 E+00$ & $0.00 \mathrm{E}+00$ & $0.00 E+00$ & $0.00 E+00$ & $0.00 E+00$ & $0.00 \mathrm{E}+00$ & $0.00 \mathrm{E}+00$ & $0.00 E+00$ \\
\hline$k$ & $0.00 E+00$ & $1.71 E+01$ & $0.00 E+00$ & $1.41 E+01$ & $1.72 \mathrm{E}+01$ & $0.00 E+00$ & $0.00 E+00$ & $0.00 E+00$ & $1.70 E+01$ & $0.00 \mathrm{E}+00$ \\
\hline Li & $0.00 E+00$ & $2.49 E-01$ & $0.00 E+00$ & $2.04 \mathrm{E}-01$ & $2.49 \mathrm{E}-01$ & $0.00 E+00$ & $0.00 E+00$ & $0.00 E+00$ & $2.46 \mathrm{E}-01$ & $0.00 E+00$ \\
\hline $\mathrm{Mg}$ & $0.00 E+00$ & $7.93 E+02$ & $0.00 \mathrm{E}+00$ & $6.51 \mathrm{E}+02$ & $7.93 \mathrm{E}+02$ & $0.00 \mathrm{E}+00$ & $0.00 E+00$ & $0.00 \mathrm{E}+00$ & $7.85 E+02$ & $0.00 E+00$ \\
\hline$M n$ & $0.00 E+00$ & $3.53 E+02$ & $0.00 \mathrm{E}+00$ & $2.90 \mathrm{E}+02$ & $3.53 \mathrm{E}+02$ & $0.00 \mathrm{E}+00$ & $0.00 E+00$ & $0.00 \mathrm{E}+00$ & $3.49 \mathrm{E}+02$ & $0.00 E+00$ \\
\hline Mo & $0.00 E+00$ & $1.09 \mathrm{E}-01$ & $0.00 E+00$ & $8.96 \mathrm{E}-02$ & $1.09 \mathrm{E}-01$ & $0.00 \mathrm{E}+00$ & $0.00 E+00$ & $0.00 \mathrm{E}+00$ & $1.08 E-01$ & $0.00 E+00$ \\
\hline $\mathrm{Na}$ & $0.00 E+00$ & $2.11 \mathrm{E}+03$ & $0.00 E+00$ & $1.73 E+03$ & $2.11 \mathrm{E}+03$ & $0.00 \mathrm{E}+00$ & $2.25 \mathrm{E}+04$ & $0.00 \mathrm{E}+00$ & $2.34 \mathrm{E}+03$ & $0.00 E+00$ \\
\hline $\mathrm{Ni}$ & $0.00 E+00$ & $2.02 \mathrm{E}+00$ & $0.00 \mathrm{E}+00$ & $1.66 \mathrm{E}+00$ & $2.02 E+00$ & $0.00 E+00$ & $0.00 E+00$ & $0.00 E+00$ & $2.00 E+00$ & $0.00 E+00$ \\
\hline $\mathrm{NO3}$ & $0.00 E+00$ & $5.13 E-01$ & $0.00 E+00$ & $4.21 \mathrm{E}-01$ & $5.13 E-01$ & $0.00 E+00$ & $0.00 E+00$ & $0.00 E+00$ & 5.07E-01 & $0.00 E+00$ \\
\hline $\overrightarrow{\mathrm{Pb}}$ & $0.00 E+00$ & 1.23E-01 & $0.00 E+00$ & $1.01 \mathrm{E}-01$ & 1.23E-01 & $0.00 E+00$ & $0.00 E+00$ & $0.00 E+00$ & $1.22 \mathrm{E}-01$ & $0.00 \mathrm{E}+00$ \\
\hline $\mathrm{SiO2}$ & $0.00 E+00$ & $1.85 \mathrm{E}+02$ & $0.00 \mathrm{E}+00$ & $1.52 \mathrm{E}+02$ & $1.85 E+02$ & $0.00 E+00$ & $0.00 E+00$ & $0: 00 E+00$ & $1.83 \mathrm{E}+02$ & $0.00 E+00$ \\
\hline 504 & $4.54 \mathrm{E}+04$ & $1.52 E+04$ & $0.00 E+00$ & $1.26 \mathrm{E}+05$ & $1.02 E+04$ & $5.37 \mathrm{E}+03$ & $0.00 E+00$ & $5.35 E+03$ & $1.01 E+04$ & $1.43 E+04$ \\
\hline $5 r$ & $0.00 \mathrm{E}+00$ & $2.58 \mathrm{E}+00$ & $0.00 E+00$ & $2.12 \mathrm{E}+00$ & $2.58 \mathrm{E}+00$ & $0.00 \mathrm{E}+00$ & $0.00 E+00$ & $0.00 E+00$ & $2.55 E+00$ & $0.00 E+00$ \\
\hline $\mathrm{Ti}$ & $0.00 E+00$ & $1.48 \mathrm{E}-01$ & $0.00 E+00$ & $1.21 \mathrm{E}-01$ & $1.48 \mathrm{E}-01$ & $0.00 E+00$ & $0.00 E+00$ & $0.00 E+00$ & $1.46 \mathrm{E}-01$ & $0.00 E+00$ \\
\hline $\mathrm{v}$ & $0.00 E+00$ & $1.98 \mathrm{E}-01$ & $0.00 E+00$ & 1.63E-01 & $1.98 \mathrm{E}-01$ & $0.00 E+00$ & $0.00 E+00$ & $0.00 E+00$ & $1.96 \mathrm{E}-01$ & $0.00 E+00$ \\
\hline $2 n$ & $0.00 E+00$ & $1.00 \mathrm{E}+03$ & $0.00 E+00$ & $8.23 E+02$ & $1.00 E+03$ & $0.00 E+00$ & $0.00 E+00$ & $0.00 E+00$ & $9.91 \mathrm{E}+02$ & $0.00 \mathrm{E}+00$ \\
\hline $2 r$ & $0.00 E+00$ & $5.69 \mathrm{E}-03$ & $0.00 E+00$ & $4.68 \mathrm{E}-03$ & $5.69 \mathrm{E}-03$ & $0.00 E+00$ & $0.00 E+00$ & $0.00 E+00$ & 5.63E-03 & $0.00 E+00$ \\
\hline $\mathrm{H2O2}$ & $0.00 E+00$ & $0.00 E+00$ & $0.00 \mathrm{E}+00$ & $0.00 \mathrm{E}+00$ & $0.00 E+00$ & $0.00 \mathrm{E}+00$ & $0.00 E+00$ & $0.00 E+00$ & $0.00 E+00$ & $0.00 \mathrm{E}+00$ \\
\hline $\mathrm{pH}$ & 1 & 2.7 & $(10 \mathrm{M} \mathrm{OH}-1$ & 4.5 & 4.5 & 0.94864935 & $(1 \mathrm{MOH}-1$ & 2.5 & 4.5 & 0.51887677 \\
\hline total flow & 54.93 & 526.98 & 3.84 & 22.44 & 508.38 & 50.90 & 5.66 & 51.07 & 513.87 & 52.96 \\
\hline TDS & $6.14 E+04$ & $2.15 \mathrm{E}+04$ & $1.67 \mathrm{E}+05$ & $1.91 E+05$ & $1.51 E+04$ & $5.37 E+03$ & $2.25 E+04$ & $8.82 E+03$ & $1.49 E+04$ & $1.43 E+04$ \\
\hline
\end{tabular}


Table E.1. Stream FLow Material Balance Showing Nonselective Concentration of All Constituents from Feedwater

\begin{tabular}{|c|c|c|c|c|c|c|c|c|c|c|}
\hline \multicolumn{11}{|l|}{ Component Material Balance } \\
\hline \\
\hline $\begin{array}{l}\text { (all values, except } \mathrm{pH} \text { and total } \\
\text { flow are given as } \mathrm{ppm}) ; \mathrm{pH}=\mathrm{pH}\end{array}$ & & & & & & & & & & \\
\hline & STREAM & STREAM & STREAM & STREAM & STREAM & STREAM & STREAM & STREAM & STREAM & STREAM \\
\hline Component & 21 & 22 & 23 & 24 & 25 & 26 & 27 & 28 & 29 & 30 \\
\hline $\mathrm{Ag}$ & $0.00 E+00$ & $0.00 E+00$ & 5.47E-03 & $0.00 E+00$ & $0.00 E+00$ & $0.00 E+00$ & $5.40 \mathrm{E}-03$ & $2.44 E+04$ & $0.00 E+00$ & $0.00 E+00$ \\
\hline Al & $0.00 E+00$ & $0.00 E+00$ & $0.00 E+\infty 0$ & $0.00 E+00$ & $0.00 E+00$ & $0.00 E+00$ & $0.00 E+00$ & $0.00 E+00$ & $0.00 E+00$ & $0.00 E+00$ \\
\hline As & $0.00 E+00$ & $0.00 E+00$ & $0.00 E+00$ & $0.00 E+00$ & $0.00 E+00$ & $0.00 E+00$ & $0.00 E+00$ & $0.00 E+00$ & $0.00 E+00$ & $0.00 E+00$ \\
\hline$B$ & $0.00 E+00$ & $0.00 E+00$ & 7.34E-01 & $0.00 E+00$ & $0.00 E+00$ & $0.00 E+00$ & $7.25 \mathrm{E}-01$ & $0.00 E+00$ & $7.25 \mathrm{E}-01$ & $0.00 E+00$ \\
\hline$C_{a}$ & $0.00 E+00$ & $0.00 E+00$ & $3.75 E+01$ & $0.00 E+00$ & $0.00 E+00$ & $0.00 E+00$ & $3.70 E+01$ & $0.00 E+00$ & $3.70 E+01$ & $0.00 E+00$ \\
\hline$c d$ & $0.00 E+00$ & $3.00 E+01$ & $0.00 E+00$ & $0.00 E+00$ & $0.00 E+00$ & $0.00 E+00$ & $0.00 E+00$ & $0.00 E+00$ & $0.00 E+00$ & $0.00 E+00$ \\
\hline CI & $0.00 E+00$ & $0.00 E+00$ & $2.14 E+01$ & $0.00 E+00$ & $0.00 E+00$ & $0.00 E+00$ & $2.12 E+01$ & $0.00 E+00$ & $2.12 \mathrm{E}+01$ & $0.00 E+00$ \\
\hline$C_{0}$ & $0.00 E+00$ & $3.16 E+01$ & $0.00 E+00$ & $0.00 E+00$ & $0.00 E+00$ & $0.00 E+00$ & $0.00 E+00$ & $0.00 E+00$ & $0.00 E+00$ & $0.00 E+00$ \\
\hline $\mathrm{Cr}_{\mathrm{r}}$ & $0.00 E+00$ & $0.00 E+00$ & $9.98 \mathrm{E}-02$ & $0.00 E+00$ & $0.00 E+00$ & $0.00 E+00$ & $9.86 \mathrm{E}-02$ & $4.46 \mathrm{E}+05$ & $0.00 E+00$ & $0.00 E+00$ \\
\hline$c_{u}$ & $0.00 E+00$ & $0.00 E+00$ & $0.00 E+00$ & $0.00 E+00$ & $0.00 E+00$ & $0.00 E+00$ & $0.00 E+00$ & $0.00 E+00$ & $0.00 E+00$ & $0.00 E+00$ \\
\hline$F$ & $0.00 E+00$ & $0.00 E+00$ & $3.78 \mathrm{E}+01$ & $0.00 E+00$ & $0.00 E+00$ & $0.00 E+00$ & $3.73 E+01$ & $0.00 E+00$ & $3.73 E+01$ & $0.00 E+00$ \\
\hline $\mathrm{Fe}$ & $0.00 E+00$ & $0.00 E+00$ & $0.00 E+00$ & $0.00 E+00$ & $0.00 E+00$ & $0.00 E+00$ & $0.00 E+00$ & $0.00 E+00$ & $0.00 E+00$ & $0.00 E+00$ \\
\hline$K$ & $0.00 E+00$ & $0.00 E+00$ & $1.65 E+01$ & $0.00 E+00$ & $0.00 E+00$ & $0.00 E+00$ & $1.63 E+01$ & $0.00 \mathrm{E}+00$ & $1.63 \mathrm{E}+01$ & $0.00 E+00$ \\
\hline$L i$ & $0.00 E+00$ & $0.00 E+00$ & $2.39 \mathrm{E}-01$ & $0.00 E+00$ & $0.00 E+00$ & $0.00 E+00$ & $2.36 \mathrm{E}-01$ & $0.00 E+00$ & $2.36 \mathrm{E}-01$ & $0.00 E+00$ \\
\hline $\mathrm{Mg}$ & $0.00 E+00$ & $0.00 E+00$ & $7.61 E+02$ & $0.00 \mathrm{E}+00$ & $0.00 E+00$ & $0.00 E+00$ & $7.52 E+02$ & $0.00 E+00$ & $7.52 \mathrm{E}+02$ & $0.00 E+00$ \\
\hline $\mathrm{Mn}$ & $0.00 E+00$ & $0.00 E+00$ & $3.39 E+02$ & $0.00 E+00$ & $0.00 E+00$ & $3.37 \mathrm{E}+03$ & $0.00 E+00$ & $0.00 E+00$ & $0.00 \mathrm{E}+00$ & $0.00 E+00$ \\
\hline Mo & $0.00 E+00$ & $0.00 E+00$ & $1.05 \mathrm{E}-01$ & $0.00 E+00$ & $0.00 E+00$ & $0.00 E+00$ & $1.04 \mathrm{E}-01$ & $0.00 E+00$ & $1.04 E-01$ & $0.00 E+00$ \\
\hline $\mathrm{Na}$ & $2.25 E+04$ & $0.00 E+00$ & $2.96 E+03$ & $0.00 E+00$ & $2.25 E+04$ & $0.00 E+00$ & $3.20 E+03$ & $0.00 E+00$ & $3.20 \mathrm{E}+03$ & $0.00 E+00$ \\
\hline $\mathrm{Ni}$ & $0.00 E+00$ & $1.92 E+01$ & $0.00 E+00$ & $0.00 E+00$ & $0.00 E+00$ & $0.00 E+00$ & $0.00 E+00$ & $0.00 E+00$ & $0.00 E+00$ & $0.00 E+00$ \\
\hline NO3 & $0.00 E+00$ & $0.00 E+00$ & $4.92 \mathrm{E}-01$ & $0.00 E+00$ & $0.00 E+00$ & $0.00 E+00$ & $4.86 \mathrm{E}-01$ & $0.00 E+00$ & $4.86 \mathrm{E}-01$ & $0.00 E+00$ \\
\hline $\mathrm{Pb}$ & $0.00 E+00$ & $0.00 E+00$ & $1.18 \mathrm{E}-01$ & $0.00 E+00$ & $0.00 E+\infty$ & $0.00 E+00$ & $1.17 \mathrm{E}-01$ & $5.30 E+05$ & $0.00 E+00$ & $0.00 E+00$ \\
\hline $\mathrm{SiO2}$ & $0.00 E+00$ & $0.00 E+00$ & $1.78 E+02$ & $0.00 E+00$ & $0.00 E+00$ & $0.00 E+00$ & $1.75 E+02$ & $0.00 E+00$ & $1.75 E+02$ & $0.00 E+00$ \\
\hline SO4 & $0.00 E+00$ & $1.42 E+04$ & $9.80 E+03$ & $5.89 E+03$ & $0.00 E+00$ & $6.88 E+03$ & $9.68 \mathrm{E}+03$ & $0.00 E+00$ & $9.68 \mathrm{E}+03$ & $0.00 E+00$ \\
\hline $\mathrm{Sr}$ & $0.00 E+00$ & $0.00 E+00$ & $2.48 E+00$ & $0.00 E+00$ & $0.00 E+00$ & $0.00 E+00$ & $2.45 E+00$ & $0.00 E+00$ & $2.45 E+00$ & $0.00 E+00$ \\
\hline $\mathrm{Ti}$ & $0.00 E+00$ & $0.00 E+00$ & $1.42 \mathrm{E}-01$ & $0.00 E+00$ & $0.00 E+00$ & $0.00 E+00$ & $1.40 \mathrm{E}-01$ & $0.00 E+00$ & $1.40 E-01$ & $0.00 E+00$ \\
\hline v & $0.00 E+00$ & $0.00 E+00$ & $1.90 \mathrm{E}-01$ & $0.00 E+00$ & $0.00 E+00$ & $0.00 E+00$ & $1.88 \mathrm{E}-01$ & $0.00 E+00$ & $1.88 E-01$ & $0.00 E+00$ \\
\hline $2 n$ & $0.00 E+00$ & $9.52 \mathrm{E}+03$ & $0.00 E+00$ & $0.00 E+00$ & $0.00 E+00$ & $0.00 E+00$ & $0.00 E+00$ & $0.00 E+00$ & $0.00 E+00$ & $0.00 E+00$ \\
\hline $\mathbf{Z r}$ & $0.00 E+00$ & $0.00 E+00$ & 5.47E-03 & $0.00 E+00$ & $0.00 E+00$ & $0.00 E+00$ & 5.40E-03 & $0.00 E+00$ & 5.40E-03 & $0.00 E+00$ \\
\hline $\mathrm{H2O2}$ & $0.00 E+00$ & $0.00 E+00$ & $0.00 E+00$ & $0.00 E+00$ & $0.00 E+00$ & $0.00 E+00$ & $0.00 E+00$ & $0.00 E+00$ & $0.00 E+00$ & $0.00 E+00$ \\
\hline $\mathrm{pH}$ & $(1 \mathrm{M} \mathrm{OH}-1$ & 3.5 & 5.5 & 0.90819389 & $(1 \mathrm{M} \mathrm{OH}-)$ & 4.5 & 6.5 & of & 6.5 & 7 \\
\hline total flow & 16.15 & 53.47 & 529.51 & 63.17 & 6.68 & 53.35 & 536.01 & 0.00 & 536.01 & 74.75 \\
\hline TDS & $2.25 E+04$ & $2.38 \mathrm{E}+04$ & $1.41 E+04$ & $5.89 \mathrm{E}+03$ & $2.25 E+04$ & $9.24 E+03$ & $1.39 E+04$ & $1.00 E+06$ & $1.39 E+04$ & \\
\hline
\end{tabular}


Table E.1. Stream FLow Material Balance Showing Nonselective Concentration of All Constituents from Feedwater

\begin{tabular}{|c|c|c|c|c|c|c|c|c|c|}
\hline \multicolumn{10}{|l|}{ Component Material Balance } \\
\hline \multicolumn{10}{|l|}{ basis: Stream $1=1000_{\mathrm{g}}$ (total) } \\
\hline \multicolumn{10}{|l|}{$\begin{array}{l}\text { (all values, except } \mathrm{pH} \text { and total } \\
\text { flow are given as } \mathrm{ppm}) ; \mathrm{pH}=\mathrm{pH} \\
\text { units, total flow }=\text { grams. }\end{array}$} \\
\hline & STREAM & STREAM & STREAM & STREAM & STREAM & STREAM & STREAM & STREAM & STREAM \\
\hline Component & 31 & 32 & 33 & 34 & 35 & 36 & 37 & 38 & 39 \\
\hline $\mathrm{Ag}$ & $0.00 \mathrm{E}+00$ & $0.00 E+00$ & $0.00 E+00$ & $0.00 E+00$ & $0.00 \mathrm{E}+00$ & $0.00 E+00$ & $0.00 E+00$ & $0.00 E+00$ & $0.00 E+00$ \\
\hline Al & $0.00 E+00$ & $0.00 E+00$ & $0.00 E+00$ & $0.00 \mathrm{E}+00$ & $0.00 E+00$ & $0.00 E+00$ & $0.00 E+00$ & $0.00 E+00$ & $0.00 \mathrm{E}+00$ \\
\hline As & $0.00 E+00$ & $0.00 E+00$ & $0.00 \mathrm{E}+00$ & $0.00 E+00$ & $0.00 E+00$ & $0.00 E+00$ & $0.00 E+00$ & $0.00 E+00$ & $0.00 E+00$ \\
\hline $\mathbf{B}$ & $0.00 E+00$ & $0.00 E+00$ & $0.00 E+00$ & 7.32E-01 & $0.00 E+00$ & $6.02 E-01$ & 7.30E-01 & $0.00 E+00$ & 7.07E-01 \\
\hline $\mathrm{Ca}$ & $0.00 E+00$ & $0.00 E+00$ & $0.00 E+00$ & $3.74 \mathrm{E}+01$ & 1.67E + 05 & $4.26 \mathrm{E}+04$ & $5.82 \mathrm{E}+01$ & $0.00 E+00$ & $5.64 E+01$ \\
\hline $\mathrm{Cd}$ & $0.00 E+00$ & $0.00 E+00$ & $0.00 E+00$ & $0.00 E+00$ & $0.00 E+00$ & $0.00 E+00$ & $0.00 E+00$ & $0.00 E+00$ & $0.00 E+00$ \\
\hline $\mathrm{Cl}$ & $0.00 E+00$ & $0.00 E+00$ & $9.90 E+01$ & $6.78 E+00$ & $0.00 E+00$ & $5.57 E+00$ & $6.77 \mathrm{E}+00$ & $0.00 E+00$ & $6.55 E+00$ \\
\hline $\mathrm{Co}$ & $0.00 E+00$ & $0.00 E+00$ & $0.00 E+00$ & $0.00 E+00$ & $0.00 E+00$ & $0.00 E+00$ & $0.00 E+00$ & $0.00 \mathrm{E}+00$ & $0.00 \mathrm{E}+00$ \\
\hline $\mathrm{Cr}$ & $0.00 E+00$ & $0.00 E+00$ & $0.00 E+00$ & $0.00 E+00$ & $0.00 E+00$ & $0.00 E+00$ & $0.00 E+00$ & $0.00 E+00$ & $0.00 \mathrm{E}+00$ \\
\hline $\mathrm{Cu}$ & $0.00 E+00$ & $0.00 E+00$ & $0.00 E+00$ & $0.00 E+00$ & $0.00 E+00$ & $0.00 E+00$ & $0.00 \mathrm{E}+00$ & $0.00 \mathrm{E}+00$ & $0.00 E+00$ \\
\hline$F$ & $0.00 E+00$ & $0.00 E+00$ & $1.74 \mathrm{E}+02$ & $1.20 \mathrm{E}+01$ & $0.00 E+00$ & $9.82 E+00$ & $1.19 E+01$ & $0.00 E+00$ & $1.15 \mathrm{E}+01$ \\
\hline $\mathrm{Fe}$ & $0.00 E+00$ & $0.00 E+00$ & $0.00 E+00$ & $0.00 E+00$ & $0.00 E+00$ & $0.00 E+00$ & $0.00 E+00$ & $0.00 E+00$ & $0.00 E+00$ \\
\hline$k$ & $0.00 E+00$ & $1.14 E+02$ & $0.00 E+00$ & $0.00 E+00$ & $0.00 E+00$ & $0.00 E+00$ & $0.00 E+00$ & $0.00 E+00$ & $0.00 E+00$ \\
\hline $\mathrm{Li}$ & $0.00 E+00$ & $1.65 \mathrm{E}+00$ & $0.00 E+00$ & $0.00 E+00$ & $0.00 E+00$ & $0.00 E+00$ & $0.00 E+00$ & $0.00 E+00$ & $0.00 \mathrm{E}+00$ \\
\hline $\mathrm{Mg}$ & $0.00 \mathrm{E}+00$ & $0.00 E+00$ & $0.00 \mathrm{E}+00$ & $7.60 \mathrm{E}+02$ & $0.00 E+00$ & $2.55 E+04$ & $0.00 E+00$ & $0.00 E+00$ & $0.00 E+00$ \\
\hline $\mathrm{Mn}$ & $0.00 E+00$ & $0.00 E+00$ & $0.00 E+00$ & $0.00 E+00$ & $0.00 E+00$ & $0.00 E+00$ & $0.00 E+00$ & $0.00 E+00$ & $0.00 E+00$ \\
\hline Mo & $0.00 E+00$ & $0.00 E+00$ & $0.00 \mathrm{E}+00$ & $1.05 \mathrm{E}-01$ & $0.00 E+00$ & 8.69E-02 & $1.04 \mathrm{E}-01$ & $0.00 E+00$ & $1.01 \mathrm{E}-01$ \\
\hline $\mathrm{Na}$ & $0.00 E+00$ & $2.24 \mathrm{E}+04$ & $0.00 E+00$ & $0.00 \mathrm{E}+00$ & $0.00 E+00$ & $0.00 E+00$ & $0.00 E+00$ & $0.00 E+00$ & $0.00 E+00$ \\
\hline $\mathrm{Ni}$ & $0.00 E+00$ & $0.00 E+00$ & $0.00 E+00$ & $0.00 E+00$ & $0.00 E+00$ & $0.00 \mathrm{E}+00$ & $0.00 E+00$ & $0.00 E+00$ & $0.00 E+00$ \\
\hline NO3 & $0.00 E+00$ & $0.00 E+00$ & $2.27 E+00$ & $1.56 \mathrm{E}-01$ & $0.00 \mathrm{E}+00$ & $1.28 \mathrm{E}-01$ & $1.55 \mathrm{E}-01$ & $0.00 E+00$ & 1.50E-01 \\
\hline $\mathrm{Pb}$ & $0.00 E+00$ & $0.00 E+00$ & $0.00 \mathrm{E}+00$ & $0.00 E+00$ & $0.00 E+00$ & $0.00 E+00$ & $0.00 E+00$ & $0.00 E+00$ & $0.00 E+00$ \\
\hline $\mathrm{SiO} 2$ & $0.00 E+00$ & $0.00 E+00$ & $0.00 \mathrm{E}+00$ & $1.77 \mathrm{E}+02$ & $0.00 E+00$ & $5.96 \mathrm{E}+03$ & $0.00 E+00$ & $0.00 E+00$ & $0.00 E+00$ \\
\hline SO4 & $0.00 E+00$ & $0.00 E+00$ & $4.52 E+04$ & $3.10 E+03$ & $0.00 E+00$ & $1.02 E+05$ & $6.59 E+01$ & $1.52 E+03$ & $1.12 E+02$ \\
\hline $\mathrm{Sr}$ & $0.00 E+00$ & $0.00 E+00$ & $0.00 E+00$ & $2.47 E+00$ & $0.00 E+00$ & $2.03 E+00$ & $2.47 \mathrm{E}+00$ & $0.00 E+00$ & $2.39 E+00$ \\
\hline $\mathrm{Ti}$ & $0.00 E+00$ & $0.00 E+00$ & $0.00 E+00$ & $1.41 \mathrm{E}-01$ & $0.00 E+00$ & $1.16 \mathrm{E}-01$ & $1.41 \mathrm{E}-01$ & $0.00 E+00$ & 1.37E-01 \\
\hline v & $0.00 E+00$ & $0.00 E+00$ & $0.00 E+00$ & $1.90 \mathrm{E}-01$ & $0.00 E+00$ & $1.56 \mathrm{E}-01$ & $1.90 \mathrm{E}-01$ & $0.00 E+00$ & 1.84E-01 \\
\hline $\mathrm{Zn}$ & $0.00 E+00$ & $0.00 E+00$ & $0.00 E+00$ & $0.00 E+00$ & $0.00 E+00$ & $0.00 E+00$ & $0.00 \mathrm{E}+00$ & $0.00 E+00$ & $0.00 E+00$ \\
\hline $\mathrm{Zr}$ & $0.00 E+00$ & $0.00 \mathrm{E}+00$ & $0.00 \mathrm{E}+00$ & $5.46 \mathrm{E}-03$ & $0.00 E+00$ & $4.48 E-03$ & $5.44 \mathrm{E}-03$ & $0.00 E+00$ & 5.27E-03 \\
\hline $\mathrm{H} 2 \mathrm{O} 2$ & $0.00 E+00$ & $0.00 E+00$ & $0.00 \mathrm{E}+00$ & $0.00 E+00$ & $0.00 E+00$ & $0.00 E+00$ & $0.00 \mathrm{E}+00$ & $0.00 E+00$ & $0.00 \mathrm{E}+00$ \\
\hline$p H$ & 7 & $(1 \mathrm{M} \mathrm{OH}-)$ & $(1 \mathrm{MH}+1)$ & 6.5 & $(10 \mathrm{M} \mathrm{OH}-1$ & 11 & 11 & 1.5 & 7 \\
\hline total flow & 74.75 & 76.47 & 78.31 & 530.72 & 4.10 & 15.79 & 519.02 & 16.98 & 536.00 \\
\hline TDS & of & $2.25 \mathrm{E}+04$ & $4.55 E+04$ & $4.10 E+03$ & $1.67 E+05$ & $1.76 \mathrm{E}+05$ & $1.47 \mathrm{E}+02$ & $1.52 \mathrm{E}+03$ & $1.90 E+02$ \\
\hline
\end{tabular}




\section{Appendix F}

Stream Flow Material Balance for Flowsheet

Showing Semiselective Separation of Constituents from Feedwater Using Solvent Extraction 


\section{Appendix F}

\section{Stream Flow Material Balance for Flowsheet Showing Semiselective Separation of Constituents from Feedwater Using Solvent Extraction}

Figure F. 1 is an integrated flowsheet for recovering constituents from Berkeley Pit water that includes a nonselective separation of aluminum, copper, iron, manganese, and zinc in a single extraction unit. The extractant is treated with a series of strip circuits to selectively recover each of these metals for further refining. The treated water stream is further treated to recover magnesium for regenerating the extractant and removing sulfate to meet treatment criteria. A simplified material balance is provided in Table F.1. 


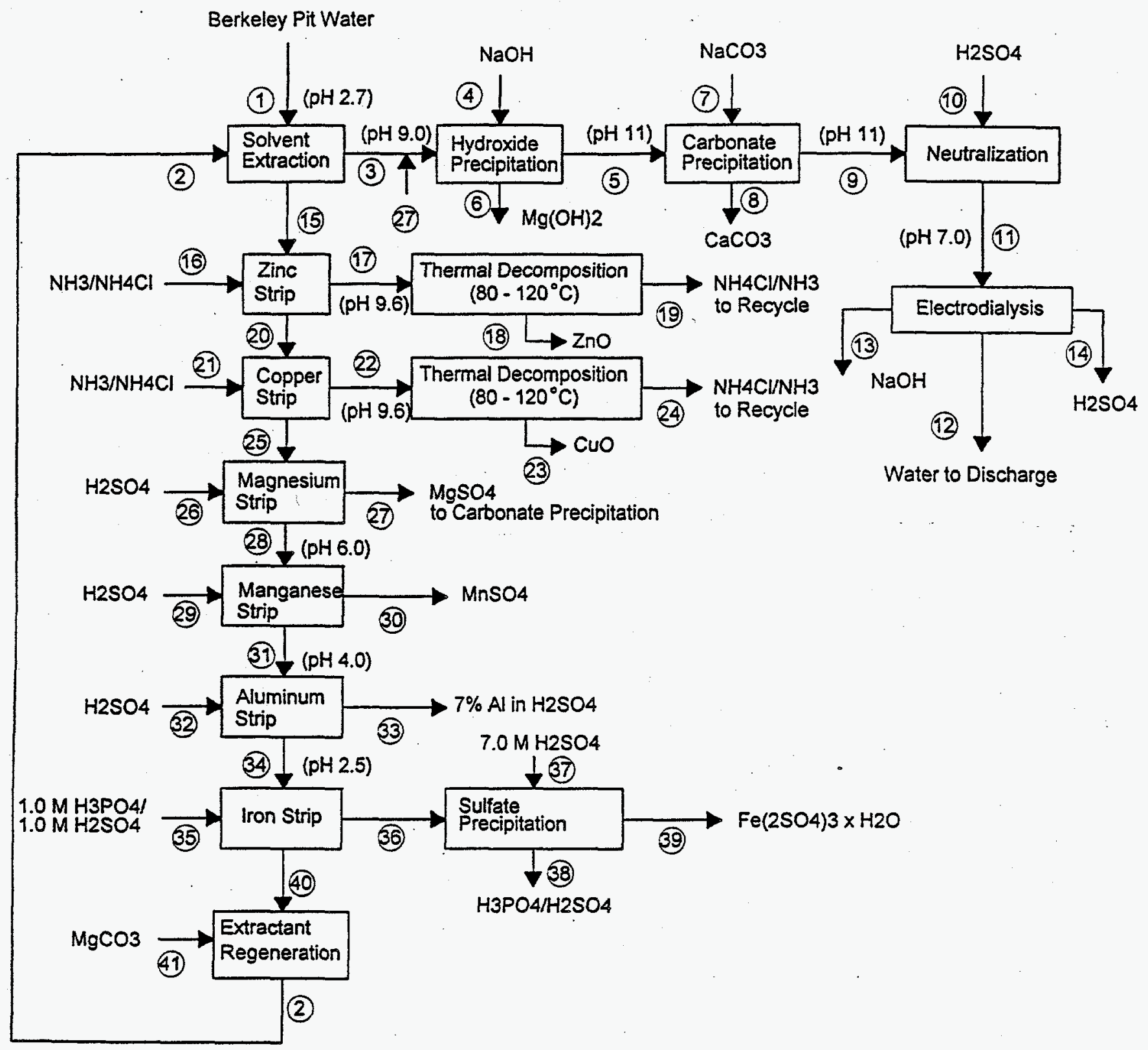

Figure F.1. Flowsheet Showing Semiselective Separation of Constituents from Feedwater Using Solvent Extraction 
Figure F.1 Stream Flow Material Balance Showing Semiselective Separation of Constituents from Feedwater using Solvent Extraction

\begin{tabular}{|c|c|c|c|c|c|c|c|c|c|c|c|}
\hline \multicolumn{12}{|c|}{ Component Material Balance } \\
\hline \multicolumn{12}{|c|}{ basis: stream $1=1000 \mathrm{~g}$ (fotal) } \\
\hline \multicolumn{12}{|c|}{$\begin{array}{l}\text { given as grams; } \mathrm{pH}=\mathrm{pH} \text { units, } \\
\text { TDS }=\mathrm{ppm} \text {. }\end{array}$} \\
\hline & STREAM & STREAM & STREAM & STREAM & STREAM & STREAM & STREAM & STREAM & STREAM & STREAM & STREAM \\
\hline Component & 1 & 2 & 3 & 4 & 5 & 6 & 7 & 8 & 9 & 10 & 11 \\
\hline $\mathrm{Ag}$ & $6.00 \mathrm{E}-06$ & $0.00 E+00$ & $0.00 \mathrm{E}+00$ & $0.00 E+00$ & $0.00 E+00$ & $0.00 E+00$ & $0.00 E+00$ & $0.00 E+00$ & $0.00 E+00$ & $0.00 E+00$ & $0.00 E+00$ \\
\hline Al & $2.79 E-01$ & $0.00 E+00$ & $0.00 E+00$ & $0.00 E+00$ & $0.00 E+00$ & $0.00 E+00$ & $0.00 E+00$ & $0.00 E+00$ & $0.00 E+00$ & $0.00 E+00$ & $0.00 E+00$ \\
\hline As & $5.32 \mathrm{E}-04$ & $0.00 \mathrm{E}+00$ & $5.32 \mathrm{E}-04$ & $0.00 E+00$ & $5.32 \mathrm{E}-04$ & $0.00 \mathrm{E}+00$ & $0.00 E+00$ & $5.32 \mathrm{E}-04$ & $0.00 E+00$ & $0.00 E+00$ & $0.00 E+00$ \\
\hline B & $4.03 \mathrm{E}-04$ & $0.00 E+00$ & $4.03 \mathrm{E}-04$ & $0.00 \mathrm{E}+00$ & 4.03E-04 & $0.00 E+00$ & $0.00 E+00$ & $0.00 E+00$ & 4.03E-04 & $0.00 E+00$ & $4.03 E-04$ \\
\hline $\mathrm{Ca}$ & $4.78 \mathrm{E}-01$ & $0.00 E+00$ & $4.78 \mathrm{E}-01$ & $0.00 E+00$ & $4.78 \mathrm{E}-01$ & $0.00 E+00$ & $0.00 \mathrm{E}+00$ & $4.78 \mathrm{E}-01$ & $0.00 E+00$ & $0.00 E+00$ & $0.00 E+00$ \\
\hline $\mathrm{Cd}$ & 1.67E-03 & $0.00 E+00$ & $0.00 E+00$ & $0.00 E+00$ & $0.00 E+00$ & $0.00 E+00$ & $0.00 \mathrm{E}+00$ & $0.00 E+00$ & $0.00 E+00$ & $0.00 E+00$ & $0.00 \mathrm{E}+00$ \\
\hline Co & $1.75 \mathrm{E}-03$ & $0.00 E+00$ & $0.00 E+00$ & $0.00 \mathrm{E}+00$ & $0.00 E+00$ & $0.00 E+00$ & $0.00 \mathrm{E}+00$ & $0.00 E+00$ & $0.00 E+00$ & $0.00 E+00$ & $0.00 E+00$ \\
\hline $\mathrm{Cr}$ & 5.48E-05 & $0.00 E+00$ & $0.00 \mathrm{E}+00$ & $0.00 E+00$ & $0.00 E+00$ & $0.00 E+00$ & $0.00 E+00$ & $0.00 \mathrm{E}+00$ & $0.00 \mathrm{E}+00$ & $0.00 E+00$ & $0.00 E+00$ \\
\hline $\mathrm{Cu}$ & $1.84 \mathrm{E}-01$ & $0.00 E+00$ & $0.00 E+00$ & $0.00 E+00$ & $0.00 E+00$ & $0.00 E+00$ & $0.00 \mathrm{E}+00$ & $0.00 E+00$ & $0.00 \mathrm{E}+00$ & $0.00 E+00$ & $0.00 E+00$ \\
\hline $\mathrm{Fe}$ & $8.75 \mathrm{E}-01$ & $0.00 E+00$ & $0.00 E+00$ & $0.00 E+00$ & $0.00 E+00$ & $0.00 E+00$ & $0.00 E+00$ & $0.00 E+00$ & $0.00 E+00$ & $0.00 E+00$ & $0.00 E+00$ \\
\hline $\mathbf{K}$ & $1.81 \mathrm{E}-02$ & $0.00 \mathrm{E}+00$ & $1.81 \mathrm{E}-02$ & $0.00 E+00$ & $1.81 \mathrm{E}-02$ & $0.00 E+00$ & $0.00 E+00$ & $0.00 E+00$ & $1.81 \mathrm{E}-02$ & $0.00 E+00$ & $1.81 E-02$ \\
\hline Li & $2.62 \mathrm{E}-04$ & $0.00 E+00$ & $2.62 E-04$ & $0.00 E+00$ & $2.62 E-04$ & $0.00 E+00$ & $0.00 E+00$ & $0.00 \mathrm{E}+00$ & $2.62 E-04$ & $0.00 E+00$ & $2.62 E-04$ \\
\hline $\mathrm{Mg}$ & $4.18 E-01$ & $1.42 \mathrm{E}+00$ & $1.51 E+00$ & $0.00 E+00$ & $0.00 \mathrm{E}+00$ & $1.84 E+00$ & $0.00 E+00$ & $0.00 E+00$ & $0.00 E+00$ & $1.84 \mathrm{E}+00$ & $0.00 E+00$ \\
\hline $\mathrm{Mn}$ & $1.86 \mathrm{E}-01$ & $0.00 \mathrm{E}+00$ & $0.00 \mathrm{E}+00$ & $0.00 E+00$ & $0.00 \mathrm{E}+00$ & $0.00 \mathrm{E}+00$ & $0.00 E+00$ & $0.00 E+00$ & $0.00 E+00$ & $0.00 E+00$ & $0.00 \mathrm{E}+00$ \\
\hline Mo & 5.75E-05 & $0.00 E+00$ & $5.75 \mathrm{E}-05$ & $0.00 E+00$ & $5.75 \mathrm{E}-05$ & $0.00 E+00$ & $0.00 E+00$ & $0.00 E+00$ & 6.76E-05 & $0.00 E+00$ & $5.75 E-05$ \\
\hline $\mathrm{Na}$ & $6.88 \mathrm{E}-02$ & $0.00 \mathrm{E}+00$ & $6.88 \mathrm{E}-02$ & $3.61 E+00$ & $3.68 \mathrm{E}+00$ & $0.00 E+00$ & 5.24E-01 & $0.00 E+00$ & $4.21 E+00$ & $0.00 \mathrm{E}+00$ & $4.21 E+00$ \\
\hline $\mathrm{Ni}$ & $1.06 \mathrm{E}-03$ & $0.00 E+00$ & $0.00 \mathrm{E}+00$ & $0.00 E+00$ & $0.00 \mathrm{E}+00$ & $0.00 E+00$ & $0.00 \mathrm{E}+00$ & $0.00 E+00$ & $0.00 E+00$ & $0.00 E+00$ & $0.00 E+00$ \\
\hline $\mathrm{Pb}$ & $6.50 \mathrm{E}-05$ & $0.00 E+00$ & $0.00 \mathrm{E}+00$ & $0.00 E+00$ & $0.00 E+00$ & $0.00 E+00$ & $0.00 E+00$ & $0.00 E+00$ & $0.00 \mathrm{E}+00$ & $0.00 E+00$ & $0.00 E+00$ \\
\hline $\mathrm{SiO2}$ & $9.76 \mathrm{E}-02$ & $0.00 \mathrm{E}+00$ & $9.75 \mathrm{E}-02$ & $0.00 E+00$ & $9.75 \mathrm{E}-02$ & $0.00 E+00$ & $0.00 E+00$ & $9.75 \mathrm{E}-02$ & $0.00 E+00$ & $0.00 E+00$ & $0.00 E+00$ \\
\hline $\mathrm{Sr}$ & $1.36 \mathrm{E}-03$ & $0.00 \mathrm{E}+00$ & $1.36 \mathrm{E}-03$ & $0.00 E+00$ & $1.36 \mathrm{E}-03$ & $0.00 \mathrm{E}+00$ & $0.00 E+00$ & $0.00 E+00$ & $1.36 \mathrm{E}-03$ & $0.00 \mathrm{E}+00$ & $1.36 \mathrm{E}-03$ \\
\hline $\mathrm{Ti}$ & $7.78 \mathrm{E}-05$ & $0.00 E+00$ & $7.78 \mathrm{E}-05$ & $0.00 E+00$ & $7.78 \mathrm{E}-05$ & $0.00 E+00$ & $0.00 \mathrm{E}+00$ & $0.00 E+00$ & $7.78 E-05$ & $0.00 E+00$ & 7.78E-05 \\
\hline $\mathrm{v}$ & $1.05 \mathrm{E}-04$ & $0.00 \mathrm{E}+00$ & $0.00 E+00$ & $0.00 E+00$ & $0.00 E+00$ & $0.00 E+00$ & $0.00 E+00$ & $0.00 E+00$ & $0.00 E+00$ & $0.00 E+00$ & $0.00 \mathrm{E}+00$ \\
\hline $\mathrm{Zn}$ & $5.28 \mathrm{E}-01$ & $0.00 E+00$ & $0.00 \mathrm{E}+00$ & $0.00 E+00$ & $0.00 E+00$ & $0.00 E+00$ & $0.00 E+00$ & $0.00 \mathrm{E}+00$ & $0.00 \mathrm{E}+00$ & $0.00 E+00$ & $0.00 E+00$ \\
\hline $\mathrm{Cl}$ & $1.20 \mathrm{E}-02$ & $0.00 E+00$ & 1.20E-02 & $0.00 E+00$ & $1.20 \mathrm{E}-02$ & $0.00 E+00$ & $0.00 E+00$ & $0.00 E+00$ & $1.20 \mathrm{E}-02$ & $0.00 E+00$ & $1.20 \mathrm{E}-02$ \\
\hline$F$ & $2.11 \mathrm{E}-02$ & $0.00 E+00$ & $2.11 \mathrm{E}-02$ & $0.00 E+00$ & $2.11 \mathrm{E}-02$ & $0.00 E+00$ & $0.00 \mathrm{E}+00$ & $2.11 \mathrm{E}-02$ & $0.00 E+00$ & $0.00 \mathrm{E}+00$ & $0.00 \mathrm{E}+00$ \\
\hline NO3 & $2.75 \mathrm{E}-04$ & $0.00 E+00$ & $2.75 \mathrm{E}-04$ & $0.00 E+00$ & $2.76 \mathrm{E}-04$ & $0.00 E+00$ & $0.00 E+00$ & $0.00 E+00$ & $2.75 \mathrm{E}-04$ & $0.00 E+00$ & $2.75 \mathrm{E}-04$ \\
\hline SO4 & $7.39 \mathrm{E}+00$ & $0.00 E+00$ & $7.39 \mathrm{E}+00$ & $0.00 \mathrm{E}+00$ & $8.67 E+00$ & $0.00 \mathrm{E}+00$ & $0.00 E+00$ & $0.00 E+00$ & 8.67E +00 & $1.20 \mathrm{E}-01$ & $8.79 \mathrm{E}+00$ \\
\hline PO4 & $0.00 E+00$ & $0.00 E+00$ & $0.00 E+00$ & $0.00 E+00$ & $0.00 E+00$ & $0.00 E+00$ & $0.00 E+00$ & $0.00 E+00$ & $0.00 E+00$ & $0.00 \mathrm{E}+00$ & $0.00 E+00$ \\
\hline $\mathrm{NH3}$ & $0.00 E+00$ & $0.00 \mathrm{E}+00$ & $0.00 \mathrm{E}+00$ & $0.00 E+00$ & $0.00 E+00$ & $0.00 \mathrm{E}+00$ & $0.00 \mathrm{E}+00$ & $0.00 E+00$ & $0.00 E+00$ & $0.00 E+00$ & $0.00 E+00$ \\
\hline $\mathrm{NH4}$ & $0.00 \mathrm{E}+00$ & $0.00 E+00$ & $0.00 \mathrm{E}+00$ & $0.00 E+00$ & $0.00 E+00$ & $0.00 E+00$ & $0.00 \mathrm{E}+00$ & $0.00 E+00$ & $0.00 E+00$ & $0.00 \mathrm{E}+00$ & $0.00 E+00$ \\
\hline Water & $9.89 \mathrm{E}+02$ & $0.00 E+00$ & $9.89 \mathrm{E}+02$ & $9.03 E+01$ & $1.08 \mathrm{E}+03$ & $0.00 \mathrm{E}+00$ & $0.00 E+00$ & $0.00 \mathrm{E}+00$ & $1.08 E+03$ & $1.00 \mathrm{E}+01$ & $1.09 \mathrm{E}+03$ \\
\hline Extractant & $0.00 \mathrm{E}+00$ & $3.34 \mathrm{E}+02$ & $0.00 E+00$ & $0.00 E+00$ & $0.00 E+00$ & $0.00 \mathrm{E}+00$ & $0.00 \mathrm{E}+00$ & $0.00 E+00$ & $0.00 \mathrm{E}+00$ & $0.00 \mathrm{E}+00$ & $0.00 E+00$ \\
\hline $\mathrm{pH}$ & 2.70 & NA & 9.00 & 13.20 & 11.40 & NA & 11.00 & NA & 11.40 & 0.82 & 7.00 \\
\hline total flow & 1000.00 & 335.35 & 999.04 & 93.94 & 1096.68 & 1.84 & 0.52 & 0.60 & 1096.61 & 11.96 & 1106.73 \\
\hline TDS & $1.06 E+04$ & $0.00 E+00$ & $9.61 \mathrm{E}+03$ & $3.85 E+04$ & $1.18 E+04$ & $1.00 E+06$ & $1.00 E+06$ & $1.00 E+06$ & $1.18 \mathrm{E}+04$ & $1.64 E+05$ & $1.18 \mathrm{E}+04$ \\
\hline
\end{tabular}




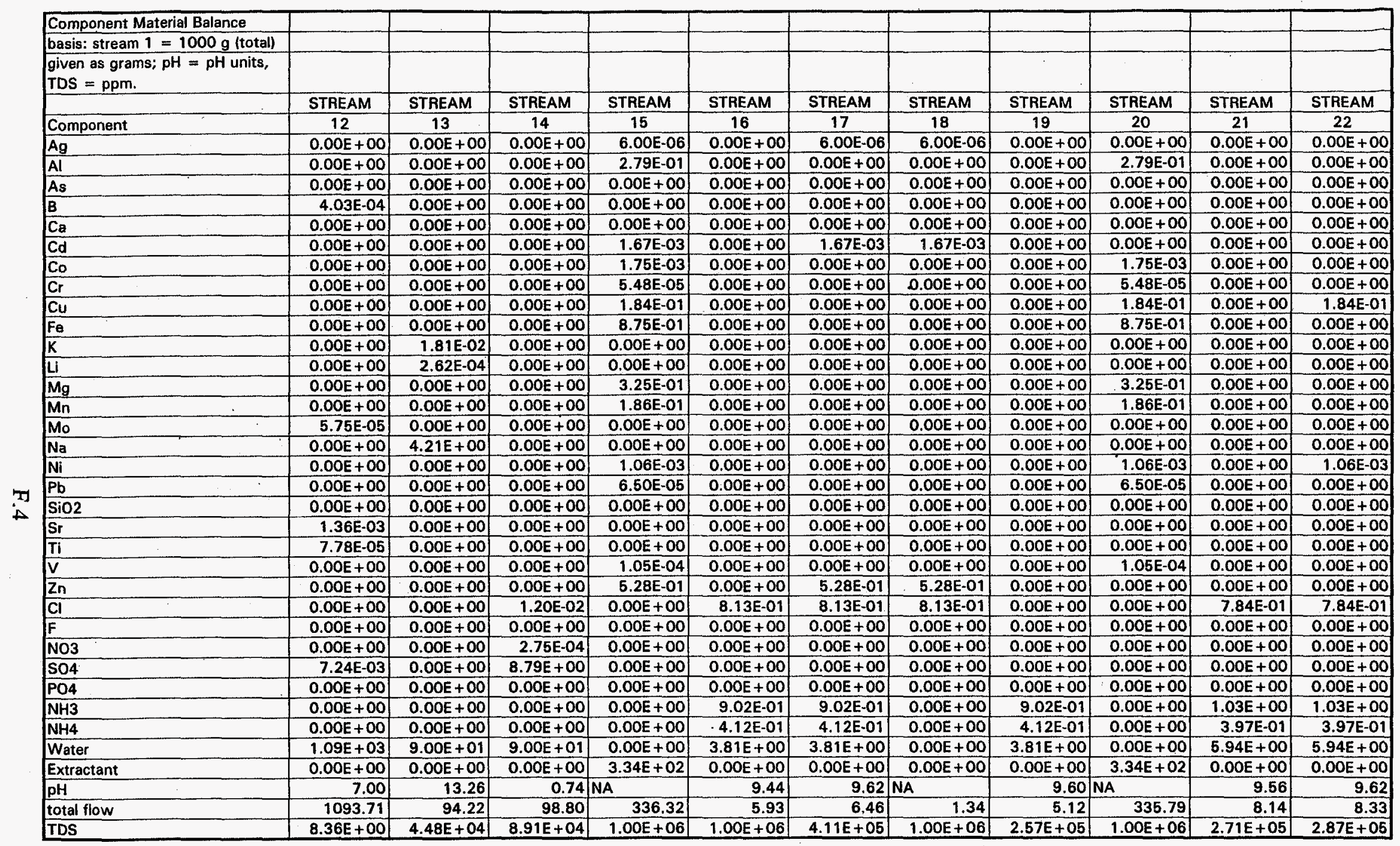


Figure F.1 Stream Flow Material Balance Showing Semiselective Separation of Constituents from Feedwater using Solvent Extraction

\begin{tabular}{|c|c|c|c|c|c|c|c|c|c|c|c|}
\hline \multicolumn{12}{|c|}{ Component Material Balance } \\
\hline \multicolumn{12}{|c|}{ basis: stream $1=1000 \mathrm{~g}$ (totall) } \\
\hline \multicolumn{12}{|c|}{$\begin{array}{l}\text { given as grams; } \mathrm{pH}=\mathrm{pH} \text { units, } \\
\text { TDS }=\mathrm{ppm} \text {. }\end{array}$} \\
\hline & STREAM & STREAM & STREAM & STREAM & STREAM & STREAM & STREAM & STREAM & STREAM & STREAM & STREAM \\
\hline Component & 23 & 24 & 25 & 26 & 27 & 28 & 29 & 30 & 31 & 32 & 33 \\
\hline $\mathrm{Ag}$ & $0.00 E+00$ & $0.00 E+00$ & $0.00 E+00$ & $0.00 E+00$ & $0.00 E+00$ & $0.00 E+00$ & $0.00 E+00$ & $0.00 E+00$ & $0.00 E+00$ & $0.00 E+00$ & 0 \\
\hline Al & $0.00 E+00$ & $0.00 E+00$ & $2.79 E-01$ & $0.00 E+00$ & $0.00 E+00$ & $2.79 \mathrm{E}-01$ & $0.00 E+00$ & $0.00 E+00$ & $2.79 E-01$ & $0.00 E+00$ & 0.27895 \\
\hline As & $0.00 E+00$ & $0.00 E+00$ & $0.00 E+00$ & $0.00 E+00$ & $0.00 E+00$ & $0.00 E+00$ & $0.00 E+00$ & $0.00 E+00$ & $0.00 E+00$ & $0.00 E+00$ & 0 \\
\hline B & $0.00 E+00$ & $0.00 E+00$ & $0.00 E+00$ & $0.00 E+00$ & $0.00 E+00$ & $0.00 E+00$ & $0.00 E+00$ & $0.00 E+00$ & $0.00 E+00$ & $0.00 E+00$ & \\
\hline $\mathbf{C a}$ & $0.00 E+00$ & $0.00 E+00$ & $0.00 E+00$ & $0.00 E+00$ & $0.00 E+00$ & $0.00 E+00$ & $0.00 E+00$ & $0.00 E+00$ & $0.00 E+00$ & $0.00 E+00$ & 0 \\
\hline Cd & $0.00 E+00$ & $0.00 E+00$ & $0.00 E+00$ & $0.00 E+00$ & $0.00 E+00$ & $0.00 E+00$ & $0.00 E+00$ & $0.00 E+00$ & $0.00 E+00$ & $0.00 E+00$ & 0 \\
\hline Co & $0.00 E+00$ & $0.00 E+00$ & $1.75 E-03$ & $0.00 E+00$ & $0.00 E+00$ & $1.75 \mathrm{E}-03$ & $0.00 E+00$ & $0.00 E+00$ & $1.75 \mathrm{E}-03$ & $0.00 E+00$ & 0.00175 \\
\hline $\mathrm{Cr}_{\mathrm{r}}$ & $0.00 E+00$ & $0.00 E+00$ & 5.48E-05 & $0.00 E+00$ & $0.00 E+00$ & $5.48 E-05$ & $0.00 E+00$ & $0.00 E+00$ & $5.48 \mathrm{E}-05$ & $0.00 E+00$ & $5.476 \mathrm{E}-05$ \\
\hline Cu & $1.84 \mathrm{E}-01$ & $0.00 E+00$ & $0.00 E+00$ & $0.00 \mathrm{E}+00$ & $0.00 E+00$ & $0.00 E+00$ & $0.00 E+00$ & $0.00 E+00$ & $0.00 E+00$ & $0.00 E+00$ & 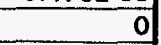 \\
\hline $\mathrm{Fe}$ & $0.00 E+00$ & $0.00 E+00$ & $8.75 \mathrm{E}-01$ & $0.00 E+00$ & $0.00 E+00$ & $8.75 \mathrm{E}-01$ & $0.00 E+00$ & $0.00 E+00$ & $8.75 \mathrm{E}-01$ & $0.00 E+00$ & 0 \\
\hline $\mathbf{K}$ & $0.00 E+00$ & $0.00 E+00$ & $0.00 E+00$ & $0.00 E+00$ & $0.00 E+00$ & $0.00 E+00$ & $0.00 E+00$ & $0.00 E+00$ & $0.00 E+00$ & $0.00 E+00$ & \\
\hline $\mathrm{Li}$ & $0.00 E+00$ & $0.00 E+00$ & $0.00 E+00$ & $0.00 E+00$ & $0.00 E+00$ & $0.00 E+00$ & $0.00 E+00$ & $0.00 E+00$ & $0.00 E+00$ & $0.00 E+00$ & \\
\hline $\mathrm{Mg}$ & $0.00 E+00$ & $0.00 E+00$ & 3.25E-01 & $0.00 E+00$ & $3.25 \mathrm{E}-01$ & $0.00 E+00$ & $0.00 E+00$ & $0.00 E+00$ & $0.00 E+00$ & $0.00 E+00$ & \\
\hline$M n$ & $0.00 E+00$ & $0.00 E+00$ & $1.86 \mathrm{E}-01$ & $0.00 E+00$ & $0.00 E+00$ & $1.86 \mathrm{E}-01$ & $0.00 E+00$ & $1.86 \mathrm{E}-01$ & $0.00 E+00$ & $0.00 E+00$ & \\
\hline Mo & $0.00 E+00$ & $0.00 E+00$ & $0.00 E+00$ & $0.00 E+00$ & $0.00 E+00$ & $0.00 E+00$ & $0.00 E+00$ & $0.00 E+00$ & $0.00 E+00$ & $0.00 E+00$ & \\
\hline $\mathrm{Na}$ & $0.00 E+00$ & $0.00 E+00$ & $0.00 E+00$ & $0.00 E+00$ & $0.00 E+00$ & $0.00 E+00$ & $0.00 E+00$ & $0.00 E+00$ & $0.00 E+00$ & +00 & \\
\hline $\mathrm{Ni}$ & $0.00 E+00$ & $0.00 E+00$ & $0.00 E+00$ & $0.00 E+00$ & $0.00 E+00$ & $0.00 E+00$ & $0.00 E+00$ & $0.00 E+00$ & $0.00 E+00$ & $0.00 E+00$ & \\
\hline $\mathbf{P b}$ & $0.00 E+00$ & $0.00 E+00$ & $6.50 \mathrm{E}-05$ & $0.00 E+00$ & $0.00 E+00$ & $6.50 \mathrm{E}-05$ & $0.00 E+00$ & $6.50 \mathrm{E}-05$ & $0.00 E+00$ & $0.00 E+00$ & \\
\hline $\mathrm{SiO} 2$ & $0.00 E+00$ & $0.00 E+00$ & $0.00 E+00$ & $0.00 E+00$ & $0.00 E+00$ & $0.00 E+00$ & $0.00 E+00$ & $0.00 E+00$ & $0.00 E+00$ & $0.00 E+00$ & \\
\hline $\mathrm{Sr}$ & $0.00 E+00$ & $0.00 E+00$ & $0.00 E+00$ & $0.00 E+00$ & $0.00 E+00$ & $0.00 E+00$ & $0.00 E+00$ & $0.00 E+00$ & $0.00 E+00$ & $0.00 E+00$ & \\
\hline $\mathbf{T i}$ & $0.00 E+00$ & $0.00 E+00$ & $0.00 E+00$ & $0.00 E+00$ & $0.00 E+00$ & $0.00 E+00$ & $0.00 E+00$ & $0.00 E+00$ & $0.00 E+00$ & $0.00 E+00$ & \\
\hline $\mathbf{v}$ & $0.00 E+00$ & $0.00 E+00$ & $1.05 \mathrm{E}-04$ & $0.00 E+00$ & $0.00 E+00$ & $1.05 \mathrm{E}-04$ & $0.00 E+00$ & $0.00 E+00$ & $1.05 \mathrm{E}-04$ & $0.00 E+00$ & \\
\hline $2 n$ & $0.00 E+00$ & $0.00 E+00$ & $0.00 E+00$ & $0.00 E+00$ & $0.00 E+00$ & $0.00 E+00$ & $0.00 E+00$ & $0.00 E+00$ & $0.00 E+00$ & $0.00 E+00$ & \\
\hline ci & $0.00 E+00$ & $7.84 \mathrm{E}-01$ & $0.00 E+00$ & $0.00 E+00$ & $0.00 E+00$ & $0.00 E+00$ & $0.00 E+00$ & $0.00 E+00$ & $0.00 E+00$ & $0.00 \mathrm{E}+00$ & \\
\hline $\mathbf{F}$ & $0.00 E+00$ & $0.00 E+00$ & $0.00 E+00$ & $0.00 E+00$ & $0.00 E+00$ & $0.00 E+00$ & $0.00 E+00$ & $0.00 E+00$ & $0.00 E+00$ & $0.00 E+00$ & \\
\hline NO3 & $0.00 E+00$ & $0.00 E+00$ & $0.00 E+00$ & $0.00 E+.00$ & $0.00 E+00$ & $0.00 E+00$ & $0.00 E+00$ & $0.00 E+00$ & $0.00 E+00$ & & \\
\hline SO4 & $0.00 E+00$ & $0.00 E+00$ & $0.00 E+00$ & $1.28 \mathrm{E}+00$ & $1.28 \mathrm{E}+00$ & $0.00 E+00$ & $3.25 \mathrm{E}-01$ & $3.25 \mathrm{E}-01$ & $0.00 E+\infty 0$ & $1.49 E+00$ & 1.4922784 \\
\hline PO4 & $0.00 E+00$ & $0.00 E+00$ & $0.00 E+00$ & $0.00 E+00$ & $0.00 E+00$ & $0.00 E+00$ & $0.00 E+00$ & $0.00 E+00$ & $0.00 E+00$ & $0.00 E+00$ & 等 \\
\hline $\mathrm{NH3}$ & $0.00 E+00$ & $1.03 E+00$ & $0.00 E+00$ & $0.00 E+00$ & $0.00 E+00$ & $0.00 E+00$ & $0.00 E+00$ & $0.00 E+00$ & $0.00 E+00$ & $0.00 E+00$ & \\
\hline $\mathrm{NH4}$ & $0.00 E+00$ & 3.97E-01 & $0.00 E+00$ & $0.00 E+00$ & $0.00 \mathrm{E}+00$ & $0.00 E+00$ & $0.00 E+00$ & $0.00 E+00$ & $0.00 E+00$ & $0.00 E+00$ & 0 \\
\hline Water & $0.00 E+00$ & $5.94 \mathrm{E}+00$ & $0.00 E+00$ & $3.93 E+00$ & $3.93 \mathrm{E}+00$ & $0.00 E+00$ & $3.82 E+00$ & $3.82 E+00$ & $0.00 E+00$ & $2.29 \mathrm{E}+00$ & 2.2894373 \\
\hline Extractant & $0.00 E+00$ & $0.00 E+00$ & $3.34 \mathrm{E}+02$ & $0.00 E+00$ & $0.00 E+00$ & $3.34 E+02$ & $0.00 E+00$ & $0.00 E+00$ & $3.34 E+02$ & 0 & \\
\hline $\mathrm{pH}$ & NA & 9.56 & $=$ & $\mathrm{MH}+1$ & 6.00 & A & $1.7 \mathrm{MH}+1$ & 4.00 & IA & $0.6 \mathrm{MH}+1$ & 2.50 \\
\hline total flow & 0.18 & 8.14 & 60 & 5.22 & 5.54 & 335.28 & 4.15 & 4.33 & 335.09 & 3.78 & 4.06 \\
\hline TDS & $1.00 E+06$ & $2.71 E+05$ & $1.00 E+06$ & $2.46 E+05$ & $2.90 E+05$ & $1.00 E+06$ & $7.84 E+04$ & $1.18 \mathrm{E}+05$ & $1.00 E+06$ & $3.95 \mathrm{E}+05$ & $4.36 E+05$ \\
\hline
\end{tabular}









\section{Appendix G}

\section{Stream Flow Material Balance for Flowsheet Showing Semiselective Separation of Constituents from Feedwater Using Precipitation}




\section{Appendix G}

\section{Stream Flow Material Balance for Flowsheet Showing Semiselective Separation of Constituents from Feedwater Using Precipitation}

Figure G.1 is an integrated flowsheet for recovering constituents from Berkeley Pit water that includes a semiselective separation step to separate a zinc-rich precipitate from calcium and magnesium, followed by a two-stage leaching process to selectively leach zinc from the sludge for recovery in an electrowinning process. A simplified material balance is provided in Table G.1. • 




Figure G.1. Flowsheet Showing Semiselective Separation of Constituents from Feedwater Stream Using Precipitation 
Table G.1. Stream Flow Material Balance Showing Semiselective Separation of Constituents from Feedwater Using Precipitation

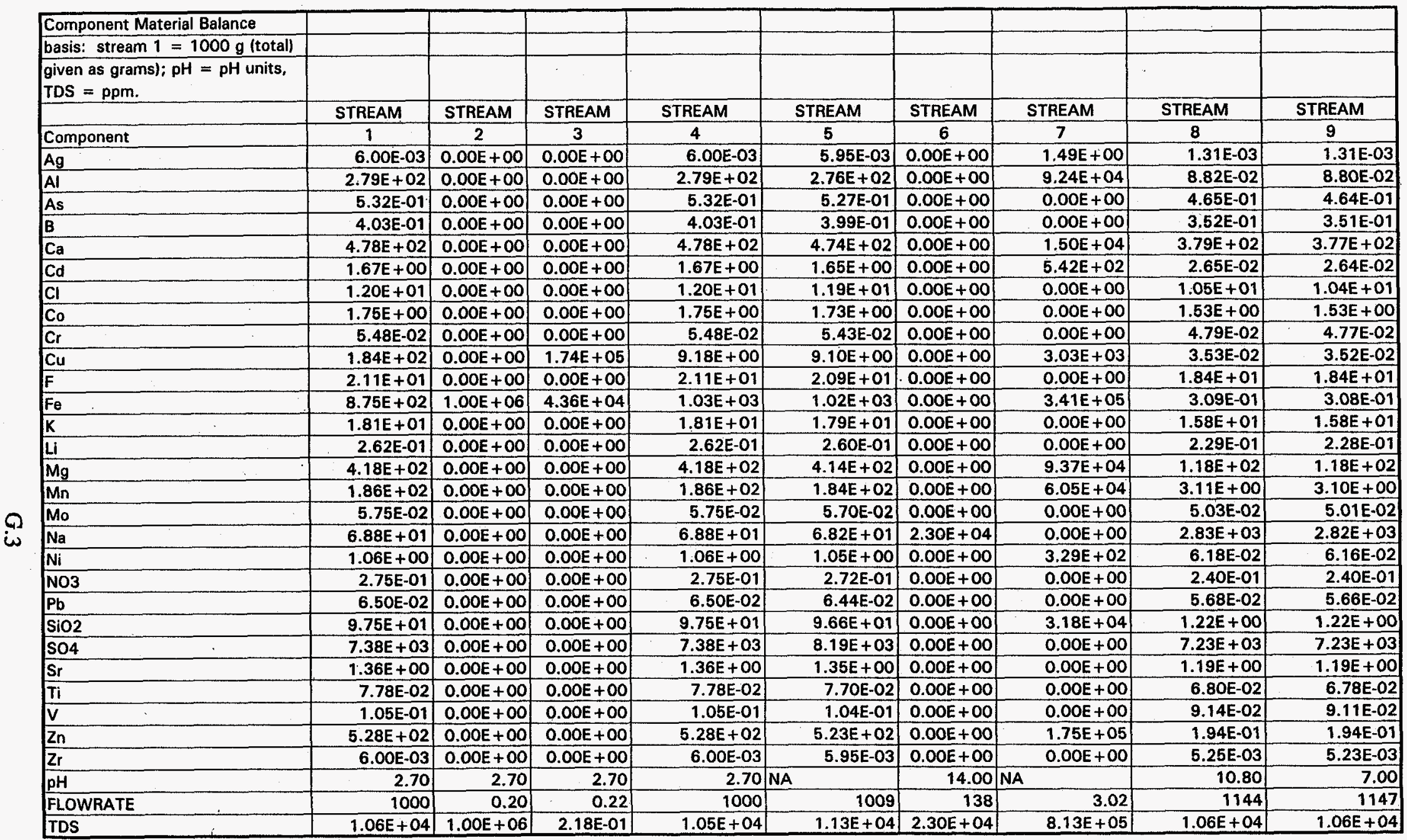


Table G.1. Stream Flow Material Balance Showing Semiselective Separation of Constituents from Feedwater Using Precipitation

a

\begin{tabular}{|c|c|c|c|c|c|c|c|c|}
\hline \multicolumn{9}{|c|}{ Component Material Balance } \\
\hline \multicolumn{9}{|c|}{ basis: stream $1=1000 \mathrm{~g}$ (total) } \\
\hline \multicolumn{9}{|c|}{$\begin{array}{l}\text { given as grams); } \mathrm{pH}=\mathrm{pH} \text { units, } \\
\text { TDS }=\mathrm{ppm} \text {. }\end{array}$} \\
\hline & STREAM & STREAM & STREAM & STREAM & STREAM & STREAM & STREAM & STREAM \\
\hline Component & 10 & 11. & 12 & 13 & 14 & 15 & 20 & 26 \\
\hline $\mathrm{Ag}$ & 2.24E-04 & $0.00 E+00$ & $1.28 \mathrm{E}-03$ & 7.93E-03 & $1.53 \mathrm{E}-05$ & $0.00 E+00$ & $0.00 E+00$ & $1.49 E+00$ \\
\hline $\mathrm{Al}$ & $1.51 \mathrm{E}-02$ & $0.00 E+00$ & 8.62E-02 & 5.33E-01 & 1.03E-03 & $0.00 E+00$ & $0.00 E+00$ & $9.24 \mathrm{E}+04$ \\
\hline As & 7.94E-02 & $0.00 E+00$ & 4.54E-01 & $2.81 \mathrm{E}+00$ & $5.41 \mathrm{E}-03$ & $0.00 E+00$ & $0.00 E+00$ & $0.00 \mathrm{E}+00$ \\
\hline $\mathrm{B}$ & 6.00E-02 & $0.00 E+00$ & 3.44E-01 & $2.13 E+00$ & 4.09E-03 & $0.00 E+00$ & $0.00 E+00$ & $0.00 E+00$ \\
\hline $\mathrm{Ca}$ & $6.46 \mathrm{E}+01$ & $0.00 E+00$ & $3.70 \mathrm{E}+02$ & $2.29 \mathrm{E}+03$ & $4.40 E+00$ & $0.00 \mathrm{E}+00$ & $0.00 E+00$ & $1.50 \mathrm{E}+04$ \\
\hline $\mathrm{Cd}$ & $4.52 \mathrm{E}-03$ & $0.00 E+00$ & $2.59 \mathrm{E}-02$ & $1.60 \mathrm{E}-01$ & $3.08 \mathrm{E}-04$ & $0.00 \mathrm{E}+00$ & $0.00 E+00$ & $5.42 \mathrm{E}+02$ \\
\hline $\mathrm{Cl}$ & $0.00 \mathrm{E}+00$ & $1.70 E+02$ & $5.22 \mathrm{E}-01$ & $3.23 E+00$ & $6.21 \mathrm{E}-03$ & $0.00 \mathrm{E}+00$ & $0.00 E+00$ & $0.00 E+00$ \\
\hline Co & 2.61E-01 & $0.00 E+00$ & $1.49 E+00$ & $9.25 \mathrm{E}+00$ & $1.78 \mathrm{E}-02$ & $0.00 E+00$ & $0.00 E+00$ & $0.00 E+00$ \\
\hline $\mathrm{Cr}$ & $8.17 \mathrm{E}-03$ & $0.00 E+00$ & $4.68 \mathrm{E}-02$ & $2.89 \mathrm{E}-01$ & 5.67E-04 & $0.00 E+00$ & $0.00 E+00$ & $0.00 E+00$ \\
\hline $\mathrm{Cu}$ & $6.02 \mathrm{E}-03$ & $0.00 E+00$ & $3.45 \mathrm{E}-02$ & 2.13E-01 & $4.10 \mathrm{E}-04$ & $0.00 E+00$ & $0.00 \mathrm{E}+00$ & $3.03 E+03$ \\
\hline$F$ & $0.00 \mathrm{E}+00$ & $2.99 \mathrm{E}+02$ & $9.19 \mathrm{E}-01$ & $5.69 E+00$ & $1.09 \mathrm{E}-02$ & $0.00 E+00$ & $0.00 E+00$ & $0.00 \mathrm{E}+00$ \\
\hline $\mathrm{Fe}$ & $5.27 \mathrm{E}-02$ & $0.00 \mathrm{E}+00$ & 3.02E-01 & $1.87 E+00$ & $3.59 \mathrm{E}-03$ & $0.00 E+00$ & $0.00 E+00$ & $3.41 E+05$ \\
\hline$K$ & $1.28 \mathrm{E}+02$ & $0.00 E+00$ & $7.88 \mathrm{E}-01$ & $4.87 \mathrm{E}+00$ & $9.38 \mathrm{E}-03$ & $0.00 E+00$ & $0.00 E+00$ & $0.00 \mathrm{E}+00$ \\
\hline $\mathrm{Li}$ & $1.86 E+00$ & $0.00 E+00$ & $1.14 \mathrm{E}-02$ & $7.06 \mathrm{E}-02$ & $1.36 \mathrm{E}-04$ & $0.00 E+00$ & $0.00 E+00$ & $0.00 E+00$ \\
\hline $\mathrm{Mg}$ & $2.02 \mathrm{E}+01$ & $0.00 \mathrm{E}+00$ & $1.15 E+02$ & $7.15 E+02$ & $1.37 \mathrm{E}+00$ & $0.00 E+00$ & $0.00 E+00$ & $9.37 E+04$ \\
\hline $\mathrm{Mn}$ & 5.31E-01 & $0.00 E+00$ & $3.04 \mathrm{E}+00$ & $1.88 E+01$ & $3.62 \mathrm{E}-02$ & $0.00 \mathrm{E}+00$ & $0.00 E+00$ & $6.05 E+04$ \\
\hline Mo & $8.58 \mathrm{E}-03$ & $0.00 E+00$ & $4.91 \mathrm{E}-02$ & $3.04 \mathrm{E}-01$ & $5.85 \mathrm{E}-04$ & $0.00 \mathrm{E}+00$ & $0.00 \mathrm{E}+00$ & $0.00 E+00$ \\
\hline $\mathrm{Na}$ & $2.28 \mathrm{E}+04$ & $0.00 E+00$ & $1.53 E+02$ & $9.47 \mathrm{E}+02$ & $1.83 E+00$ & $2.30 \mathrm{E}+04$ & $0.00 E+00$ & $0.00 \mathrm{E}+00$ \\
\hline $\mathrm{Ni}$ & $1.05 \mathrm{E}-02$ & $0.00 E+00$ & $6.03 \mathrm{E}-02$ & 3.73E-01 & $7.18 \mathrm{E}-04$ & $0.00 \mathrm{E}+00$ & $0.00 \mathrm{E}+00$ & $3.29 \mathrm{E}+02$ \\
\hline NO3 & $0.00 \mathrm{E}+00$ & $3.90 E+00$ & $1.20 \mathrm{E}-02$ & $7.41 \mathrm{E}-02$ & $1.43 \mathrm{E}-04$ & $0.00 E+00$ & $0.00 E+00$ & $0.00 E+00$ \\
\hline $\mathrm{Pb}$ & $9.70 \mathrm{E}-03$ & $0.00 E+00$ & 5.55E-02 & $3.44 \mathrm{E}-01$ & $6.61 \mathrm{E}-04$ & $0.00 \mathrm{E}+00$ & $0.00 E+00$ & $0.00 E+00$ \\
\hline SiO2 & $2.09 \mathrm{E}-01$ & $0.00 \mathrm{E}+00$ & $1.20 \mathrm{E}+00$ & $7.40 \mathrm{E}+00$ & $1.42 \mathrm{E}-02$ & $0.00 \mathrm{E}+00$ & $0.00 E+00$ & $3.18 \mathrm{E}+04$ \\
\hline 504 & $0.00 E+00$ & $9.51 E+04$ & $1.68 \mathrm{E}+03$ & $1.04 E+04$ & $2.00 E+01$ & $0.00 \mathrm{E}+00$ & $0.00 E+00$ & $0.00 E+00$ \\
\hline $\mathrm{Sr}$ & 2.03E-01 & $0.00 E+00$ & $1.16 \mathrm{E}+00$ & $7.19 \mathrm{E}+00$ & $1.38 \mathrm{E}-02$ & $0.00 \mathrm{E}+00$ & $0.00 E+00$ & $0.00 E+00$ \\
\hline $\mathrm{Ti}$ & $1.16 \mathrm{E}-02$ & $0.00 E+00$ & 6.64E-02 & 4.11E-01 & 7.91E-04 & $0.00 E+00$ & $0.00 E+00$ & $0.00 \mathrm{E}+00$ \\
\hline$v$ & $1.56 \mathrm{E}-02$ & $0.00 E+00$ & 8.93E-02 & $5.52 \mathrm{E}-01$ & $1.06 \mathrm{E}-03$ & $0.00 \mathrm{E}+00$ & $0.00 E+00$ & $0.00 E+00$ \\
\hline $2 n$ & $3.31 \mathrm{E}-02$ & $0.00 \mathrm{E}+00$ & $1.90 \mathrm{E}-01$ & $1.17 E+00$ & $2.26 \mathrm{E}-03$ & $0.00 \mathrm{E}+00$ & $1.75 \mathrm{E}+05$ & $0.00 \mathrm{E}+00$ \\
\hline $\mathrm{Zr}$ & $8.95 \mathrm{E}-04$ & $0.00 \mathrm{E}+00$ & $5.12 \mathrm{E}-03$ & $3.17 \mathrm{E}-02$ & $0.00 \mathrm{E}+00$ & $0.00 \mathrm{E}+00$ & $0.00 E+00$ & $0.00 E+00$ \\
\hline $\mathrm{pH}$ & 14.00 & -0.30 & 6.99 & 6.49 & 7.00 & 14.00 & NA & NA \\
\hline FLOWRATE & 134 & 67.0 & 1147 & 184 & 964 & 138 & 0.65 & 2.37 \\
\hline TDS & $2.30 E+04$ & $9.56 \mathrm{E}+04$ & $2.33 \mathrm{E}+03$ & $1.44 \mathrm{E}+04$ & $2.77 \mathrm{E}+01$ & $2.30 \mathrm{E}+04$ & $1.00 E+06$ & $6.38 \mathrm{E}+05$ \\
\hline
\end{tabular}




\section{Distribution}

No of

Copies

Offsite

B.F. Monzyk

Battelle Memorial Institute 505 King Avenue

Columbus, $\mathrm{OH} 43201-2693$
No of

Copies

Onsite

49 Pacific Northwest Laboratory

E.G. Baker

P2-38

M.F. Beuhler

P2-38

M.R. Elmore

K3-75

R.E. Engelman

K9-48

H.F. Freeman

P2-38

M.A. Gerber (30)

P2-38

R.T. Hallen

P2-38

E.O. Jones

K3-75

W.L. Kuhn

$\mathrm{K} 2-21$

R.J. Orth

K3-75

S.J. Ortiz

P8-38

M.E. Peterson (2)

K2-47

Distr.1 